University of Redlands

\title{
Introducing Web GIS to a Remote Island: \\ Long Caye, Lighthouse Reef, Belize
}

A Major Individual Project submitted in partial satisfaction of the requirements

for the degree of Master of Science in Geographic Information Systems

by

Jessica Marie Altamira

Ruijin Ma, Ph.D., Committee Chair

Mark Kumler, Ph.D.

April 2019 

Introducing Web GIS to a Remote Island: Long Caye, Lighthouse Reef, Belize

Copyright @ $\odot 2019$

by

Jessica Marie Altamira 

The report of Jessica Marie Altamira is approved.

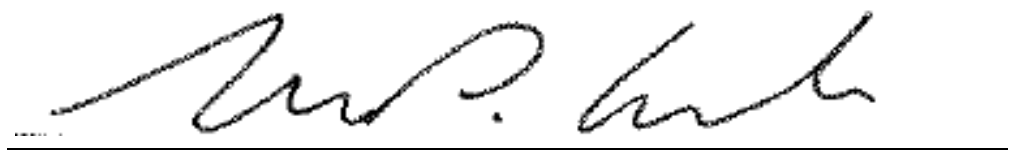

Mark Kumler, Ph.D.

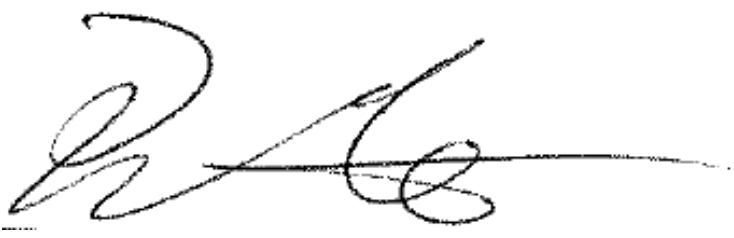

Ruijin Ma, Ph.D., Committee Chair

April 2019 



\section{Acknowledgements}

There are not enough words to express my gratitude for the technical and emotional support for this major individual project. Thank you Blake Ross, Jim Cullinan, Jackson Edwards III, and Marcia Tolive for funding a trip to Long Caye. A special thanks to the crew of Huracane Diving Operations for transporting me to and from dive sites to experience the underwater treasures of Lighthouse Reef Atoll. Many thanks to Esri employee, Drew Stephens, for providing data as well as being the best project liaison. Gratitude for cartographic advice from Esri's chief cartographer, Charlie Frye, and web design tips from Pinde Fu, Esri employee, made the deliverables of higher aesthetic quality. Also, thank you to the entire faculty of the MS GIS program who provided feedback that helped this project and my overall skill development for my future careers. More specifically, thank you to my advisor Dr. Ruijin Ma for guiding me. Finally, thank you, Debbie, for being an outstanding program coordinator and good luck in Texas.

As for the emotional support, I'd like to thank MS GIS Cohorts 23, 23.5, 24, 25, and 25.5 for making this one of the most memorable years of my life. Lastly, I'd like to thank my parents, Gloria \& Rene Altamira, and my best friend, Lauren Ma, for supporting me through this journey from New Jersey to California. I love you all and I could not have asked for a better support team for this academic achievement. 



\begin{abstract}
Introducing Web GIS to a Remote Island: Long Caye, Lighthouse Reef, Belize

by

Jessica Marie Altamira

This project focuses on the flexibility of web GIS' integration at a small scale. The study area of this project was on Belize's tropical island, Long Caye. Its private owners sought to share its features to adventurous tourists and potential land investors. The effectiveness of its low-quality geographic information delivery and lack of a centralized source for property data were problematic for management to reach higher efficiency levels. The web applications created in this project serve the purpose of public education and land administration by transforming traditional descriptions of the island features onto an interactive interface. The two final deliverables were scalable applications with a target audience being either the general public or the island owners. The results paved the way for further exposure of the island to GIS to enhance the system behind maintaining Long
\end{abstract} Caye's treasures. 



\section{Table of Contents}

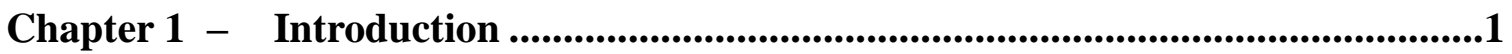

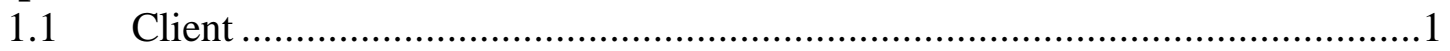

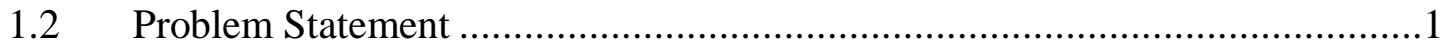

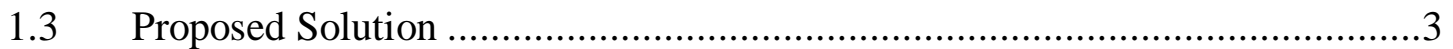

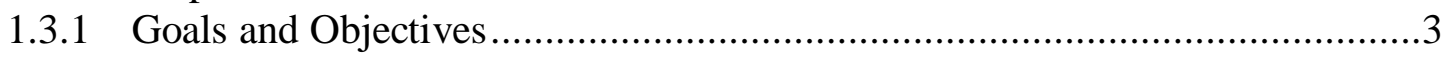

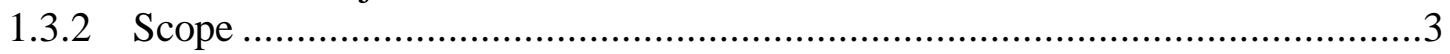

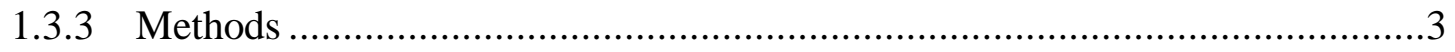

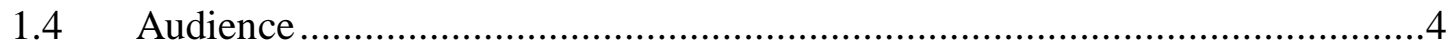

1.5 Overview of the Rest of this Report ...............................................................

Chapter 2 - Background and Literature Review ................................................................5

$2.1 \quad$ History and Tourism Motives in Long Caye ……….......................................5

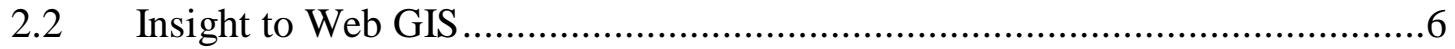

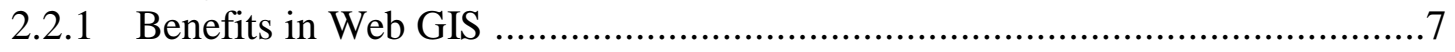

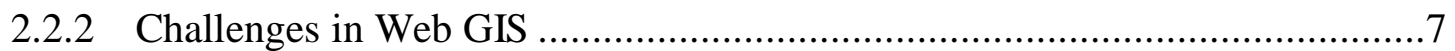

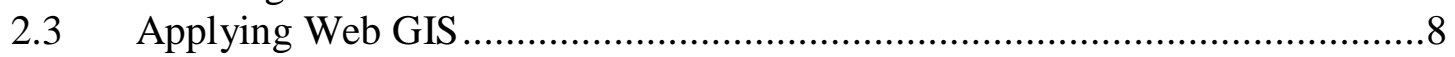

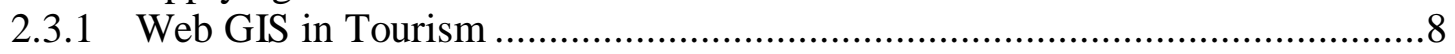

2.3.2 Web GIS in Property Management .............................................................

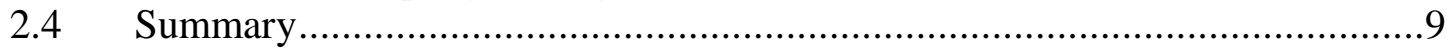

Chapter 3 - Systems Analysis and Design ......................................................................10

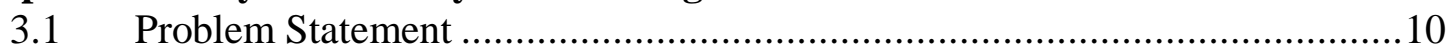

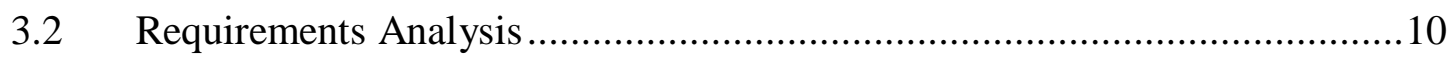

3.2.1 Functional Requirements .........................................................................10

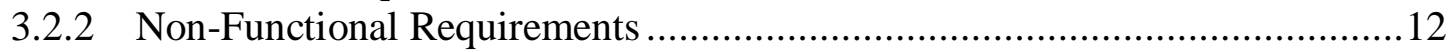

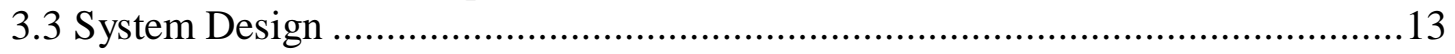

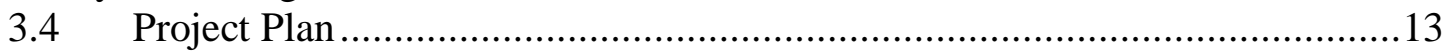

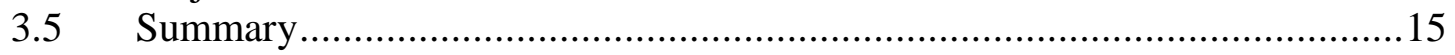

Chapter 4 - Database Design ...........................................................................................16

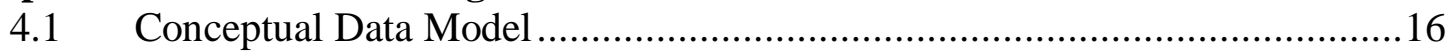

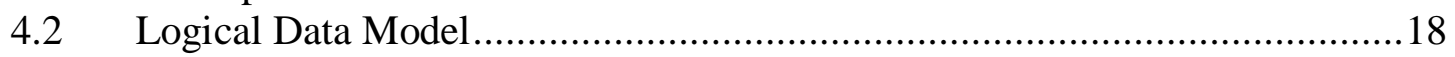

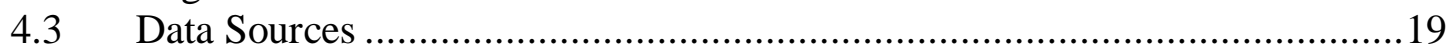

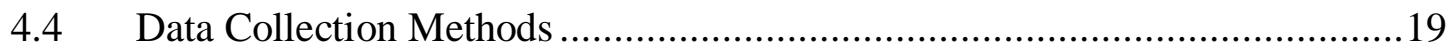

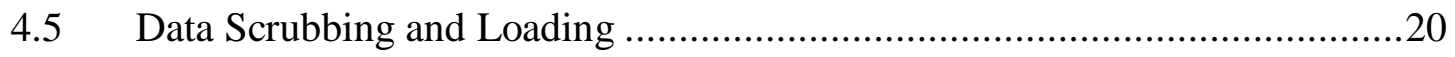

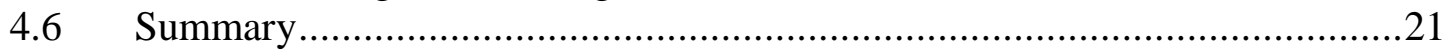

Chapter 5 - Implementation .................................................................................................22

5.1 Long Caye Geodatabase Development ……………...................................22

5.1.1 Public and Communal Dataset..................................................................22

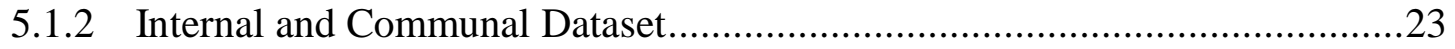

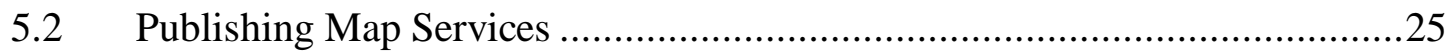

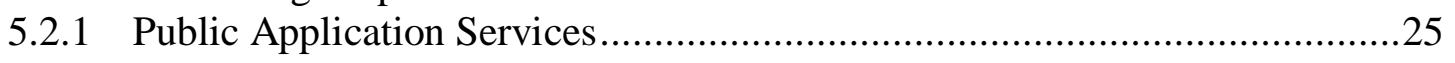

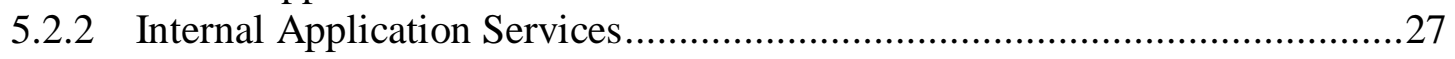

5.3 Web GIS Development and Functionality …………....................................2

5.3.1 Public Application Development and Functionality ……...............................28 
5.3.2 Internal Application Development and Functionality ......................................33

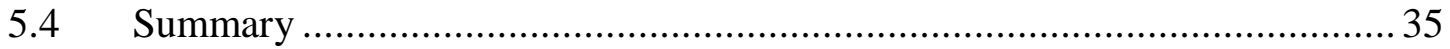

Chapter 6 - Results and Analysis...........................................................................36

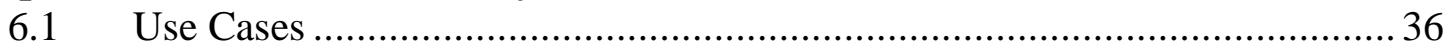

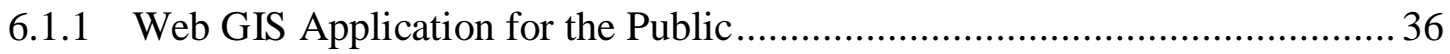

6.1.2 Web Application for the Long Caye Owners ..................................................39

$6.2 \quad$ Application Testing and Results............................................................... 43

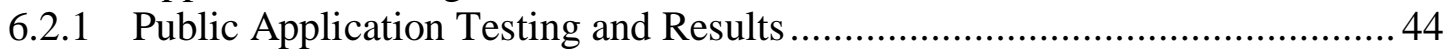

6.2.2 Internal Application Testing and Results .................................................. 44

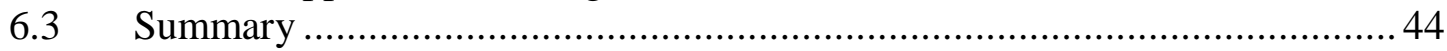

Chapter 7 - Conclusions and Future Work ..................................................................... 46

Works Cited …….......................................................................................................... 47

Appendix A. Public Application Script ........................................................................ 49

Appendix B. Internal Application Script .......................................................................65

Appendix C. Help Documentation..................................................................................... 76 


\section{Table of Figures}

Figure 1-1: Three maps that are displayed on the Long Caye website.................... 2

Figure 1-1: Feature class of the Long Caye parcels. ............................................ 2

Figure 2-1: Project study area of Long Caye at Lighthouse Reef Atoll, Belize ....... 5

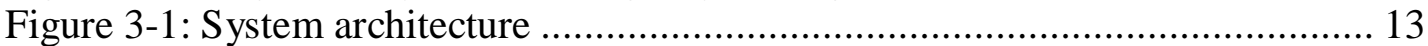

Figure 3-2: Project Gantt chart ......................................................................... 14

Figure 3-3: Descriptions of the Long Caye Ridge and Half Moon Wall dive sites .. 15

Figure 4-1: Conceptual data model for a parcel ownership transaction ................... 16

Figure 4-2: Conceptual data model for a reservation transaction ........................... 17

Figure 4-3: Conceptual data model for the resort amenities ............................... 17

Figure 4-4: Logical data model .......................................................................... 18

Figure 4-5: A segment of the trail route mapped by a GPS .............................. 20

Figure 5-1: Long Caye enterprise geodatabase components ............................... 22

Figure 5-2: Partial extent of the final public application map document ................ 23

Figure 5-3: Partial extent of the final internal application map document .............. 24

Figure 5-4: Online publishing service resource and related tasks........................... 25

Figure 5-5: Feature services for the public application ....................................... 26

Figure 5-6: Map and dynamic services for the public application .......................... 26

Figure 5-7: Feature services for the internal application ................................. 27

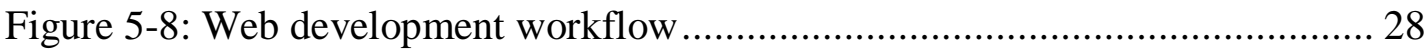

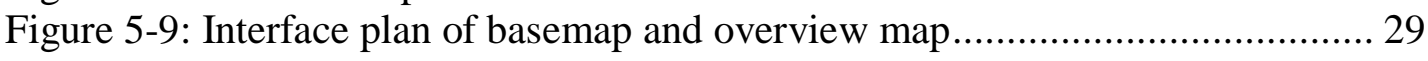

Figure 5-10: Addition of navigation tools and bookmark button........................... 30

Figure 5-11: Addition of legend, toggle, and YouTube tabs ............................... 30

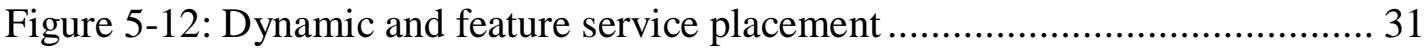

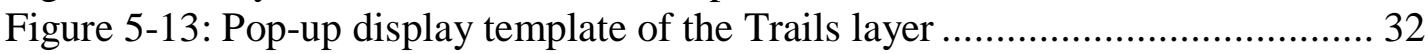

Figure 5-14: Final interface design for the public web application ........................... 32

Figure 5-15: Interface plan of basemap content with navigation tools .................... 33

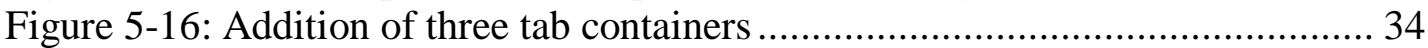

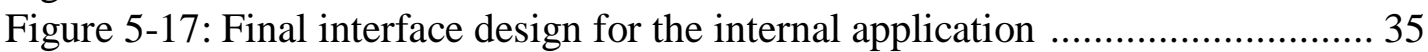

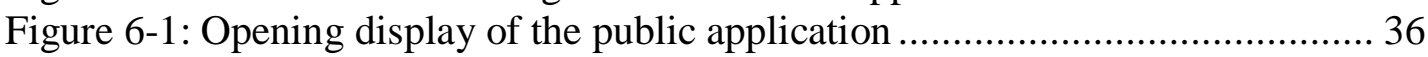

Figure 6-2: Half Moon Wall Pop-up and enlarged dive photo ............................... 37

Figure 6-3: Great Blue Hole Extent with bookmark drop down........................... 37

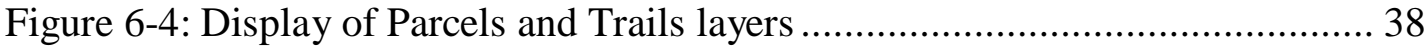

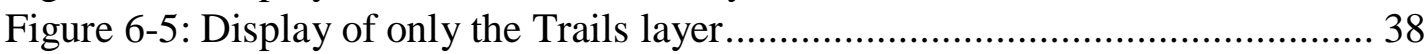

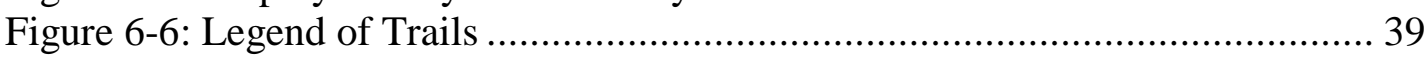

Figure 6-7: Sign-In prompt at application launch ............................................ 40

Figure 6-8: Interface for authorized user ....................................................... 40

Figure 6-9: Contents of directions tab for parcel querying.............................. 41

Figure 6-10: Search By tab with parcel ID \#22 input ........................................ 41

Figure 6-11: Highlighted result of parcel ID \#22 query ..................................... 41

Figure 6-12: Top (left) and bottom (right) half of the feature editor ..................... 42

Figure 6-13: Drawn parcel polygon with empty attributes................................... 42

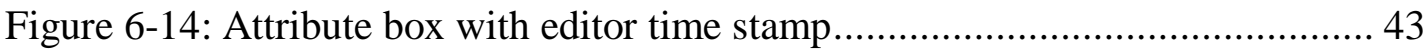

Figure 6-15: Public application testing sites .................................................... 44 


\section{List of Tables}

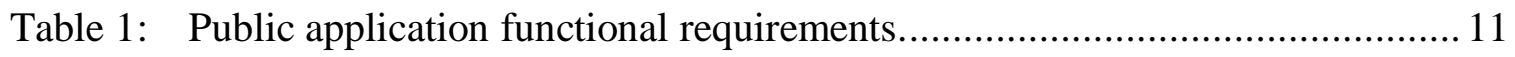

Table 2: Internal application functional requirements ....................................... 12

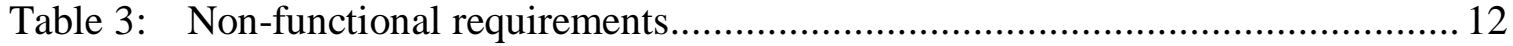




\section{List of Acronyms and Definitions}

$\begin{array}{ll}\text { API } & \text { Application Programming Interface } \\ \text { CSS } & \text { Cascading Style Sheets } \\ \text { GIS } & \text { Geographic Information Systems } \\ \text { HTML } & \text { Hypertext Markup Language } \\ \text { JPEG } & \text { Joint Photograph Expert Group } \\ \text { REST } & \text { Representational State Transfer } \\ \text { (Arc)SDE } & \text { Spatial Database Engine } \\ \text { URL } & \text { Uniform Resource Locator }\end{array}$





\section{Chapter 1 - Introduction}

Vacation operations often rely on several resources for networking and marketing. Using maps, photos, or literary descriptions are the typical method of displaying geographic information and resort amenities. Without the proper information delivery or quality resources, operations are posed with a challenge to educate potential tourists. This is an issue when operations depend solely on a single resource, such as a website, to be the main source for public outreach.

It is difficult to deliver large amounts of geographic explanations through limited types of media; fortunately, web geographic information systems (GIS) can provide better opportunities. Web GIS holds potential to efficiently combine geographic references and descriptive material onto a single interactive user-interface. Included in this report are the motives for technological methods to develop web GIS applications. This project, Introducing Web GIS to a Remote Island: Long Caye,Belize, seeked to improve the quality of public outreach and property sales management for the owners of Long Caye, Belize. This document includes details of the system planning process, data design and collection, web development, implementation, and future work for this project.

\subsection{Client}

Mr. Blake Ross is one of three majority owners of Long Caye at Lighthouse Reef Atoll. Even though the island is part of the country of Belize, it has been privately owned since the 1960s. Mr. Ross and his two business partners have developed a small resort for tourists and offer parcel sales to the general public. The motive behind the resort investment was to serve as an additional source of income to fund island or resort needs. Mr. Ross has constructed a website to educate tourists on resort amenities and for general inquiries on property sales. He manages all sales with the help of his business partners and distributes the parcel profit to fund resort needs. Blake desires to integrate GIS to improve the overall management of island operations and tourism efforts.

\subsection{Problem Statement}

Two problems were addressed during the initial course of this project. The first was the quality and quantity of geographic information delivery on the Long Caye public website. The second was the lack of a centralized data sharing system among the Long Caye owners to manage property sales data. The first problem came from poor visual spatial information for public education on the Long Caye website. Figure 1-1 displays three maps on Long Caye's website that attempt to convey the location of Long Caye. 

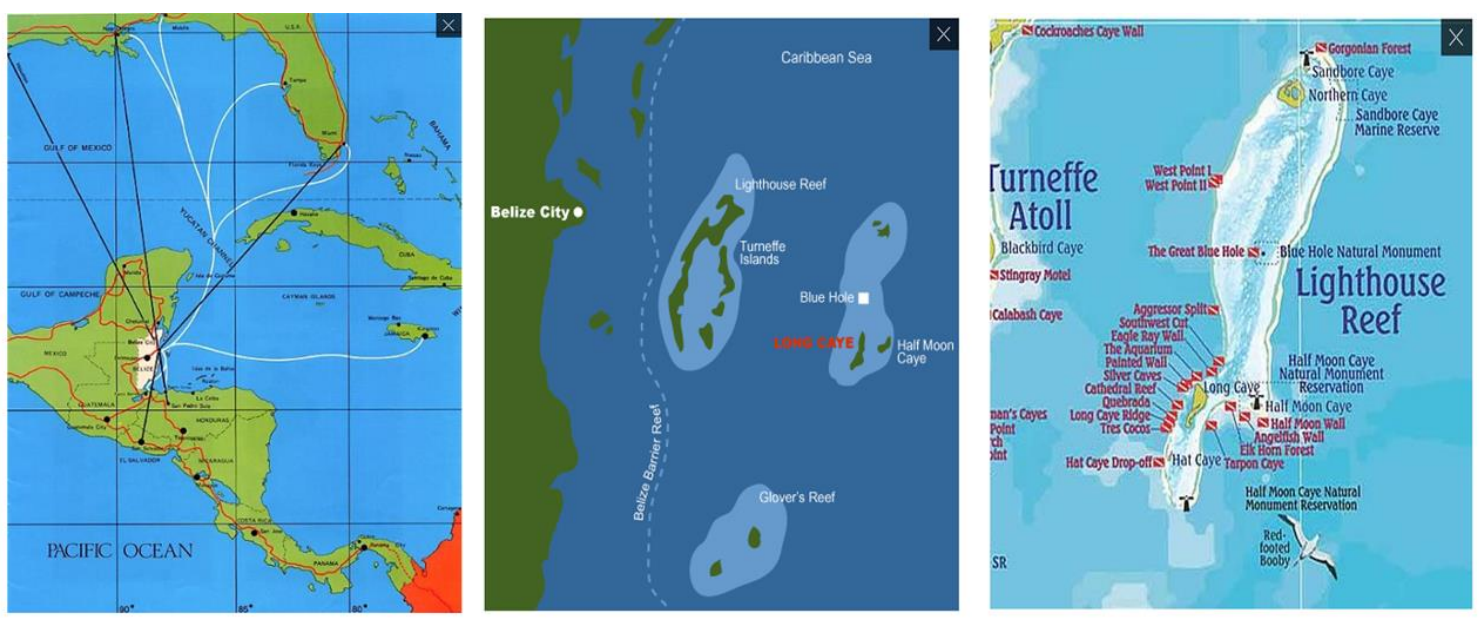

Figure 1-1: Three maps that are displayed on the Long Caye website.

While these maps contain valuable information, they are static images in JPEG (Joint Photograph Expert Group) format that are displayed in three separate viewing windows. The maps fail to display features such as hiking trails and resort locations, as well as maintain cartographic uniformity. Additionally, it is very difficult to update information on these maps. The dive site map found on the far right of Figure 1-1, has incorrect information that the owners can not correct. The delivery format of displaying three separate windows made the map transitions inconsistent and inconvenient to the average viewer.

The second problem related to low efficiency levels of maintaining a parcel sales database. The database used to monitor the land parcels was stored as an Excel file on each of the island owners' individual computers. Without a network to connect the separate sources, this management system was inefficient. This became a problem especially when the owners traveled and were not able to obtain the latest edits from each other. This also resulted in misinforming individual property owners and potential clients of parcel status. Unlike the first problem, this case had an available and editable parcel feature class as its spatial resource as seen in Figure 1-2.

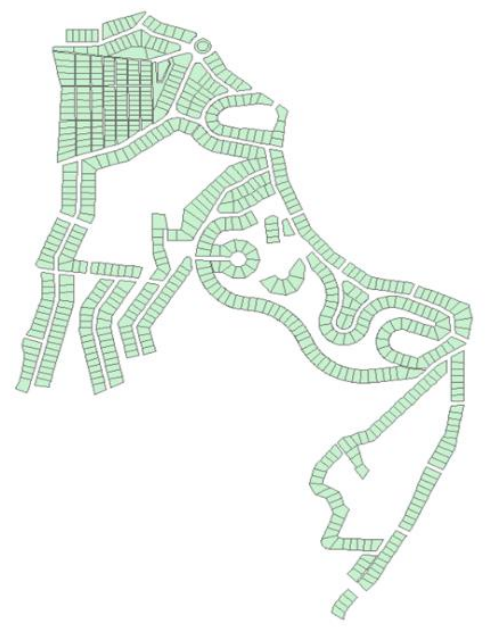

Figure 1-2: Feature class of the Long Caye parcels. 
However, it was not within the owners' expertise to effectively use the data. The owners acknowledged that improvement was necessary to raise the productivity levels of their parcel management methods.

Both problems posed a need to make its management systems and public information more effective. While the situations apply to two different audiences, this project focused on an overall demand for better quality resources to be well used.

\subsection{Proposed Solution}

Web GIS applications were the proposed solutions for the two problems. The first application allowed access to the general public on major island attractions. Web GIS was appropriate for this specific situation since an interactive application could provide the integration of different types of media to create a stimulating environment for a user. A web application also holds the flexibility to either be embedded into an available website or act as a standalone source. The second application only allowed internal access to view confidential parcel data. GIS software allowed the joining of tabular data with an existing feature class. On or off the island, owners could use the application for data edits or as planning tools for future development. With a dependency on the web and attempt to keep up with innovative technology, Web GIS applications were the most fitting solution for the needs of the Long Caye owners.

\subsubsection{Goals and Objectives}

The primary goal of this project was to help the client create spatial data resources to add to its current website and manage their parcel data. Although no web application or form of media can truly grasp the experience on Long Caye, acknowledgement of its existence was the long-term goal of the public application. The larger goal of the internal application was to direct an area of management towards a better workflow for future planning and development. Objectives to achieve success at the completion of the project relied on consistent communication with the client, meeting predetermined deadlines, and creating efficient project plans to produce essential products.

\subsubsection{Scope}

Three main components constituted the project scope. The first component was mapping features and updating the existing database. This enabled addition of data fields that were fitting for application intention. The second component encompassed data analysis and generation of map documents that were suitable for tourist education and property management. This resulted in delivered feature classes within an organized geodatabase that were published as web services. The last and final component was the web application development and interface design.

\subsubsection{Methods}

Various methods were applied to attain project completion. Research on case studies of web GIS for tourism were done to understand the motive behind interactive mapping. Consistent analysis of descriptions on features such as dive sites, hiking trails, and 
resorts, from the Long Caye website determined appropriate objects for data collection. A hand-held Trimble Juno GPS was used to map notable geographic and man-made features during a short trip to the island. The mapped features were separated into feature classes within a geodatabase. Editing of the feature classes occurred within ArcMap in order to prepare the data for publication onto an online server.

Online services were utilized for proper web development. Each feature class was published onto a web server as well as the Long Caye organizational account. By doing this, it allowed the client and developer to access the data online. JavaScript instructorled classes provided a fundamental knowledge for scripting the design and functionality of the applications. The application scripts were written, tested, documented, and delivered to the client via the web.

\subsection{Audience}

This report aims for an audience who is interested in web GIS application development. It is especially helpful for beginning JavaScript developers. The document also serves as a reference for people with a GIS background who are looking to create similar applications. Lastly, it is a source for readers looking to learn about Long Caye. applications.

\subsection{Overview of the Rest of this Report}

The remaining content of this report includes six chapters. In Chapter 2, there is an overview of previous case studies on tourism and parcel management. Project planning and design are discussed in Chapter 3. Logical and conceptual database models as well as data integration methods are explained in Chapter 4. Project implementation through JavaScript code and web design are described in Chapter 5. Use cases and application testing results are discussed in Chapter 6. The overall summary, conclusions, and potential future modifications to the project are presented in Chapter 7. 


\section{Chapter 2 - Background and Literature Review}

Exotic natural features are motivation to initiate tourism efforts. The profit from these efforts could potentially lead to a reliable source of income for a resort owner.

Maintaining the environmental value of Long Caye at Lighthouse Reef is necessary to ensure that its tourism thrives. However, a lack of technological outreach thwarts outsider awareness of such a beautiful place. This is where web GIS plays an important role, achieving what word of mouth fails to attain. Online applications can unite the concepts of sharing and managing spatial data. This chapter describes and illustrates how web GIS trends can enhance the island's foreign and internal relationships.

\subsection{History and Tourism Motives in Long Caye}

Long Caye is located within the Lighthouse Reef Atoll, just 50 miles off the coast of Belize City, Belize. It is the Belize's most eastern island, aside from the sacred Half Moon Caye. Figure 2-1 depicts the Long Caye study area.

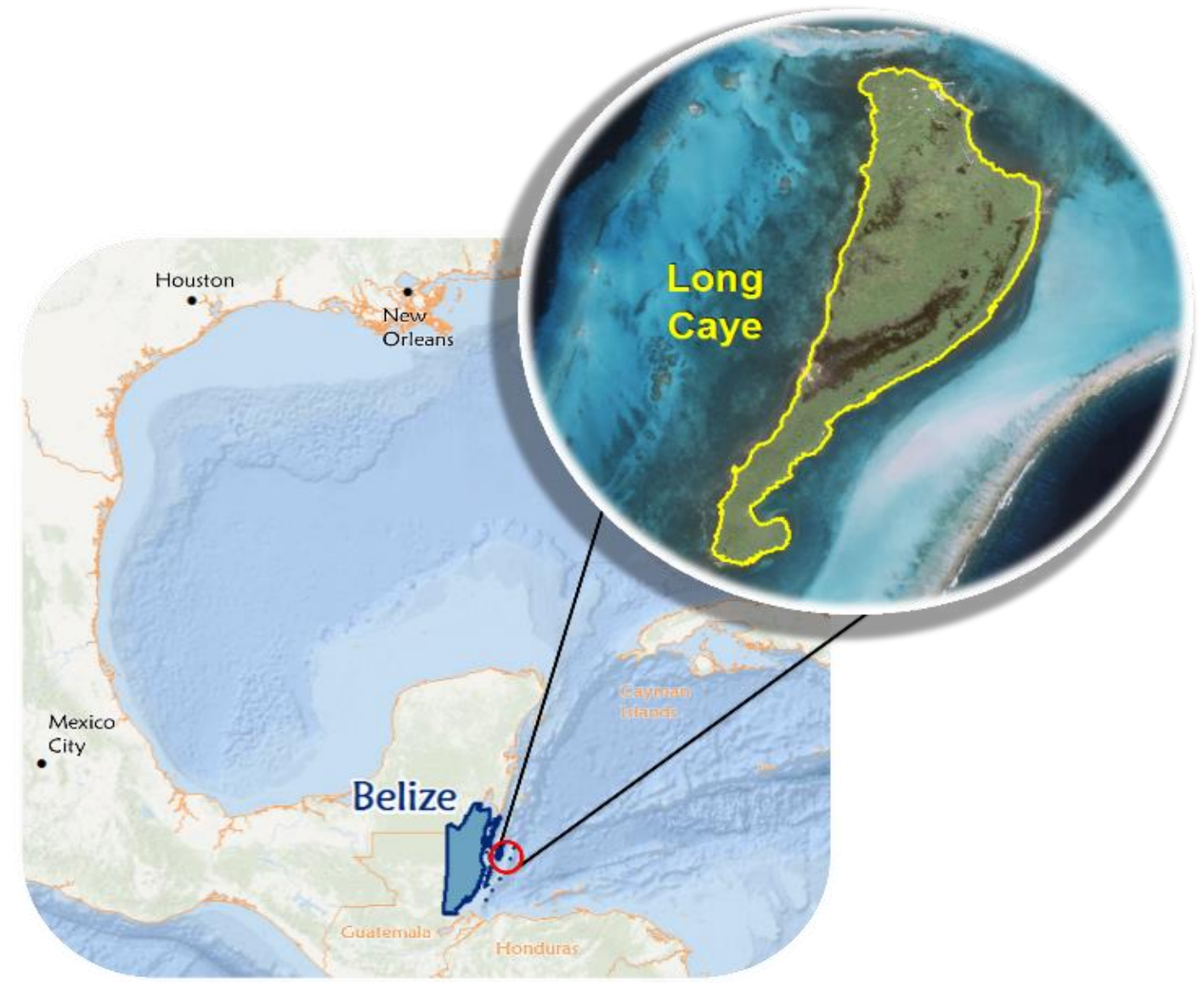

Figure 2-1: Project study area of Long Caye at Lighthouse Reef Atoll, Belize.

It is said that the island was obtained through gambling for its ownership papers.

However, since the late 1960s, the Edwards family line has inherited the legal rights. 
Sustainable development is a crucial part of life on the Cayes. The construction of the Itza Lodge and Huracan Diving Resort were developed away from the fragile environmental features as preservation efforts. Any infrastructure on the island must be raised at least 3 feet from the ground in order to avoid flattening vegetation beds or disturbing wildlife nesting grounds. Water sources are derived from fresh water brought over from the mainland to an on-site tank. Power is generated mainly by passive solar panels and communication relies on basic Wi-Fi from a satellite source.

Motives for developing the resort stemmed from Long Caye's historical features, marine structures, and physical location. Long Caye has an advantage over the mainland because its status as a paradise island is linked to activities that tourists desire for leisure and exploration (Briguglio, Butler, \& Harrison, 1996, p.1). This stands true because the resort offers bird watching, scuba diving, snorkeling, kayaking, and several other water sport activities. Long Caye's equatorial location offers a more favorable climatic setting when compared to mainland's reputation for massive amounts of annual rainfall. Tolerable-year-round weather encourages "governments of SIDS (small island developing state) [to] give tourism top priority, and attempt to maximize their island's [sic] tourism potential by further developing the industry" (Briguglio, Butler, \& Harrison, 1996, p.1). With its predetermined paradise reputation, proper resources for conservation efforts, and a steady source of income from tourism, Long Caye has the future potential to achieve successful and sustainable development.

The most significant reason why Long Caye is the more favorable area comes from its coral reefs. The exotic marine structures lure in visitors, generating " $30 \%$ of the nation's gross domestic product through the tourism it attracts, the provision of commercial fisheries products, and private sector investments in aquaculture" (Diedrich, 2007, p.1). Reliance on tourism benefits not only the island, but the entire country, as well. This solid foreign revenue factor generates a healthy portion of Belize's income and the dependency on the reef necessitates cautious marine management. Reef protection is a top priority for the country of Belize, which may lead one to infer that increasing tourism could be detrimental to maintaining reef health. However, Belize's transition into tourism has been gradual and is at such a young stage, indicating that the country "has the advantage of being able to learn from the failures and successes of its neighbors and should be proactive in its approach to tourism management" (Diedrich, 2007, p.11). The study area of this project lies completely within the reef, meaning that an island campaign and conservation efforts are critical for the success of long-term tourism and overall reef preservation.

\subsection{Insight to Web GIS}

Extending GIS to the web broadens the horizon for development opportunities. Although GIS began as a desktop application, technological innovations have enabled the integration of geographic visualization onto the World Wide Web. Instead of interacting with flat, stationary maps, "in a web-based environment with basic GIS functionalities, the map becomes dynamic, interactive and accessible to a wide selection of users as a visual communication tool" (Kraak, 2004, p.80). This type of expansion allows for a stronger level of networking and education in GIS. 


\subsubsection{Benefits in Web GIS}

Simple format and dynamic delivery are two advantages that the intent of a GIS and an Internet web browser have in common. Comprehending a message through a visual object and retrieving data as smoothly as possible is a user experience that every web GIS strives to deliver. Not only can web GIS facilitate user-friendly applications, but also online "maps are [also] used to stimulate (visual) thinking about geospatial patterns, relationships, and trends" (Kraak, 2004, p.85)". This innovation creates an opportunity for curious users to develop more open-minded perspectives. Advocating such a mentality in operators and developers amplifies the pathway for GIS growth in the future.

Web GIS benefits cater to various types of audiences with access who are accessing the platform from different sources. This kind of GIS extends to a global outreach, allows multiple users to operate on its interface, and offers a better cross-platform capability ( $\mathrm{Fu}$ \& Sun, 2011, p.15). These factors allow a better network to introduce web GIS through the use of any type of smart hardware. Using the web as the primary medium can convey GIS messages through multiple media tools on one interface.

\subsubsection{Challenges in Web GIS}

Web GIS faces a few challenges, but fortunately, many of these can be mitigated easily with certain solutions. Breaking down its mechanisms and functionality allows room for alternatives to make the system more flexible. Elements to consider for a rudimentary online GIS include server establishment, data compatibility, and generation of a graphic design.

Graphics are a key component that can hinder a desired rendering rate for dynamic maps. Web maps with high quality imagery require lots of bandwidth, meaning "connection speeds to the internet can make heavy use of graphics intolerably slow for users" (Alesheikh, Helali, \& Behroz, 2002, p.1). When working with a high demand for graphic quality, it is more appropriate to resort to desktop sources. However, web GIS proves to be more flexible by not requiring "the same resources as these (ArcView/Info) programs ... [such as] powerful computers, extensive training, and expensive site license for a site wide GIS solution" (Alesheikh, Helali, \& Behroz, 2002, p.2). Understandably every GIS has its pros and cons depending on where it is deployed or hosted. In this project, no extensive resources were required other than resources for providing fundamental functions and basic visual design.

Another obstacle to consider for online portrayal is the data display of vectors and rasters. While vector data that is delivered over the web is faster than raster processing, data transfer can be problematic with a sluggish web server. Fortunately, options for precaching both forms of data are available if the developer permits it. Advantages include a "pre-selection with raster data, and afterwards, loading of the actual vector data with the possibility of subsequently local process" (Alesheikh, Helali, \& Behroz, 2002, p.2). These main concerns of data transfer arise frequently. However, if developers acknowledge this situation, there can be many modifications to online sourcing that help overcome its downfalls. As with any piece of technology, there is always room for improvement. 


\subsection{Applying Web GIS}

As discussed in section 2.2, web GIS is quite flexible in its integration and outreach, and therefore, it can provide aid for small-to-large scale purposes. Two potential areas in which it can play an active role are in tourism and property management. Tourism can be considered as a large scalable application because of its reliance on the web. This demand of online geographic references, "points to the need for information systems [to] assist people in finding relevant information" (Ciamacca, Jansen, \& Spink, 2008, p.2). In order to deploy such a system, "network access is vital to building and sharing information products... to accommodate the introduction of a [web] GIS" (Tomlinson, 2007, p.119). This concept is crucial to not just tourism efforts, but also to property sale systems. Web GIS offers a more logical framework for the management of parcel data that lacks a proper sharing mechanism. Although this section illustrates only a few examples, web GIS is growing in its relative application for management and analysis.

\subsubsection{Web GIS in Tourism}

Currently, the Internet is the primary medium for tourists to search for geographic information. According to a cyber-study conducted by Ciamacca, Jansen, and Spink, it was concluded that within web searches in the United States, "geographic categories represent nearly $60 \%$ of travel searching, therefore travel searching appears to be very location focused" (Ciamacca, Jansen, \& Spink, 2008, p.14). This high percentage illustrates the need for web GIS applications designed for tourist campaign and education. While web GIS can satisfy various travel purposes, it is more closely associated with recreational trip planning than for planning business trips (Caneday \& Chang, 2011, p. 1436). This implies that it is extremely necessary to display accommodation details and nearby attractions to a user who is planning a trip. The quality of the geographic information delivery and the application layout are of the utmost importance to effectively teach users about the area before they arrive.

Visual design and fundamental tools can regulate the motivation for users to participate in a web GIS. Users with varying levels of exposure to the technology and experience can successfully utilize a web GIS. A conclusion from a psychological study of web users stated that the most influential factors for a web GIS respectively, were its "usefulness" and "playfulness". The usefulness aspect was deemed the fundamental factor to drive user access, while the playfulness was the primary mechanism for user engagement (Caneday \& Chang, 2011, p.1436). These are the basic criteria for judging the successfulness and attractiveness of a web GIS for tourist efforts, and these factors were heavily considered during the development of this project.

\subsubsection{Web GIS in Property Management}

Property management typically requires supervision from multiple administrators. In order for managers to implement a successful web GIS for overseeing parcel data, it must contain a sharing system. According to Roger Tomlinson, the father of GIS, an "effective sharing of application programs and data ... is one of the most important requirements of a successful GIS" (Tomlinson, 2007, p.82). Fortunately, this requirement is obtainable within a web GIS and can be applied to maintaining parcel records. This can increase the 
productivity for parcel management by permitting access to designated viewers who can edit the attributes. It also demands better data integrity because a larger audience can view any changes.

Web GIS plays an active role for improving a property management workflow. Even though parcel management has been closely associated with traditional GIS in the past, "the full potential of [web] GIS use can be realized with its application across the land records" (Esri, 2007). This is because GIS software, such as that created by Esri, can create a steady framework to facilitate consistency within a parcel management system. In relation to Tomlinson's concept of data sharing, web GIS technology can centralize parcel data online and tie it with a "steady workflow to create or update a parcel database... within and between organizations" (Esri, 2007). With a sharing technique and driven implementation, web GIS can exploit the loop holes in a parcel management system and provide solutions to make it operational on the web.

\subsection{Summary}

Examination of the literature supports the concept of online mapping for tourism efforts for Long Caye. The flexibility and ease of data delivery by means of the web can strengthen the island's tourism campaign. Compatible data types of vector and raster combinations make it possible to manipulate and display information on a large-scale level. With appropriate resources like ArcServer and essential web scripting skills, a developer can successfully create a comprehensible and manageable application. The purpose of this literature review provided a basis for project design requirements and detailed planning. 


\section{Chapter 3 - Systems Analysis and Design}

This chapter delivers information about the project planning process. Included topics are defined requirements, detailed system architecture, and project implementation tasks. Collaboration input from the developer and client resulted in the majority of the design variables. Extensive discussion of the planned procedures are reviewed in this chapter.

\subsection{Problem Statement}

There were two different problems addressed in this project. One issue was the low quality and quantity in geographic information delivery. This negatively impacted the public education efforts on the Long Caye website. Media found on the website were limited to literary descriptions, photos, and outdated maps. Site navigation required a lengthy amount of time and the interface presented an overwhelming amount of information. The second issue was the lack of a sharing system for managing a parcel database. Since there was a lack of a centralized source, edits on the database from multiple resource resulted in low management efficiency. The client needed a more effective method of reaching out to the public as well as maintaining database modifications.

\subsection{Requirements Analysis}

Prior to project development, several requirements and design concepts were addressed. Requirements were made for modifying literary descriptions from their website into a simpler format. Additional requirements were made for creating a network system for the parcel database. The final decision was to create two individual online applications. Motive behind the construction of two separate applications was because of two different problems faced by the client, each with distinct audiences. One application was intended for the general public and the other was for internal use only by the Long Caye owners. This section breaks down the functional and the non-functional requirements for both the internal and the public applications.

\subsubsection{Functional Requirements}

The functional requirements encompassed application performance to satisfy the client's needs. The requirements were made based on the assumption that data obtainment and analysis were successfully done prior to web development. The final requirements for the public application are listed in Table 1. 


\begin{tabular}{|l|l|}
\hline \multicolumn{1}{|c|}{$\begin{array}{c}\text { Public Application } \\
\text { Requirement }\end{array}$} & \multicolumn{1}{c|}{ Description } \\
\hline Attribute Display & $\begin{array}{l}\text { Allows users to click on symbols for } \\
\text { descriptive pop-ups. }\end{array}$ \\
\hline Layer Toggle & Allows users to turn desired layers on or off \\
\hline Home Extent & $\begin{array}{l}\text { Allows users to return to initial preset } \\
\text { extent. }\end{array}$ \\
\hline Bookmark Extents & $\begin{array}{l}\text { Allows users to pick from a list of popular } \\
\text { sites. }\end{array}$ \\
\hline Geodatabase Access & $\begin{array}{l}\text { Allow client to access a copy of the } \\
\text { geodatabase that contains public application } \\
\text { layers }\end{array}$ \\
\hline
\end{tabular}

Table 1. Public application functional requirements.

Five fundamental required functions were included to support a simple user interface. One of the functions required the display of feature attributes in an organized manner. A second functional requirement demanded a toggle ability to display a layer of interest. To display areas of interest, a required initial home extent and bookmarked extent function were necessary to make the application user friendly. The public application requirements stressed the display performance and listed no requirement to enable layer editing to the public users. However, any data used in the public application was required to be accessible by the client. The geodatabase access was necessary for the client to make any modifications to the feature classes in future projects. Requirements for the public application were based on educational intentions and expending the spatial resources for the client.

The internal application requirements demanded full editing capabilities for the users. The functionalities for the internal application are summarized in Table 2. 


\begin{tabular}{|l|l|}
\hline $\begin{array}{c}\text { Internal Application } \\
\text { Requirement }\end{array}$ & \multicolumn{1}{c|}{ Description } \\
\hline Query Parcel Data & $\begin{array}{l}\text { Allows user to query through all parcel data by parcel number } \\
\text { or parcel owner name }\end{array}$ \\
\hline Update Parcel Data & Allows user to change parcel attributes and save \\
\hline Restricted Access & $\begin{array}{l}\text { Allows access to correct input of username password at launch } \\
\text { of application }\end{array}$ \\
\hline Attribute Display & Allows user to manually click on a feature layer to fire a pop-up \\
\hline Geodatabase Access & $\begin{array}{l}\text { Allows client to access a copy of the geodatabase that contains } \\
\text { the internal application layers }\end{array}$ \\
\hline
\end{tabular}

\section{Table 2. Internal application functional requirements.}

Similar functional requirements between the two applications were the informative display of attributes and geodatabase access to the client. The ability to search, update, and delete each parcel object were the primary functional requirements for the internal application. Since the parcel data contained confidential details, restricted access to this application was demanded. These requirements permitted full editing capabilities for the users of the internal application.

\subsubsection{Non-Functional Requirements}

Non-functional requirements define the environment under which the developed application works properly. Both applications had the same quality and quantity of nonfunctional requirements. Table 3 lists the needed software and hardware in order to fulfill the functional requirements.

\begin{tabular}{|l|l|}
\multicolumn{1}{|c|}{\begin{tabular}{c}
\multicolumn{1}{|c|}{$\begin{array}{c}\text { Ron-Functional } \\
\text { Requirements }\end{array}$} \\
ArcMap 10.2.1 and \\
ArcSDE
\end{tabular}} & $\begin{array}{l}\text { Esri resources for database management and feature class } \\
\text { editing }\end{array}$ \\
\hline $\begin{array}{l}\text { ArcServer 10.2.1 and } \\
\text { ArcGIS Online }\end{array}$ & $\begin{array}{l}\text { Esri services for hosting the data online, in the form of } \\
\text { dynamic, annotation, or feature services }\end{array}$ \\
\hline $\begin{array}{l}\text { ArcGIS JavaScript API 3.9, } \\
\text { Dojo Toolkit }\end{array}$ & $\begin{array}{l}\text { Esri and Dojo parameter documentation for script } \\
\text { development in HTML file format }\end{array}$ \\
\hline Web Browsers & $\begin{array}{l}\text { Interprets an HTML file on the internet to display the } \\
\text { script content }\end{array}$ \\
\hline
\end{tabular}

Table 3. Non-functional requirements. 
The building blocks of the application included several software and hardware usage. ArcMap and ArcSDE were required to edit feature classes within an enterprise geodatabase. The ArcSDE communication with an online web server was necessary for web service publication. Additionally, the services were published onto an ArcGIS Online Long Caye Organizational account. The web services were called in two separate scripts that were written using the ArcGIS JavaScript API, Dojo Toolkit, and HTML (hypertext markup language) with CSS references. These scripts, delivered in HTML format, required interpretation within a web browser to properly display its content. Almost all the non-functional requirements relied on Esri products.

\subsection{System Design}

A system design was constructed to display the relationships among the required hardware and software. This design was necessary to facilitate the resources for proper development of the application. Final products for the client included a published copy of all the data onto the Long Caye online account, one public web application file, and one internal web application file. The methods for web application development was based on a predetermined system design shown in Figure 3-1.

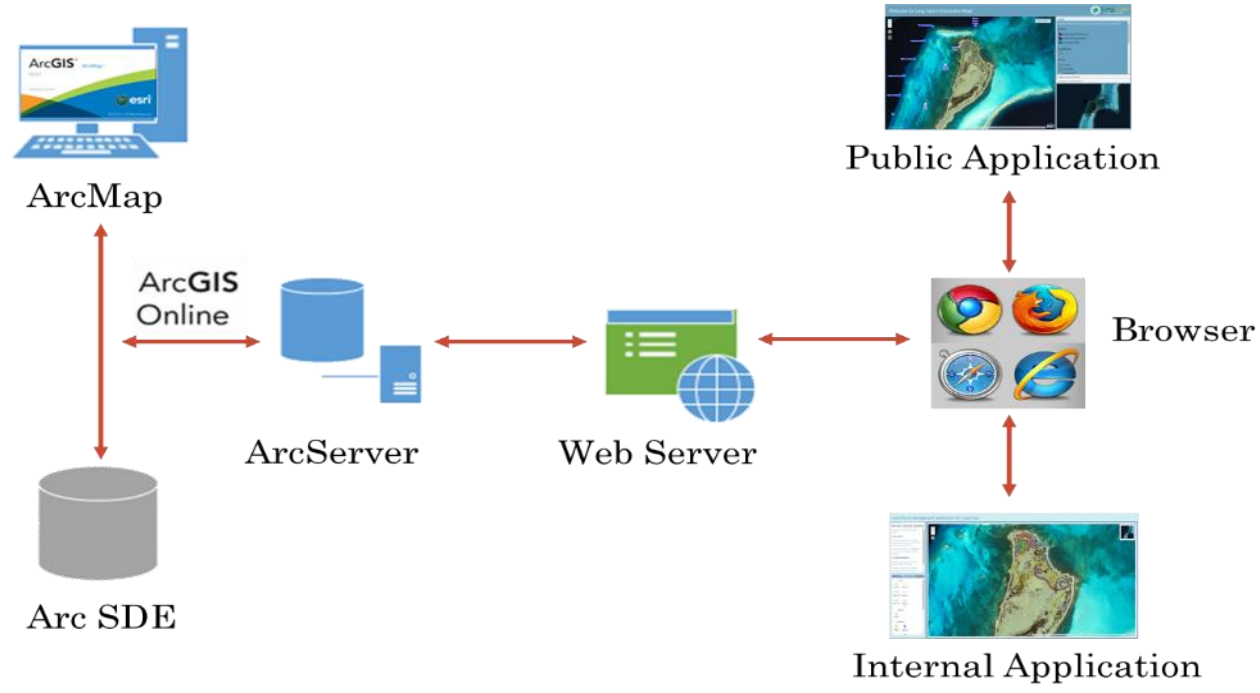

Figure 3-1: System architecture.

\subsection{Project Plan}

When the final plan was agreed upon, weekly meetings were held to update the client on the project progress. The final plan was comprised of several stages that included tasks such as data organization, requirement analysis, system design, data collection, geodatabase development, service publication, web development, and final testing of the web applications. A mitigation plan for scope creep made the public application a top priority if both applications had not been completed on time. Figure 3-2 is a Gantt chart that presents the time frame for each phase of the project. 


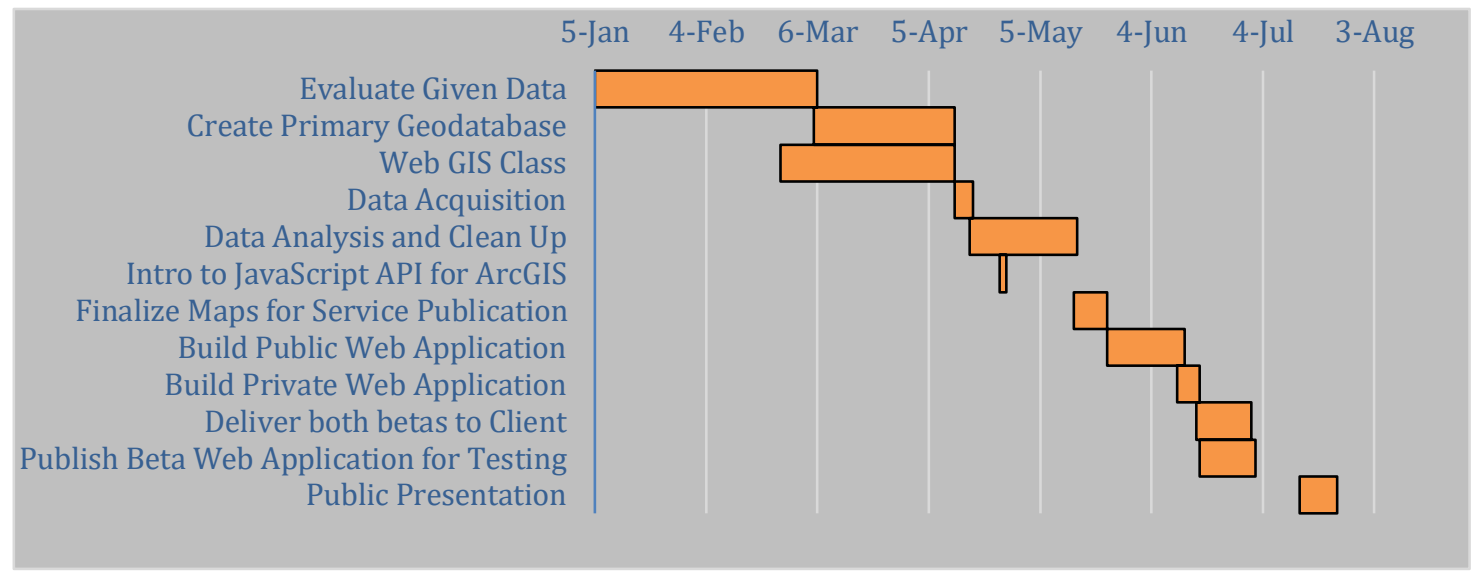

Figure 3-2: Project Gantt chart.

Slight changes to the Gantt chart were made in the phase of finalizing the maps for service publication. The time frame of this phase was extended to an additional month due to professional advice for symbology modification and for enhancing the web service quality.

The first phase was to analyze the existing Long Caye geodatabase. The geodatabase lacked any organization of its feature classes. Most of the feature classes did not contain sufficient data fields aside from an Object ID, shape field, and occasionally the feature name. Plans to add feature classes and appropriate data fields were made based on the conclusion of the geodatabase evaluation.

After extensive web site research to get familiar with major island attractions, data collection was done on the island. This second phase used Trimble GPS technology to map out features such as trails, boardwalks, scuba sites, and snorkel sites. Alternate plans to use a mobile device and GPS watch were made to ensure reliance that more than one piece of hardware was available for data collection. The data were extracted and converted to feature classes within Esri software.

The third phase was data clean up. The internal application was meant to integrate the tabular data of property information with existing parcel feature class records. As for the data fields in the public application feature classes, much of it was derived from existing descriptions or from client input. The transferred information from the Long Caye website to the dive site feature class required reading through each site description to create appropriate attribute categories. Fortunately, the descriptions were consistent in terms of site name, typical water current strength, starting visibility level, depth, and common wildlife. Figure 3-3 shows the description of the Long Caye Ridge and Half Moon Wall on the Long Caye website. 


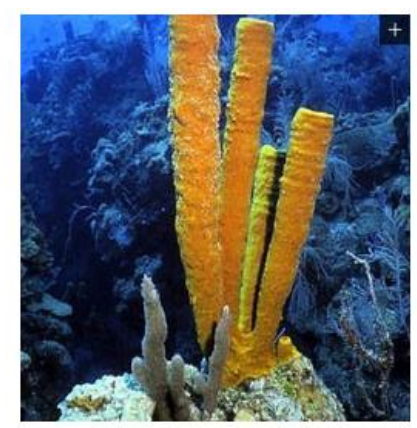

The Long Caye Ridge is located on the western side of Long Caye. It is named from a ridge of reefs sticking out that form a small peninsula just north of Tres Cocos. Spur-and-groove formations can be found on the bottom leading to the wall and a drop-off of major proportions. The grooves are perpendicular to the wall and go directly into the sea. With depths of 40 plus feet, 80 feet of visibility and minimal currents, the Long Caye Ridge is excellent for beginners. The sponges, coral and fish here are similar to those on Hat Caye Drop-off. There are many large and colorful sponges and delicate gorgonians near the drop-off and all along the wall. Below the soft coral, vase and tube sponges there are developments of finger and yellow pencil corals. You will also see coral niches for spotted crabs, lobsters, filefish and arrow blennies. This is also a great site for underwater photos.

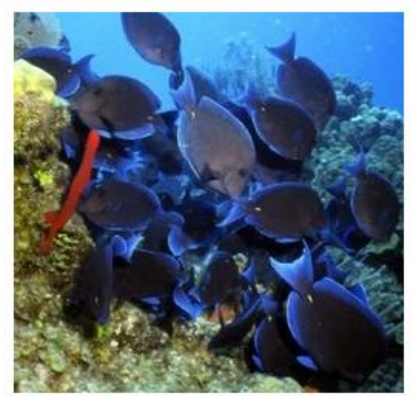

Half Moon Wall is an amazing dive spot, which includes the Half Moon Caye National

Monument. Before or after your dive you can also see the boobie bird sanctuary on Half Moon Caye. The reefs here are magnificent and diverse. The site is located just south of $\mathrm{Half}$ Moon Caye. The coral structures form There is also a sloping desolate sand flat separating the reef rim from shallow reefs by the shore. The Half Moon Wall is an excellent dive spot for the intermediate level diver. It has depths of 30 plus feet, amazing 100 feet of visibility and low-level currents. When divers go 30 feet below, they see that the reef rim has a stunning development of spurs and grooves. There is both large and small marine life on the Half Moon Wall. You will see garden eels, conch, rays, flounder, star-eye hermit crab, tilefish, manta rays, groupers. yellowtail snappers, razorfish, toadfish, spotted eagle rays, turtles and black groupers as well as various other marine creatures at the Half Moon Wall.

Figure 3-3: Descriptions of the Long Caye Ridge and Half Moon Wall dive sites.

The fourth phase included publishing several services onto ArcServer. Two dynamic map services, two tile services, and multiple feature services were published from ArcMap with ArcSDE. A tile service of a panchromatic sharpened IKONOS image was hosted by the Esri Oceans and GIS Institute organizational server to provide a detailed tile service to act as a basemap for both applications. All other web services, were also published onto the client's ArcGIS Online Organization account.

Once the services were successfully hosted online, application scripting and design commenced. This was the final phase of the project. Guidelines and sample code from the ArcGIS API for JavaScript were assimilated to fulfill the functional requirements.

Several beta applications were sent to the client for feedback on both services. The public application was also tested on web browsers in different countries. Final documentation of all the data, two functioning applications, a cleaned up geodatabase, and a copy of the web services was delivered to the client at the conclusion of the project.

\subsection{Summary}

This chapter detailed the required needs of both software and hardware for the success of the project. System architecture design was based on a mutual agreement between the developer and the client. Defined functional and non-functional requirements were essential to complete a simple user interface. Deeper insight to web design and implementation were based on data models, which are further elaborated in Chapter 4. 


\section{Chapter 4 - Database Design}

This chapter addresses a conceptual data model and a logical data model which were the building blocks for the geodatabase development. The conceptual model depicts crucial factors linked to the parcel sales system while the logical model portrays the data field details.

Section 4.1 explains the conceptual data model and the relationships among the contributing factors. In section 4.2, the logical model reveals the fields of each individual feature class. Section 4.3 exposes the sources of pre-existing data and section 4.4 delineates the data collection plan. Finally, section 4.5 discusses data clean-up procedures for web publication preparation.

\subsection{Conceptual Data Model}

These conceptual data models display the associations between the major classes that constitute the system for funding Caye operations. Figure 4-1 depicts the tasks for a parcel transaction between an island owner and an investor.

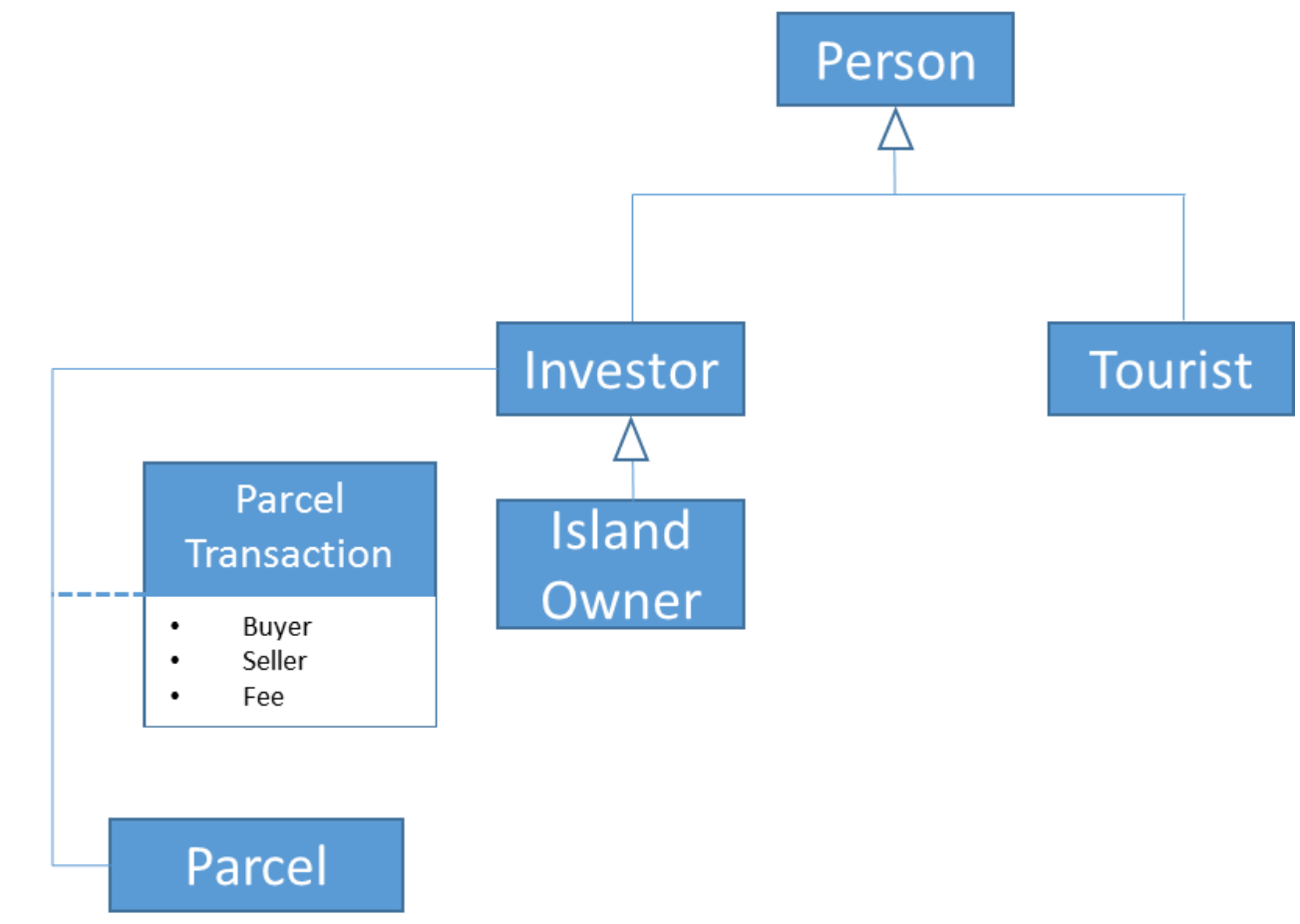

Figure 4-1: Conceptual data model for a parcel ownership transaction.

A person who participates in a parcel transaction is either an investor or an island owner. The parcel transaction requires a buyer, a seller, and a parcel fee to ensure a legal transfer of land ownership. Many of the parcel fees were distributed to the resort amenities, therefore, the resort heavily depended on the profit generated from the successful parcel transaction.

Although a person may also be a tourist, the tourist does not participate in parcel sales, but rather in reserving resort amenities. A tourist requires interaction with an island 
owner to make resort reservations. A reservation fee can also be distributed to fund necessary supplies for the resort. Figure 4-2 displays the relationship between a tourist and an island owner to undergo a reservation transaction to use a resort amenity.

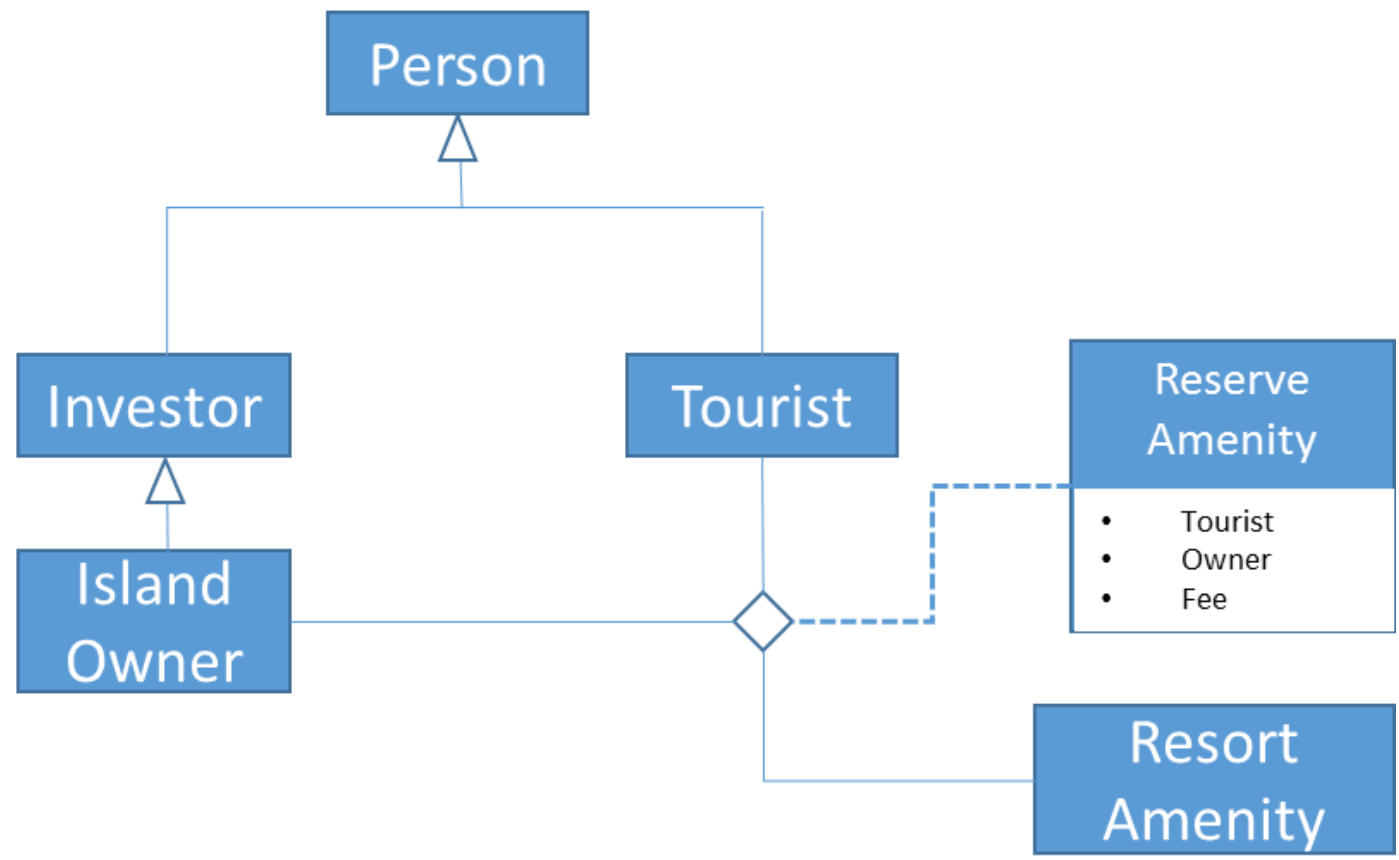

Figure 4-2: Conceptual data model for a reservation transaction.

Several amenities are offered to a person who pays the reservation fee. This includes transportation to diving sites, access to hiking trails or boardwalks, and permission to stay in the resort building. Figure 4-3 portrays the popular resort amenities.

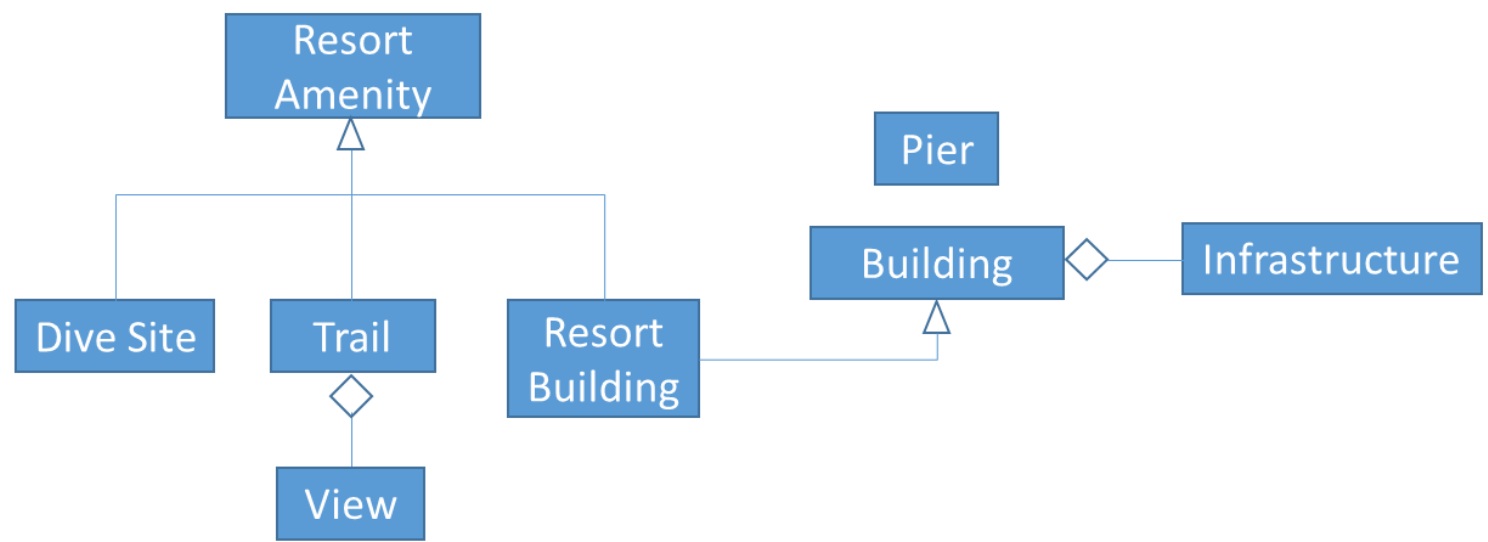

Figure 4-3: Conceptual data model for the resort amenities.

Any person, including an island owner or a parcel investor, can participate in using these facilities by paying the reservation fee. This generates an extended source of income in addition to the fees paid by tourists. 
The buildings, infrastructure and piers were not a direct component of parcel or reservation transactions because the funds to maintain these structures were derived from separate finances. These objects were the first to be developed on the island prior to the construction of the resort, therefore its funding was derived from several sources.

These three conceptual models ultimately tie together by means of a person with an associated task. A successful transaction for parcel ownership and tourist reservation can result in providing quality resort amenities. These relationships are ultimately directed towards the benefit to uphold the resort operation. With no other current source of revenue aside from reservation fees and parcel fees, the resort funds would come directly from the owners, consequently making the resort investment obsolete.

\subsection{Logical Data Model}

The conceptual data model led to the design of eight variables that could be represented as twelve operational layers. These eight variables consisted of parcels, trails, dive sites, piers, buildings, resorts, notable views, and infrastructure. The layers were according to their relationships with the two applications - public (P), internal (I), or both (C). Polygon features represented the parcels, buildings, piers and resorts. Line features represented the trails and point features represented the dive sites, infrastructure, and notable views. Fields and field types of each layer are found in Figure 4-4.

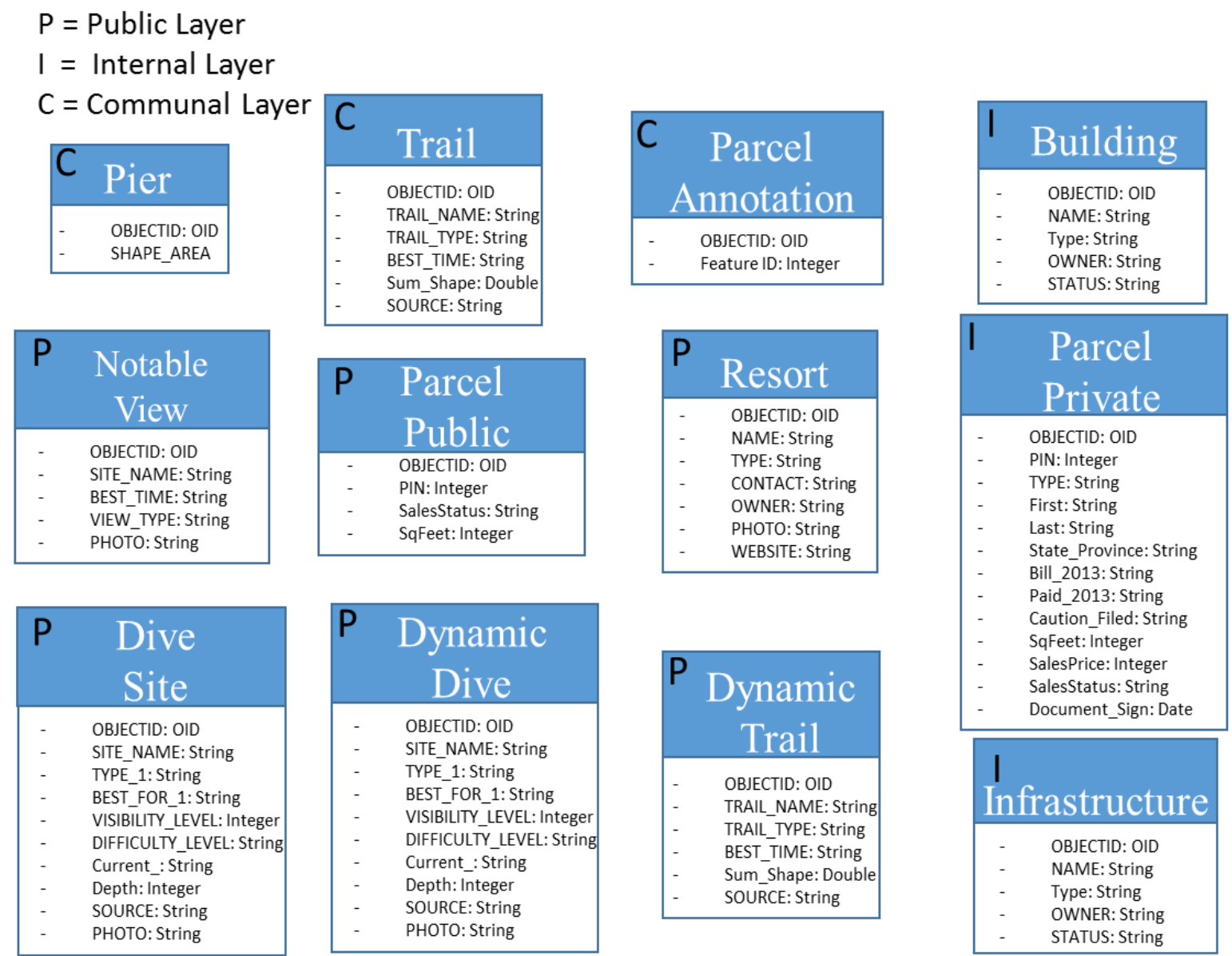

Figure 4-4: Logical data model. 
The most complex feature class was the parcels layer. This layer contained important details for each individual parcel, along with personal information about its owner. For the purpose of web development, two different versions of the parcel layer had to be created. One layer, Parcel Public, was created to conceal certain data fields for the public application, and the second layer, Parcel Private, contained all confidential fields necessary for the internal application. Both parcel layer versions were to be labeled with an independent annotation layer, also created for web GIS purposes. Duplicates of the Dive Site and Trail were created for web map display functionality, which is further discussed in Chapter 5.

\subsection{Data Sources}

Most of the data were provided by a liaison, Drew Stephens. Stephens delivered the data for the parcels, existing trails, infrastructure, and piers. The client only supplied the master database that contained parcel information. The rest of the data were received via feature classes. All the data were converted to feature classes in order to achieve compatibility within ArcMap. The parcel data were mapped by a professional surveyor and delivered as a CAD file which was later converted into a feature class in ArcMap. The project developer used GPS technology to create the remaining feature classes such as dive sites, notable views, resorts, and updated trails.

A satellite image was also provided and was used in both applications. Stephens was also the source of this raster layer. The satellite image was modified to allow public redistribution according to a license with the GeoEye IKONOS image regulations, but the specific modifications to the image were unknown. The image was hosted on the web by the GIS Institute, courtesy of network connections through Stephens.

\subsection{Data Collection Methods}

This project required a significant amount of data collection. Data collection was required for dive sites, resort buildings, and notable views, as well as for updating pre-existing trails. Dive sites were mapped because there were no previous records of the sites that could be used modified. Older dive maps had been created by visually estimating locations. To make the site locations more accurate, the project developer collected dive site areas using a handheld Trimble Juno GPS, which mapped points while the boat was anchored. For the sites that were not visited, dive master and island co-owner Jim Cullinan digitized locations as best as he could on a satellite image, as there were too many dive sites on the island to visit given a short time frame. The GPS device recorded walking and biking movements to map out the trails and boardwalks (Figure 4-5). 


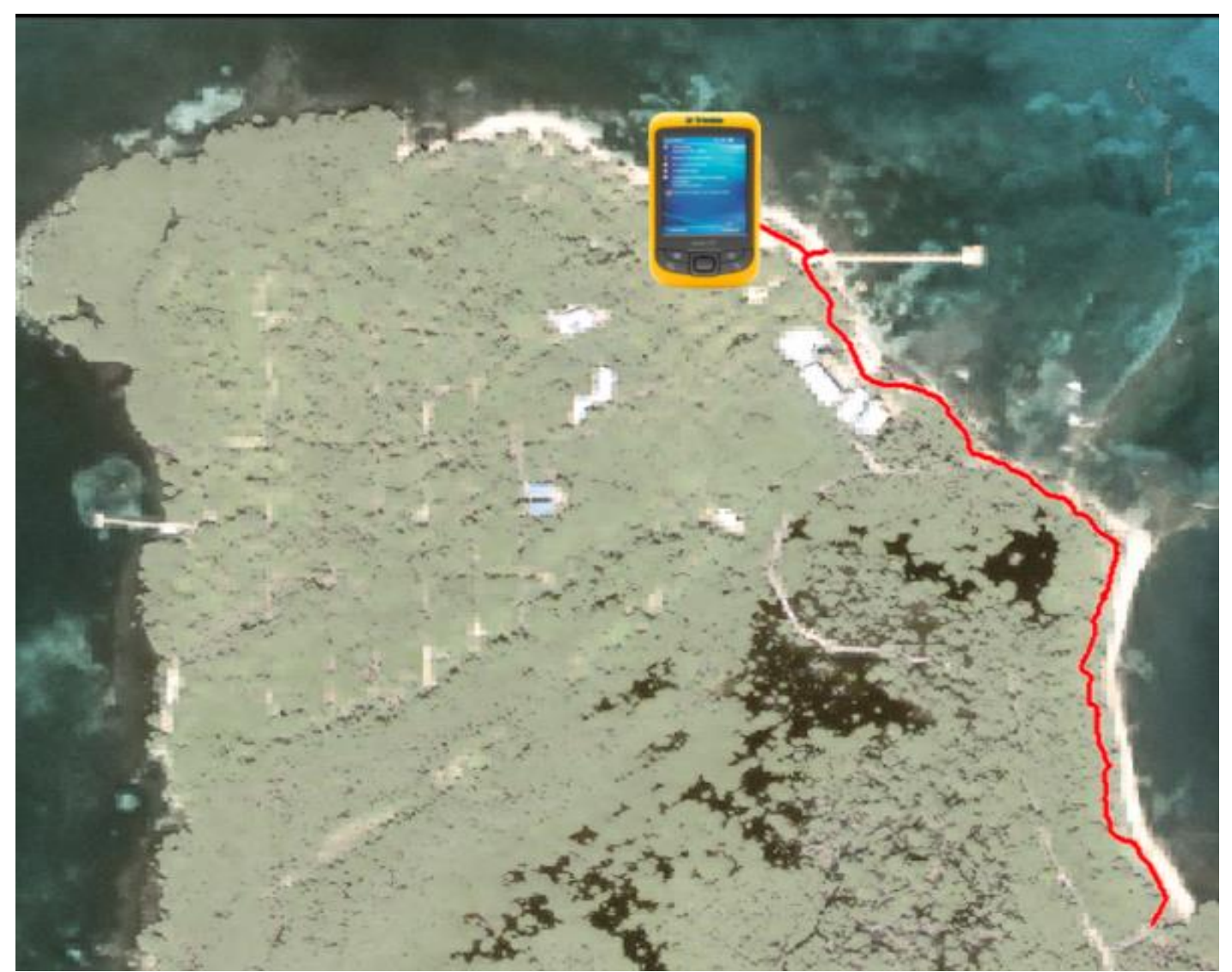

Figure 4-5: A segment of the trail route mapped by a GPS.

During this navigation, analysts noted trail names and ground types. Photos were taken through a personal GoPro camera and other graphics were collected from Cullinan's personal albums. Lastly, the developer mapped the resorts by walking around the perimeters of the Itza Lodge, Calypso House, and Huracane Operations. All the mapped data were converted to a shapefile using TerraSync software so that they could be edited in ArcMap software.

\subsection{Data Scrubbing and Loading}

Most of the data needed scrubbing, as much of it had no attributes or fields. Of all the layers, editing the parcel data required the greatest effort. In the original feature class, "Object ID" and "Shape_Area" were the only two fields. Prior to the project, analysts used a paper map of the island to determine which polygons belonged to which parcel identification numbers. After 654 polygons were assigned a number, the feature class was joined to the parcel database based on its parcel ID field and exported into a geodatabase.

To conceal the names of the parcel owners and their financial status, almost all of the parcel fields had to be removed for the public application. Although the visual symbology of both versions of the parcels was identical, this revision had to be made to allow certain audiences without authentication to view the parcels. This modification stems from an option on ArcGIS Online to share data. 
The client chose essential fields in the parcel database to join to the final parcels feature class, as not all fields in the original database were used in the latest updates. The newly collected features were with the information on the Caye website. Thus, it was quite simple to create the database for the trails, dive sites, and notable views.

While mapping trails and boardwalks, the developer encountered several physical obstacles such as territorial wildlife and fallen trees. This resulted in some crookedness in the lines. Several of the routes were walked again to ensure the precision of the data.

\subsection{Summary}

Long Caye management variables established the preliminary guidelines for the database design. Determination of the data appearance in specific applications stemmed from both of the problems and the need to protect the identity of parcel owners. Combining the variable and audience concept formed the data fields of existing and newly collected data. Modification and scrubbing of the data prepared the geodatabase components to be published onto the web, which is further discussed in Chapter 5. 


\section{Chapter 5 - Implementation}

Web GIS applications were developed as both a resource to the public for island education and a centralized database source for Long Caye owners. Section 5.1 details the Long Caye geodatabase development and final application map documents. Section 5.2 covers the requirements to publish map services online. Section 5.3 explains the public and internal application web development scripting techniques and functionality.

\subsection{Long Caye Geodatabase Development}

The feature classes of the Long Caye enterprise geodatabase were organized into three feature datasets and three tables. The dataset categories were public, internal, and communal. Figure 5-1 is a snapshot of the Long Caye geodatabase components design.

$\square \square$ LongCaye.gdb
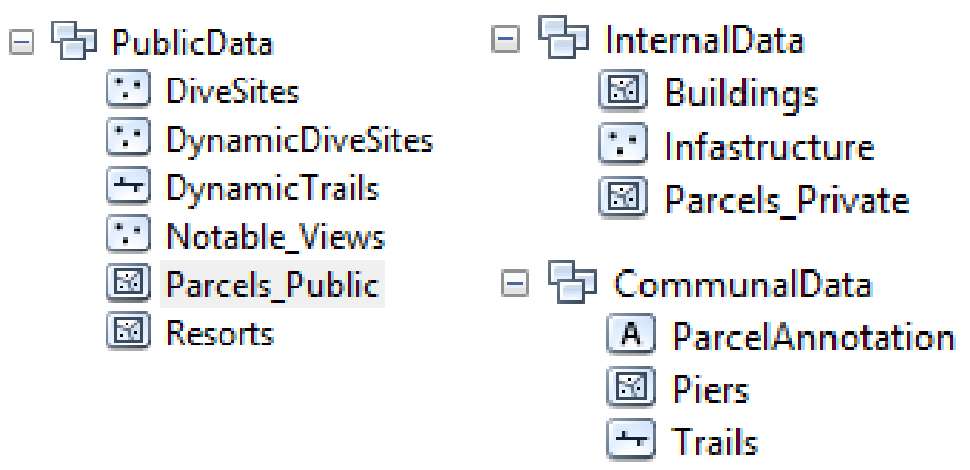

AnonymousParcels

MasterDBR44

NamedParcels

A ParcelAnnotation

NamedParcels

t.t Trails

Figure 5-1: Long Caye enterprise geodatabase components.

The category names also related to the use in the application type. All of the data were originally projected using the WGS84 UTM Zone $16 \mathrm{~N}$ coordinate system. The geographic coordinate system was the GCS WGS84. The data were re-projected to the WGS84 Web Mercator (auxiliary sphere) in order to be compatible with the basemaps used in this project. All the feature classes were stored into a file geodatabase and later exported into an enterprise geodatabase, known as Arc SDE (Spatial Data Enterprise). Many of the attributes for each feature class were added with the consideration that they would be displayed on a pop-up information windows in the web apps. Two tables, both derived from a master parcel table that the client provided, were used to join to certain parcel feature classes. One layer not featured in Figure 5-1 is the TIFF file of the GeoEye IKONOS satellite image of the study area. The satellite image was used in both applications as basemaps. The motive for the design structure of this geodatabase was to organize layers for efficient web publication and map documentation.

\subsubsection{Public and Communal Dataset}

The public dataset consisted of six feature classes. These classes included DiveSites, DynamicDive, DynamicTrail, Notable Views, Parcels Public, and Resorts. The Resorts layer originated from the existing Buildings feature class and additional GPS data 
collection. Only two of the three objects in the Resorts layer were imported from the Buildings layer. The Resorts attributes contained categories of building name, building type, operation contact information, operation owner, photo URL, and a URL to the main website. The DynamicTrails was an updated version of the initial Trails feature class that Drew Stephens provided. Trail name, ground type, photo URL, and suggested time of navigation, were the attribute fields added to the DynamicTrails feature class. The island staff recommended Notable Views, which were designated vantage points for beautiful ocean and nature vista. The Notable Views table listed the lookout name, view type, and photo URL. The Parcels Public feature class contained no information except parcel ID number and sale status after a join to the Anonymous Parcels layer. The final altered parcels layer was used to create a linked Parcel Annotation layer which was found in the communal dataset.

The dive sites were the most complex layers in terms of symbology. The site name, typical current, starting visibility depth, SCUBA certification level, wildlife sightings, and photo URL (Uniform Resource Locator) were the categories in its attribute field. There were two layers containing the same information but these were symbolized differently for two different services. One layer had advanced labeling with the intention for publishing as a dynamic service. The other layer had basic symbology and was meant to be published as a feature service. This situation was also applied to the Dynamic Trails layer, and Section 5.2.1 further explains the need for both service types. Figure 5-2 depicts the final map document for the public application with all feature classes from the public and communal datasets.

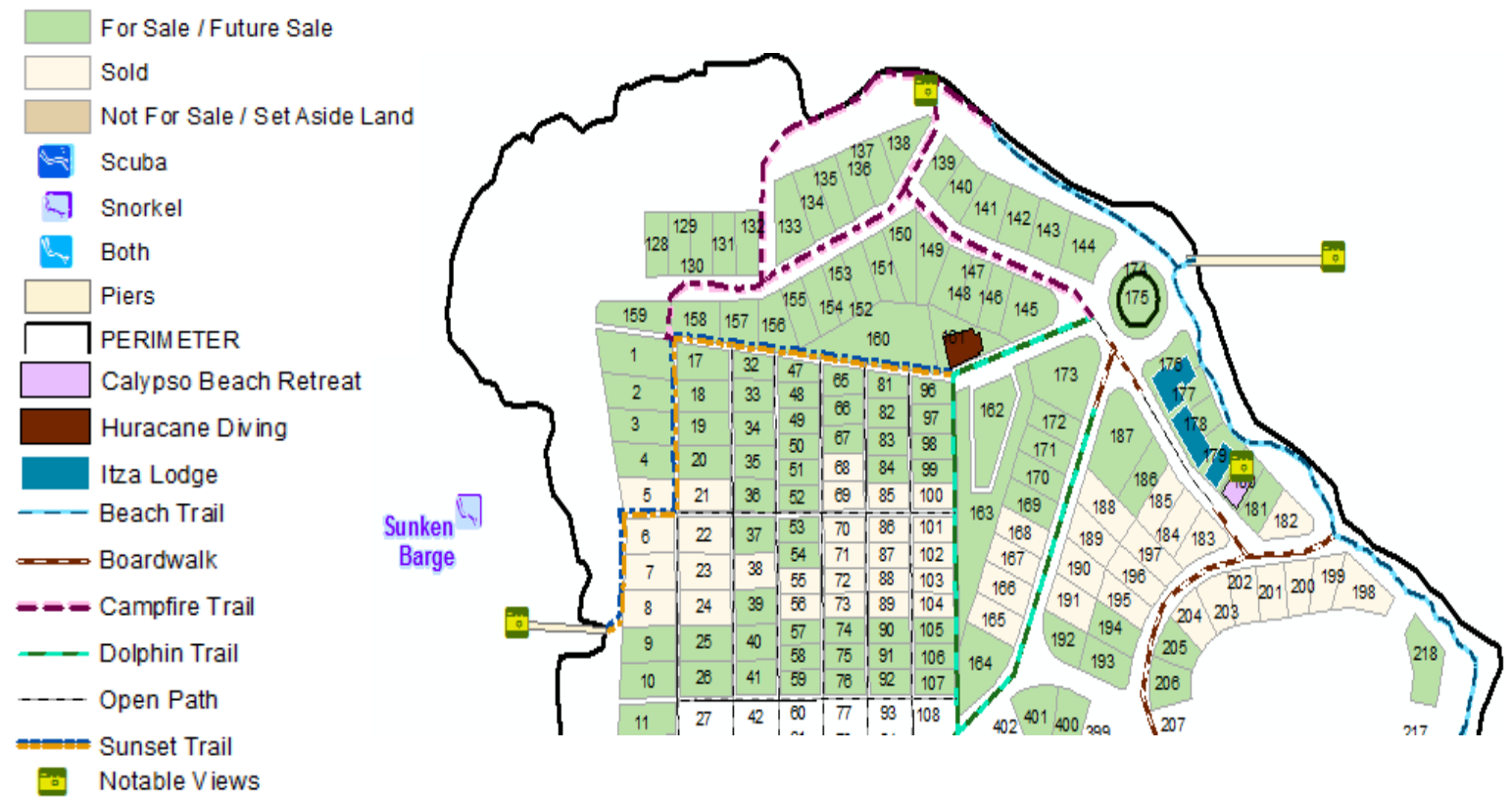

Figure 5-2: Partial extent of the final public application map document.

\subsubsection{Internal and Communal Dataset}

The internal dataset was composed of three feature classes and one annotation layer. These consisted of a parcel number annotation layer (ParcelAnnotation), a parcels 
polygon feature (Parcels_Private), an infrastructure point layer (Infrastructure), and a buildings polygon feature (Buildings).

The Buildings and Parcel Private layers were based off pre-existing feature classes. The building polygons contained no information except for shape length and area. Three fields were added to the Buildings layer, namely building operation title, status, and type. Prior to this project, a professional surveyor mapped parcel boundaries and delivered the product as a CAD file. The $\mathrm{CAD}$ file was converted into a feature class, which the client never utilized. Originally, the parcels were only labeled and never joined to any other data related to parcel sales. After sifting through the master parcel Excel file, the client approved a final list of appropriate fields. The resulting table contained 13 fields that were of the utmost importance for client needs. The final table, Named-Parcels, was then joined to the Parcels Private feature class based on parcel number.

The Infrastructure point layer was not altered significantly. This was also an existing shapefile that Stephens provided. The layer only had two data fields: ObjectID and infrastructure type. A status field and a monthly cost field were added, as these factors were necessary to the client. Similar to the other GIS data, the original feature class had not been utilized since its creation.

Other feature classes used in the final map document for both applications included the communal dataset. The Piers layer was only used for display and was not to be used in any other functionality on the web applications. Figure 5-3 shows the final map document, which includes all feature classes from the internal and communal datasets.
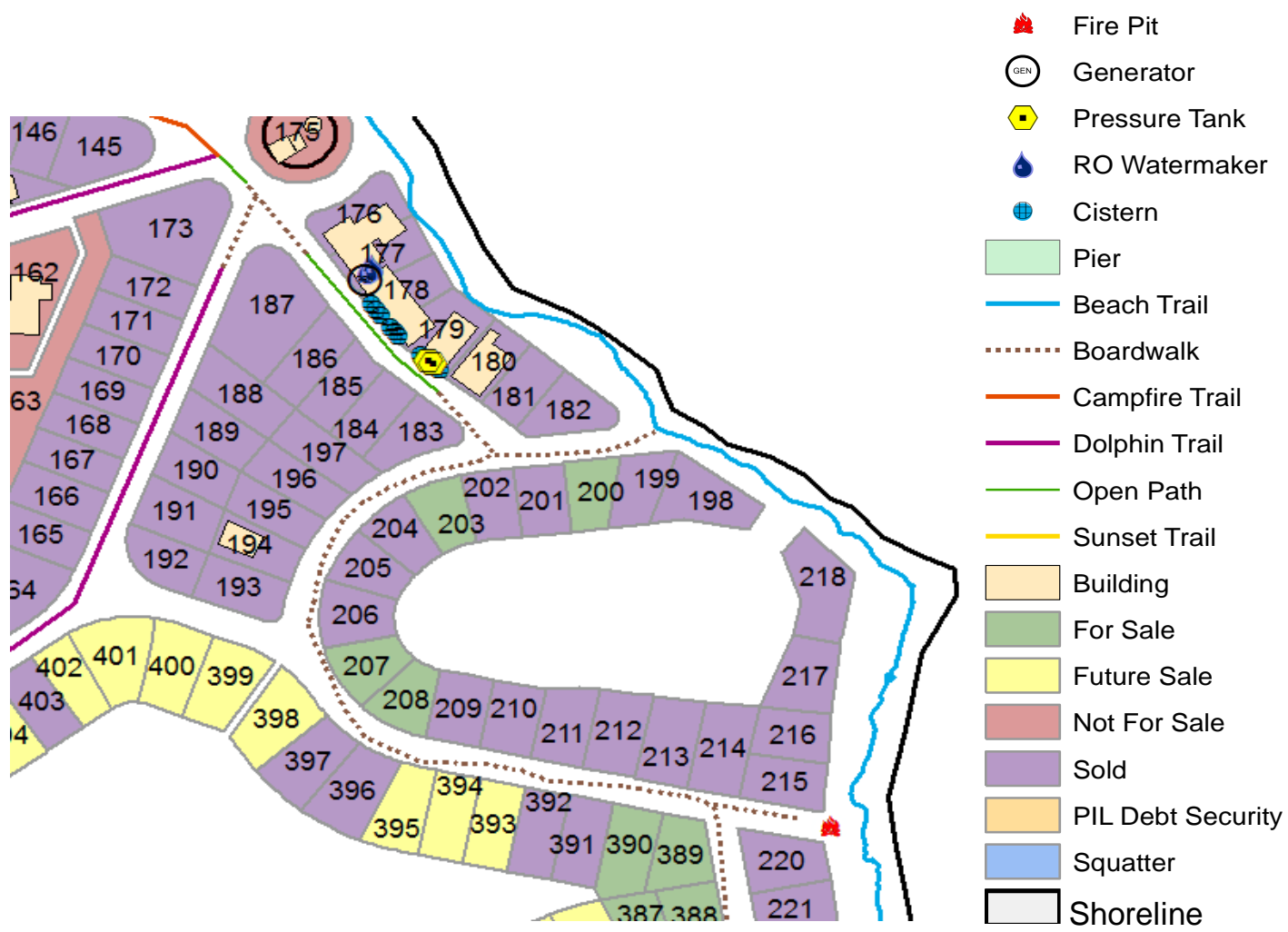

Figure 5-3: Partial extent of the final internal application map document. 


\subsection{Publishing Map Services}

After the final map documents were created for both web applications, publication onto the web commenced. Both web applications required three main resources to successfully deploy the services online. Varying types of map services were published depending on the need of the application tool functionality. These types included feature, dynamic, or tiled map services. Publishing these services required the use of ArcMap, ArcSDE, and ArcServer. Figure 5-4 shows the order in which these resources were used and lists resource-related tasks.

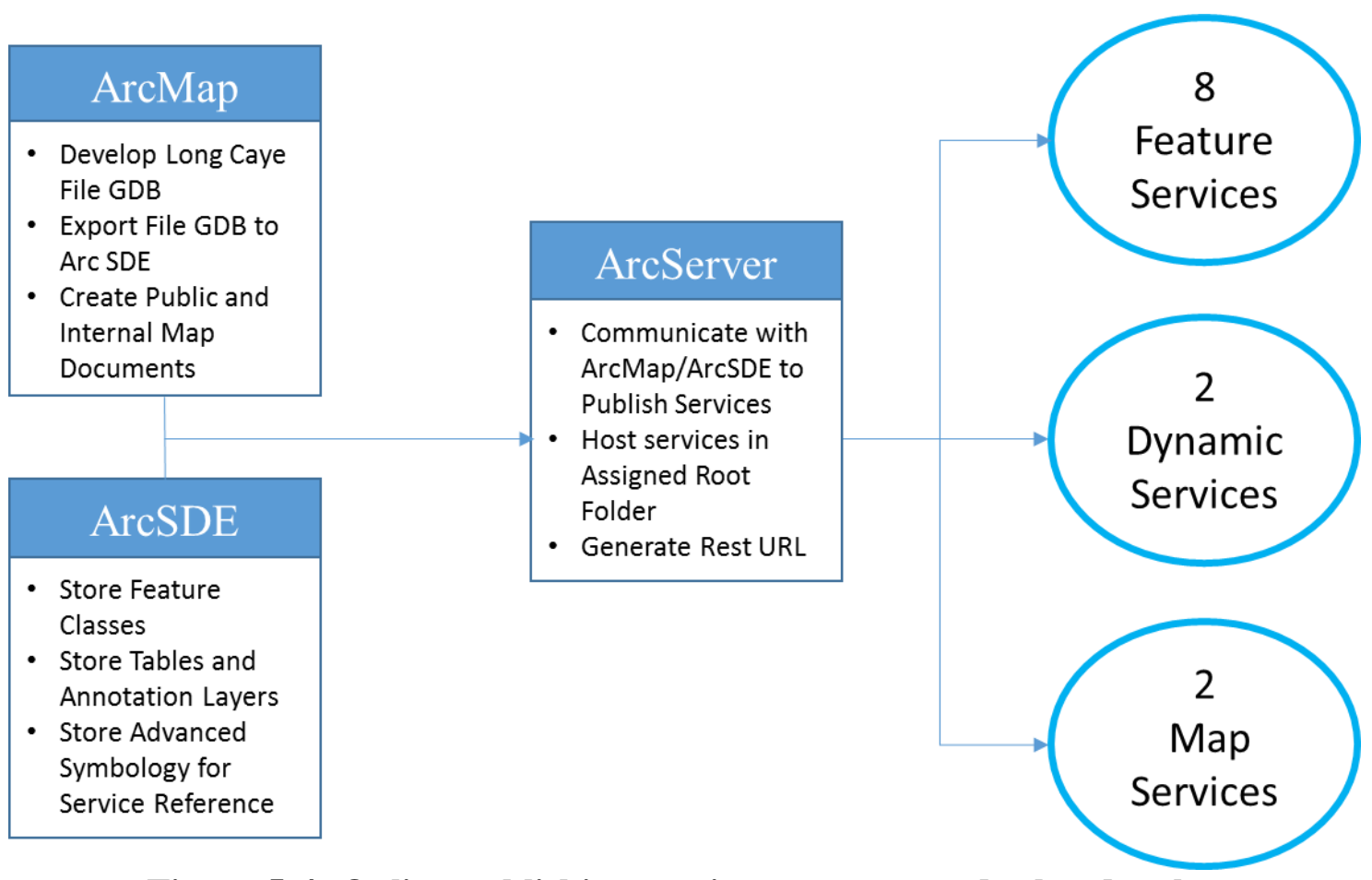

Figure 5-4: Online publishing service resources and related tasks.

\subsubsection{Public Application Services}

The public map document holds data for two of three service publications. All three service types were published for the public application. There were two components of the tile map services. One tile service generated the display of the IKONOS satellite image of the study area. This service was actually hosted on the ArcServer account of the Esri Oceans department, courtesy of Stephens. The image was slightly altered to avoid violating distribution privileges. The license required major alterations to the image in order for it to be displayed on the public application, and Stephens made these changes accordingly. The second tile service was the Piers layer, which was only meant for 
display and provided no user interaction. Feature services were applied to the dive sites, notable views, trails, parcels public, and resorts (Figure 5-5).

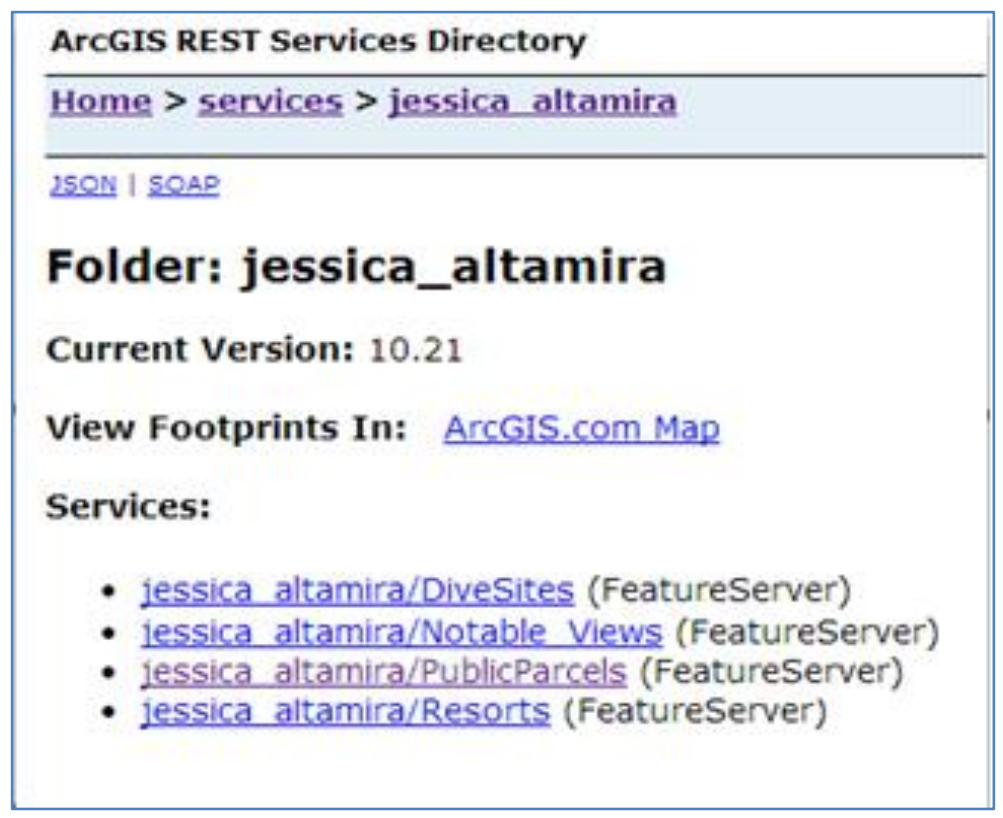

Figure 5-5: Feature services for the public application.

The benefit of feature services was that they allowed users to create, delete, query, update, or display attribute information about the dataset for web development. Attribute display functionality was required for the applications.

Lastly, two dynamic map services and two tile services were published. Advanced dive site symbology and advanced trail symbology required a dynamic map services while the piers and parcel annotation were tile services (Figure 5-6).

\begin{tabular}{l}
\hline ArcGIS REST Services Directory \\
\hline$\underline{\text { Home }>\text { services }>\text { jessica altamira }}$ \\
Folder: jessica_altamira \\
Current Version: 10.21 \\
View Footprints In: ArcGIS.com Map \\
Services: \\
- jessica altamira/DynamicDive (MapServer) \\
- jessica altamira/DynamicTrails (MapServer) \\
- jessica altamira/ParcelAnnotation (MapServer) \\
- jessica altamira/Piers (MapServer)
\end{tabular}

Figure 5-6: Map and dynamic services for the public application. 
Dynamic services enabled data to be displayed using the symbology and label styles stored in the ArcSDE. Feature services were limited to basic representations and thus capabilities like feature labels were not published. This was why there were two versions of the trails and dive sites. All of the public services were available on a web server as well as on the content page belonging to the Long Caye organizational account.

\subsubsection{Internal Application Services}

The internal map document also held data for a satellite tile service, Trails feature service, and Parcel Annotation map service, were communal services for both applications. The remaining internal feature services included the Parcels, Buildings, and Infrastructure layers (Figure 5-7).

\begin{tabular}{l}
\hline ArCGIS REST Services Directory \\
Home > services > jessica altamira > InternalDataset (FeatureServer) \\
$\underline{\text { JSON I SOAP }}$ \\
jessica_altamira/InternalDataset (FeatureServer) \\
View In: ArcGIS.com Map \\
View Footprint In: ArcGIS.com Map \\
Service Description: Infastructure, Buildings, and Parcels with Confidential Information \\
Has Versioned Data: false \\
MaxRecordCount: 1000 \\
Supported Query Formats: JSON, AMF \\
Layers: \\
$\quad$ Infastructure (0) \\
$\quad \underline{\text { Building (1) }}$ Parcel Private (2)
\end{tabular}

Figure 5-7: Feature services for the internal application.

This internal application demanded a service to allow editing and query capabilities. All the datasets were published onto the client's organizational account, which allowed the client to edit the layers without needing to modify the web application code.

\subsection{Web GIS Development and Functionality}

The services were used in scripts that included the Dojo toolkits, ArcGIS API for JavaScript, HTML, TinyPic, and CSS style sheet references. The combination of all these components is what the programming world would call mashup architecture. Mashup architecture implies calling requests to multiple services to produce an overall result (Fu $\&$ Sun, 2011, p.94). Several web services were used in the scripts requesting spatial data from Esri servers and photographs hosted on TinyPic servers. The scripts were written in Notepad++ and deployed as an HTML file on a web server. The general workflow for scripting tasks, as seen in Figure 5-8, is a continuation of the process seen in Figure 5-4. 


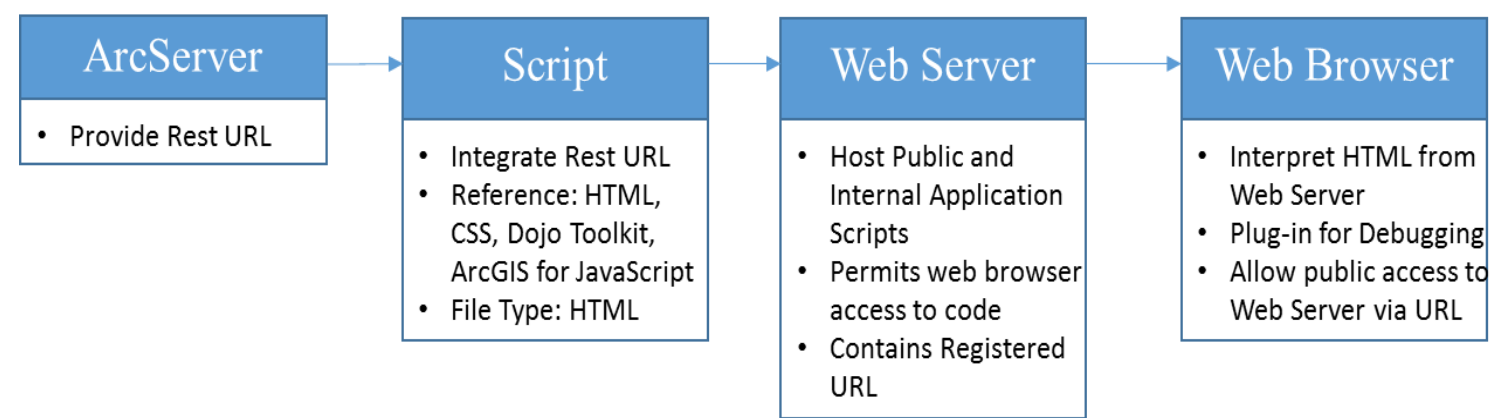

Figure 5-8: Web development workflow

During the 2014 Esri Developer Conference, many sessions featured discussion about JavaScript becoming the primary scripting language to use for web GIS.

Development trends in migrating from Silverlight and Flex to JavaScript determined the decision to use JavaScript for this web development project. Referencing the ArcGIS for JavaScript API with Dojo toolkits can provide more detailed graphics on a user interface than Flex and Silverlight (Fu \& Sun, 2011, p.97). A benefit of using JavaScript is that it is supported by most web browsers. Recently, advancement of execution speed within JavaScript have allowed high frame rates (15 frames per second) to generate, removing the demand for Flash or Java plug-ins on web browsers (Boulos, Warren, \& Yue, 2010, p.36). JavaScript code could be written within an HTML (HyperText Markup Language) file, which is a format that is readable in popular web browsers. Not only was JavaScript more popular in the programming language of web GIS, but it was also less costly in terms of resources and plug-ins when compared to other languages (Fu \& Sun, 2011, p.97). This flexibility of JavaScript web implementation provided a large range of access to the application via a basic Internet connection.

The ArcGIS for JavaScript API works with published map services by means of a REST URL. According to ArcGIS Resources, REST, or Representational State Transfer, is a protocol that allows web code to consume online services (Esri, 2014). A URL is the typical form [that REST] takes in order to display it on an interface over HTTP (Fu \& Sun, 2011, p.62). The demand for a REST URL was a crucial requirement in most of the JavaScript widget parameters. REST URLs were heavily integrated within the application scripts of this project.

\subsubsection{Public Application Development and Functionality}

Scripting the public application took priority over the scripting of the internal application. Appendix A outlines the finished script for this application. Notepad++ was the scripting tool and the Firebug plug-in on Mozilla Firefox was the debugging tool. Using the map service and web service resources, functionality and design of the application strived for a user-friendly interface. The interface designs for the applications were similar in color, though not in their overall functionality.

The functionality was broken down based on widgets. This script contained the following functions: basemap, layer addition, pop up window, legend, layer toggle, overview map, home extent, bookmarks, and map locator. This application provided more functionality widgets than the internal application so that its users could use the application with ease. 
The basemap and overview map were the primary geographic reference widgets. The basemap displayed a hybrid map, providing satellite imagery and country labels. This

map was chosen so that users could see a better representation of the atoll and its varying oceanic colors. It was also picked to blend in with the tile satellite image that was laid on top of the basemap. The overview map in the bottom-right side provided a greater extent of what the basemap displayed as seen in Figure 5-9.

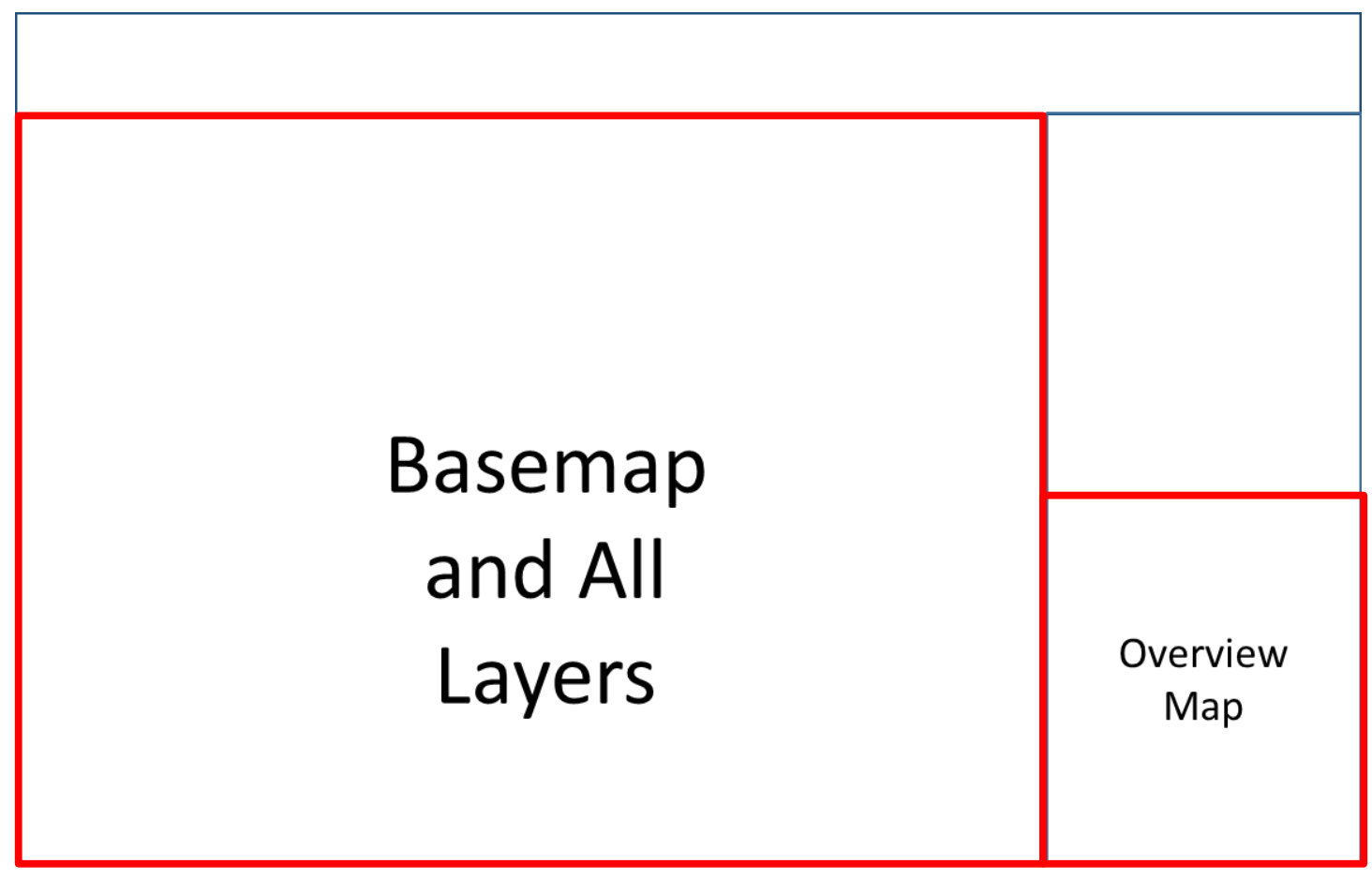

Figure 5-9: Interface plan of basemap and overview map.

There were several widgets used within the main map content box. The bookmarks displayed allowed a drop-down list of preset extents. These extents included the most popular areas near the island or on the island so that users would not have to search for these key locations. The bookmarks included extents of the Great Blue Hole National Monument and the entire atoll. They were positioned onto the map body to stimulate user interaction while navigating the map. Other geographic reference widgets were the Home Extent and Locator buttons, which were placed on top of the main map. The Home Extent button brought users to the initial extent. This extent was scripted to fit the northern half of the island and displayed all operational feature classes. The Locator button identified the location of the computer used to access the application. These navigation tools were placed along the sides of the main basemap, as seen in Figure 5-10. 


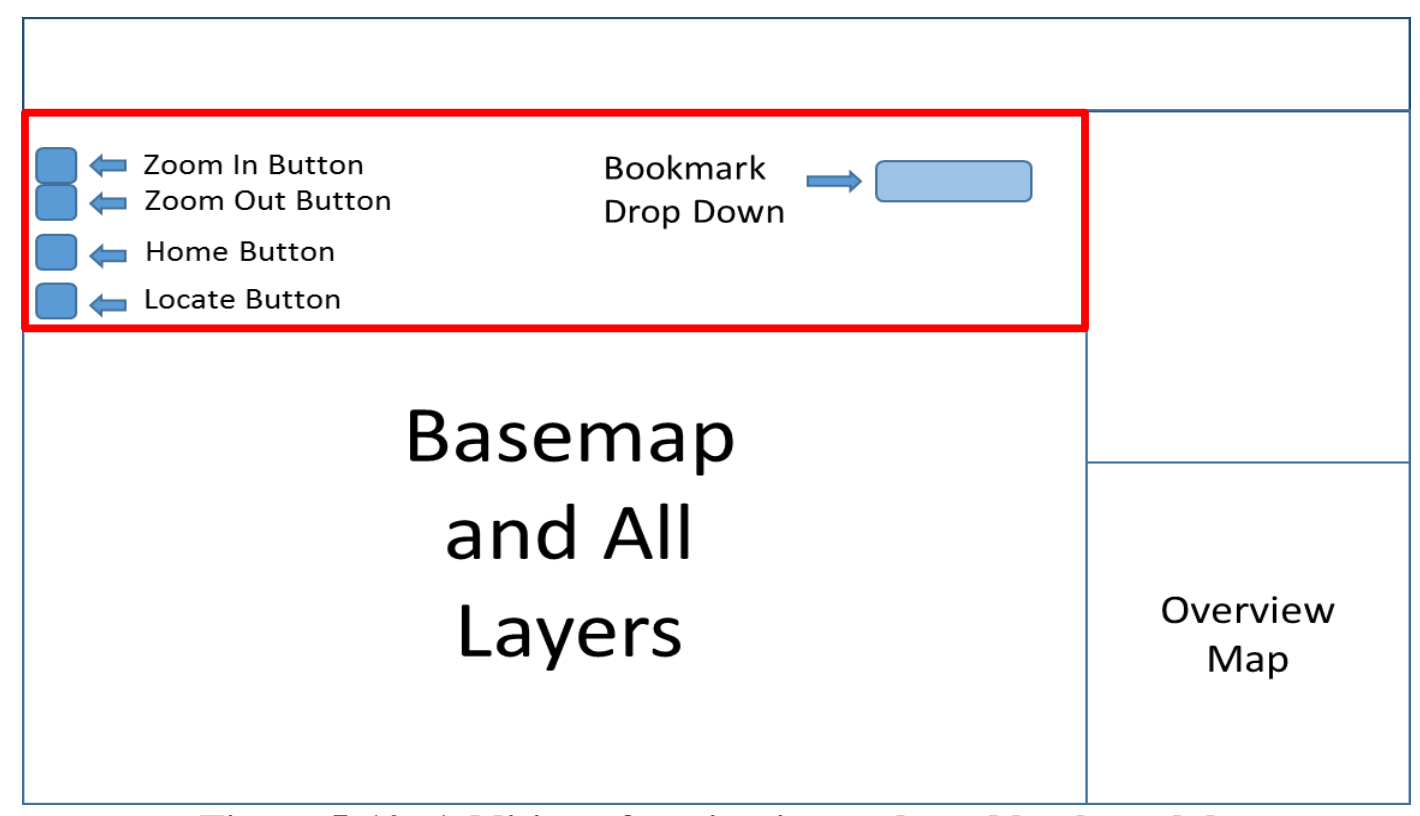

Figure 5-10: Addition of navigation tools and bookmark button.

The layer toggle and legend widgets were positioned on top of each other because their functionalities were linked. The toggle widget was scripted to hide or display layers. If a layer was turned off, it would be removed from the legend widget. Likewise, if a layer was turned back on, its symbology and title would reappear on the legend. Both widgets and a YouTube tab were placed in an accordion panel on the far right of the web page for convenience off the main map as highlighted in red in Figure 5-11.

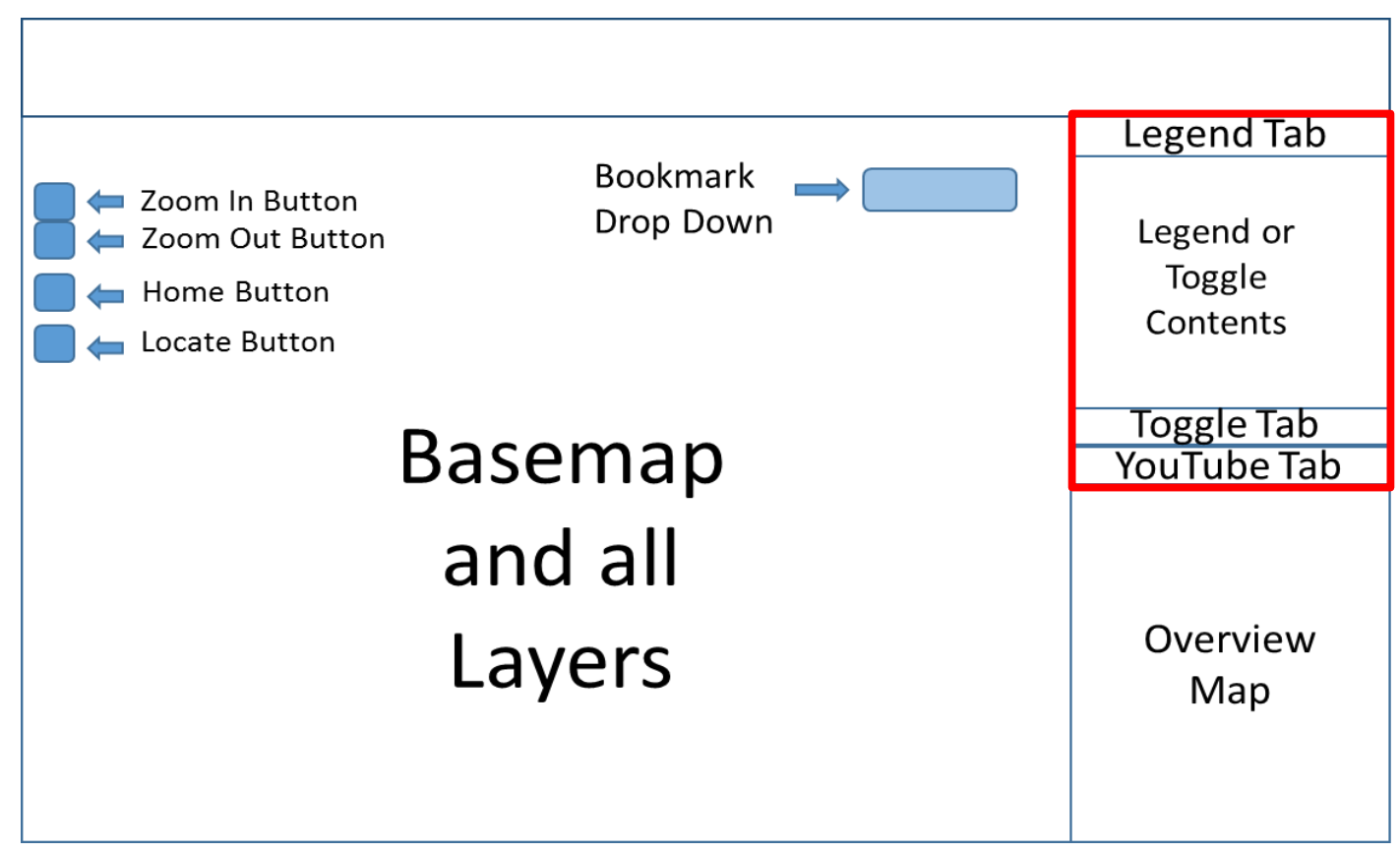

Figure 5-11: Addition of legend, toggle, and YouTube tabs. 
The layers applicable to the toggle and legend widgets were the DynamicDiveSites, DynamicTrails, NotableViews, Resorts, Parcels, and ParcelAnnotation. ParcelAnnotation was the only exception that was not displayed on the legend because it had far too many different values. However, it was displayed in the toggle layers pane.

The opacity of the DiveSites, the scuba dive site feature layer, was set to be completely transparent. The same opacity level was set for the Trails feature layer. This was done to fire popups linked to the feature layers with the parallel dynamic layers on top of them. This scripting technique had to be done because feature services do not allow advanced labeling. It was also done with consideration to resources that the client may not have in order to work with dynamic services after project completion. The parameters of the representations for the feature and dynamic layers were exactly the same, and the linked layers scaled down or up in size simultaneously. An example of the dynamic and feature layer order is displayed in Figure 5-12.

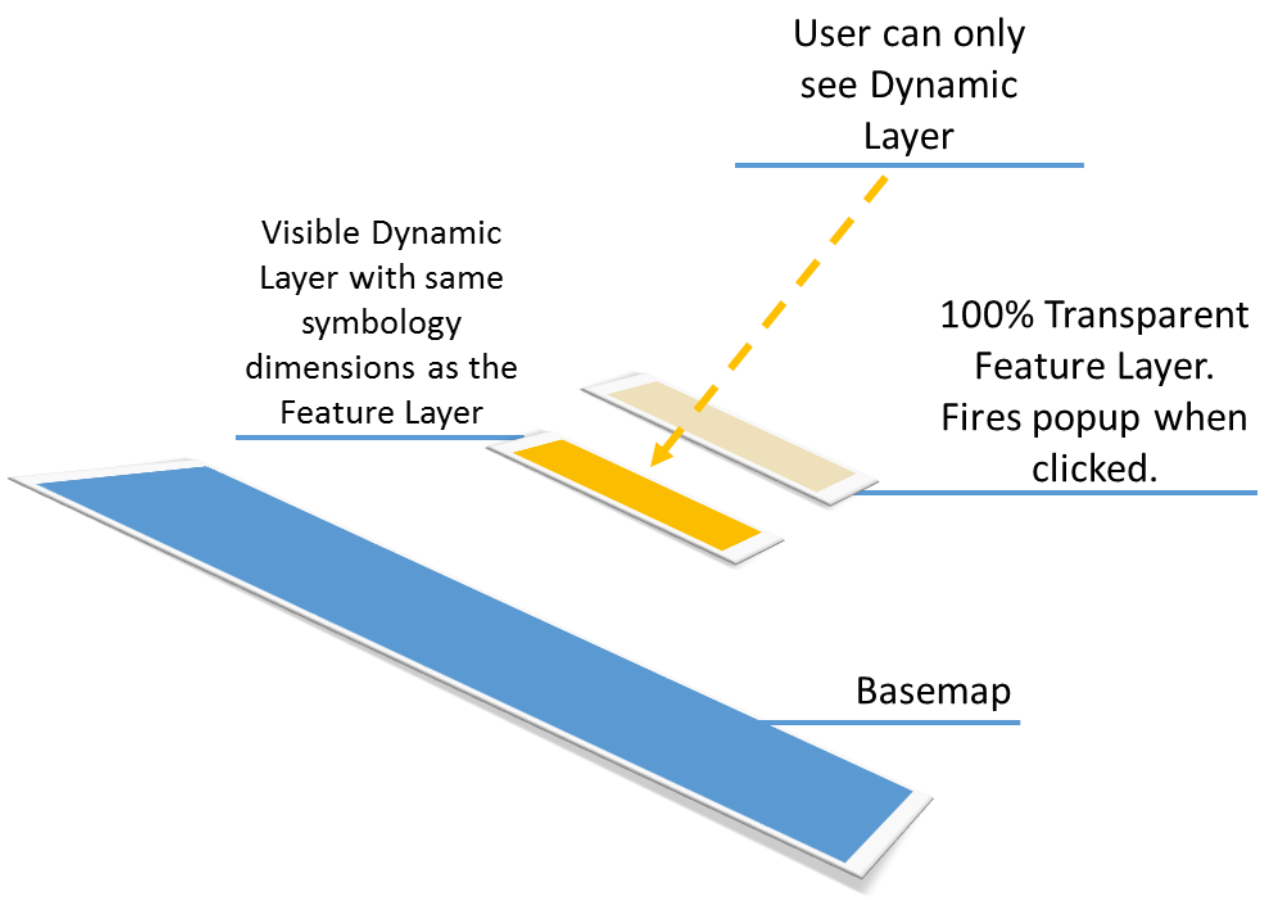

Figure 5-12: Dynamic and feature service placement. 
The pop-up window displayed literary information and appeared when users clicked a layer representation. The pop-ups were designed to match the background color of the interface. These pop-ups contained the names of feature as their titles, and depending on the layer, details about a feature would be were displayed. Figure 5-13 shows an example of the Trails layer pop-up template with fields to display.

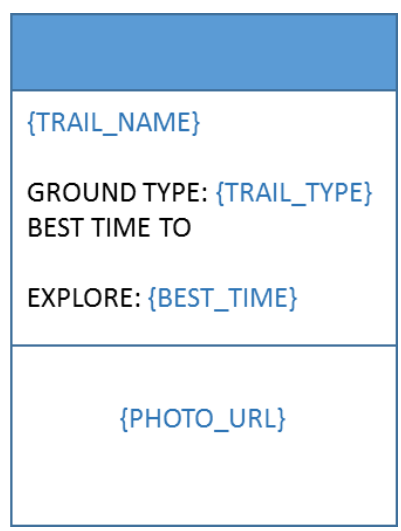

Figure 5-13: Pop-up display template of the Trails layer.

When launched, the initial map extent portrayed the entire island. With the main map taking up the greatest amount of space, a few widgets on the right-hand side panel, and a proper site banner, the resulting page focused users' attention on the main map. Figure 5-14 shows the final layout of the public application interface with widgets and layers.

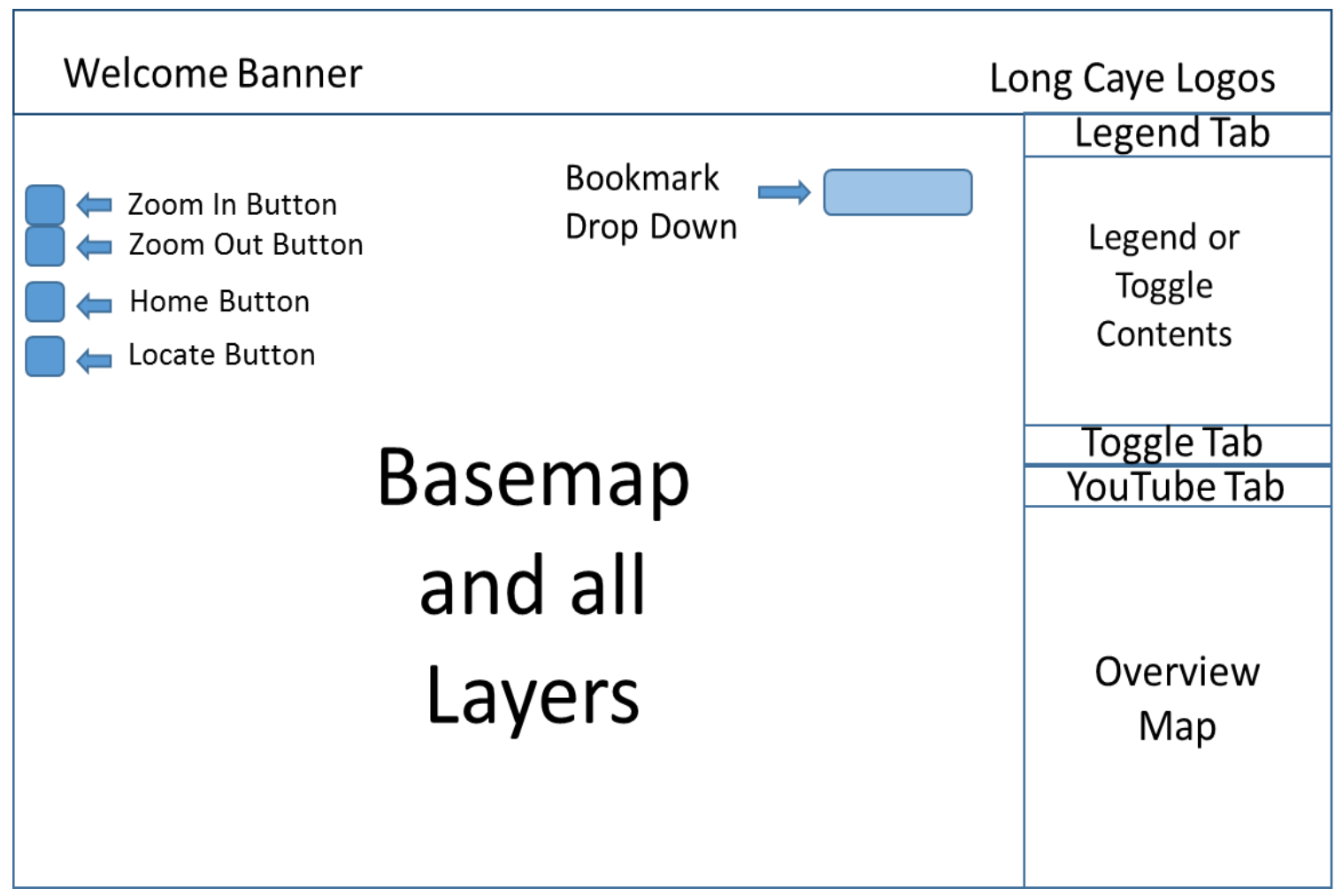

Figure 5-14: Final interface design for the public web application. 


\subsubsection{Internal Application Development and Functionality}

Even though the public application development received priority, time allowed for an internal application to be developed as well. The script for the internal application was also written in Notepad++ and debugged in Firebug. Appendix B presents the finished script for this application. This application was designed to be used only by Long Caye owners. The application and its data were intended to solely be viewed by the account members in the Long Caye ArcGIS Online Organizational group.

This script contained the following functions: basemap, layer addition, search bar, bookmarks, overview map, feature editor tool, and attribute editor. The basemap, layer addition, and overview map used the same parameters as those used in the public application. Only one tile service and one feature service were called in this script. The remaining functions were supplementary so that the owners could add, delete, update, and query the data.

The main map body was similar to the public interface main map. A Home button and a much smaller overview map were placed on top of the main map. The Home extent did not display the entire island, only featuring the northern half. This was to ensure that the users could clearly see all features on the map that need to be edited. Figure 5-15 shows the displayed interface of the main map content.

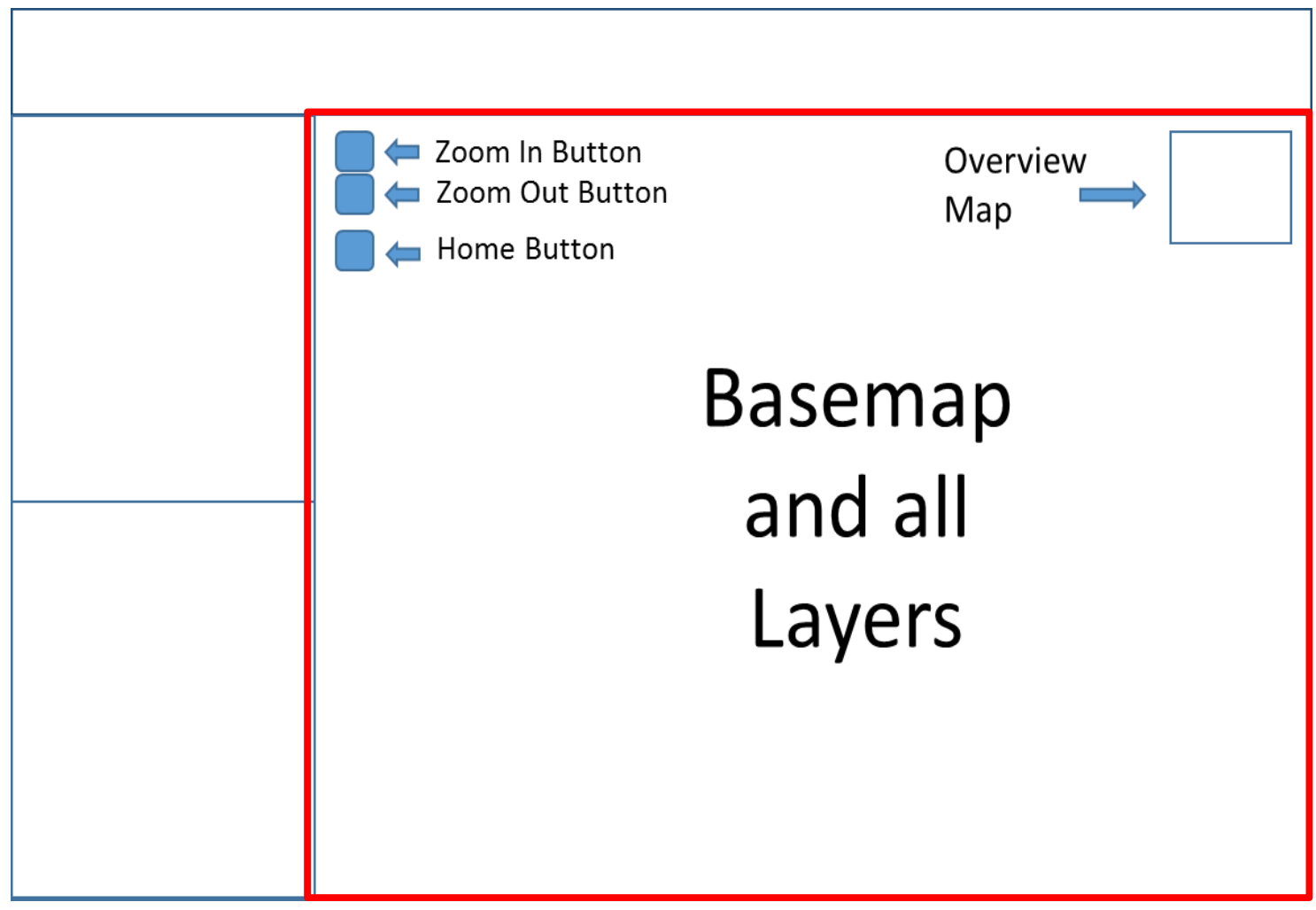

Figure 5-15: Interface plan of basemap content with navigation tools.

The left-hand pane contained all information that could produce results on the map. The top half of the pane contained three tabs. These tabs do not deal with direct editing of the data, but rather explains how to approach certain tools or provide a query of the data. 
The top half held significant literary information and multiple widgets. The first tab provides written directions about how to use the editor, the second tab provides three search bars to query parcel data, and the third tab contains an editable bookmark widget. This upper pane was designed using the Dojo Tab Container. The tabs in Figure 5-16 were designed to be grouped next to each other for easy access and efficient space usage.

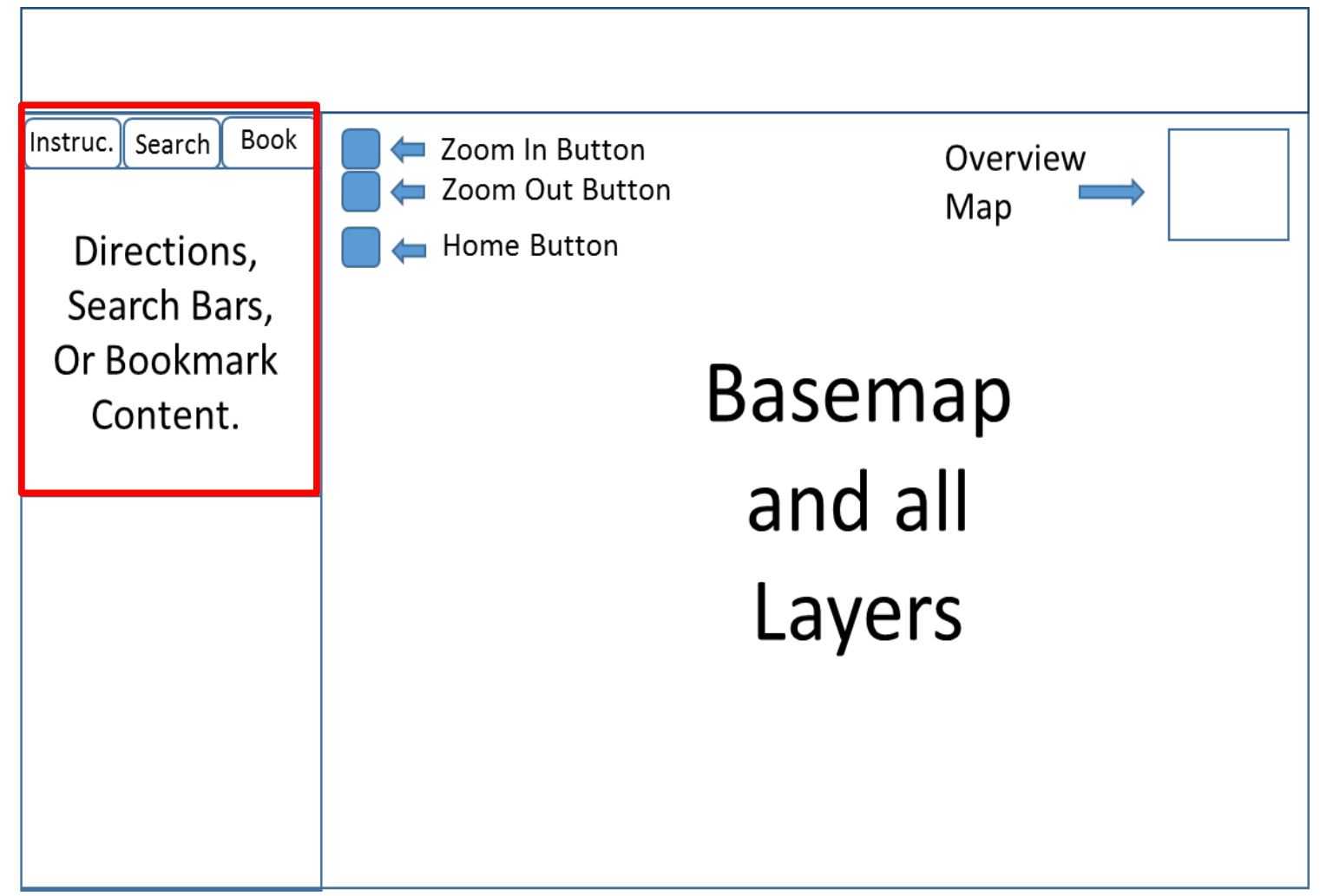

Figure 5-16: Addition of three tab containers.

The three search bars only required one to be filled, with the option of filling all three. The query "where clause" evaluated a text input and converted the text to all uppercase letters for the first and last names. This scripting technique allowed the input to match the character format in the parcel table. The parcel ID number input also read as text to match a parcel number text field in the parcel database. Inputs had to be whole numbers to produce selected results. Only selected parcels are displayed with a red outline on the polygon. The last tab, the bookmarks tab, holds the bookmark function, which has parameters to create and delete extents.

The code for a feature editor placed this widget in the bottom half of the left hand panel. This was associated with the attribute editor function, which allows for the manual text input of new attributes. The function enables operational layers to be altered using the Esri Geometry configuration reference. This tool searches for a layer's assigned geometry type as a requirement for the proper shape sketch template. The script commands newly drawn features to be added to the database and for the layer to be refreshed to display the completed feature. 
With all widgets conveniently placed, the addition of a header, and all layers displayed and responding properly, the final internal application was completed.

Although the URL to this application is public, no one can draw information without an approved authentication. Figure 5-17 depicts the final layout for the internal interface with all widget placement.

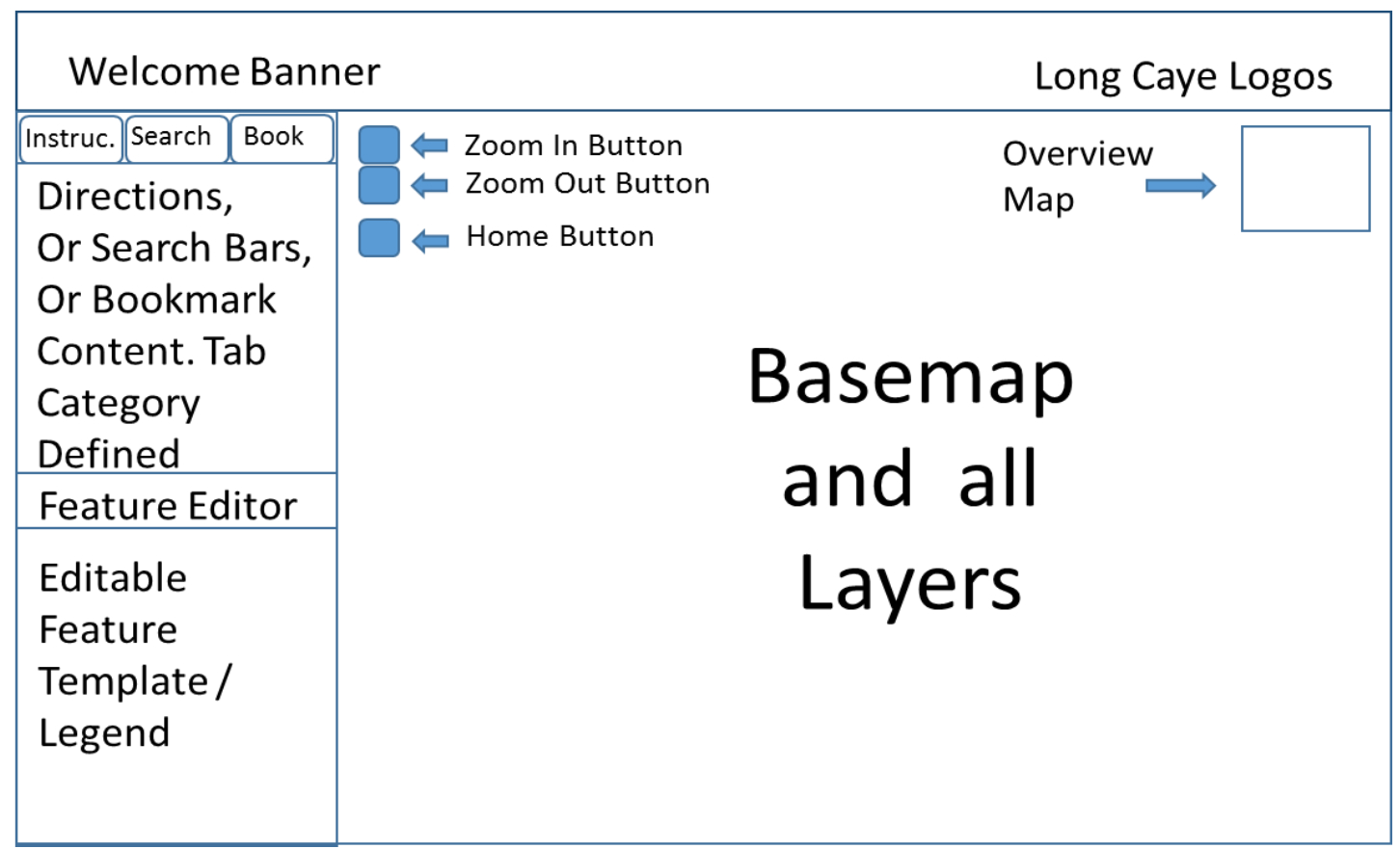

Figure 5-17: Final interface design for the internal application.

\subsection{Summary}

The Long Caye geodatabase separated feature classes either to the public or to the internal application. The feature classes were published to an online server to act as a source within a scripted code. Each application required a script to contain different functions to enable the proper display of services and widgets. Interface plans were created to generate a clean platform for the end user. This was the general phase for the web development and implementation process. 


\section{Chapter 6 - Results and Analysis}

The final applications varied in both their target audience and user experience. This section covers the intended usage of the public and internal applications within a specific audience. Section 6.1 describes two use cases, one case for each application. Section 6.2 discusses the testing experience and also lists general comments from several testers. Results of tester feedback provided the ground stage for the modifications made during the course of this project. The results also provided insight for additional web development in the future.

\subsection{Use Cases}

Previous chapters determined the need for two individual applications as solutions for two different problems. The composition of these applications discussed in Chapter 5 delivered the final user interface. The first use case represents a typical scenario for the general public using the application to learn about the island. It focuses on the layers available within the toggle tool. The second use case represents a typical scenario for a Long Caye owner looking to update the information of existing parcels and use the editing tools to plan future parcel locations.

\subsubsection{Web GIS Application for the Public}

This use case scenario assumes a user is a first time visitor to the public application. The user is a scuba diver who is interested in Long Caye diving sites and hiking trails. To access the application, the user clicks on a hyperlinked image on the Long Caye website to launch a separate window. A banner and active map components appear to the user as seen in Figure 6-1.

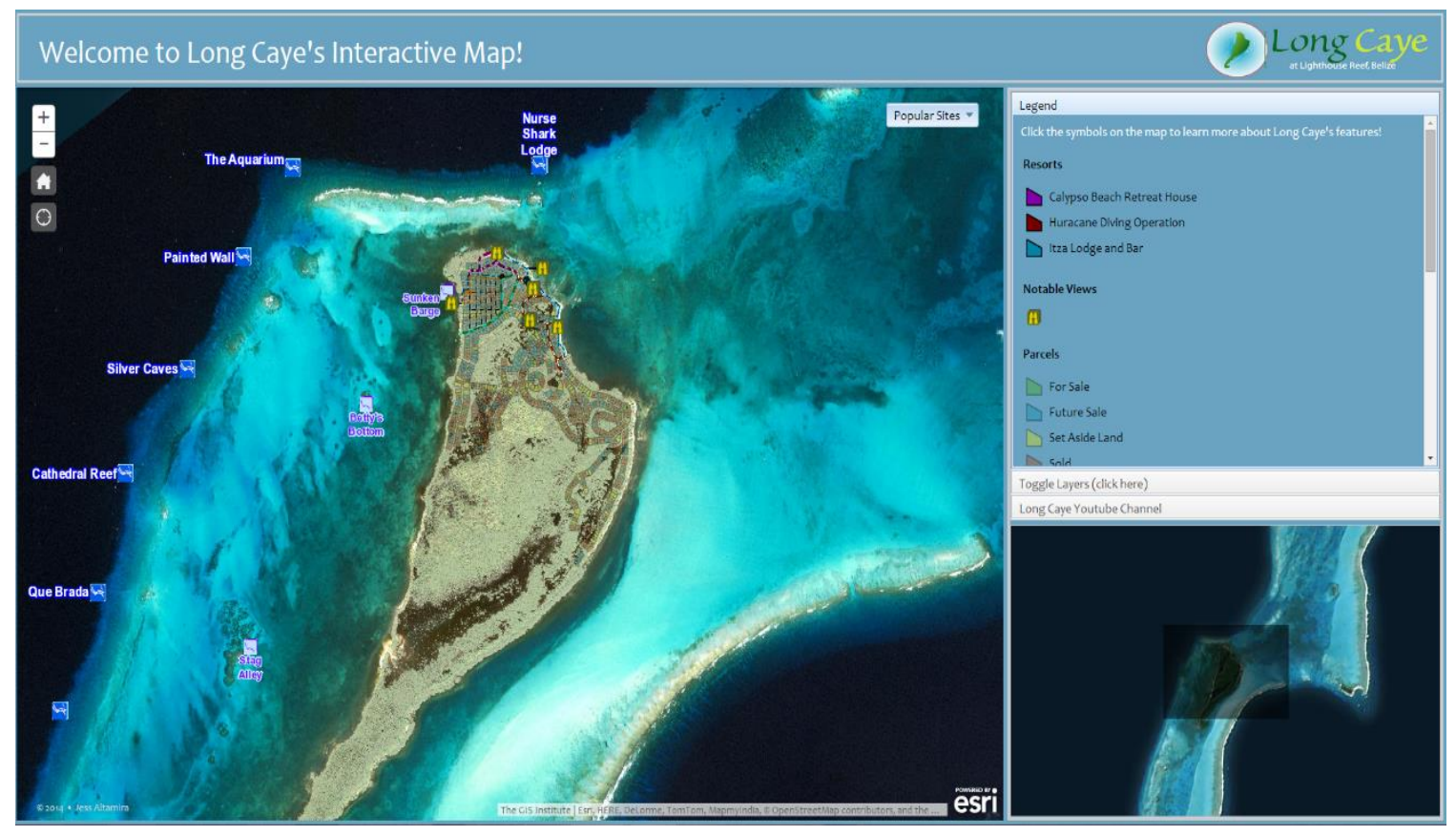

Figure 6-1: Opening display of the public application. 
To learn the meaning behind the map symbology and receive tips about how to use the application, the user reads the content within the legend on the top-right pane. The user could follow the directions to click on any map icon to launch a pop-up window with feature descriptions and photos. Figure 6-2 shows the Half Moon Wall dive site information and an enlarged version of the photo in the pop-up window.
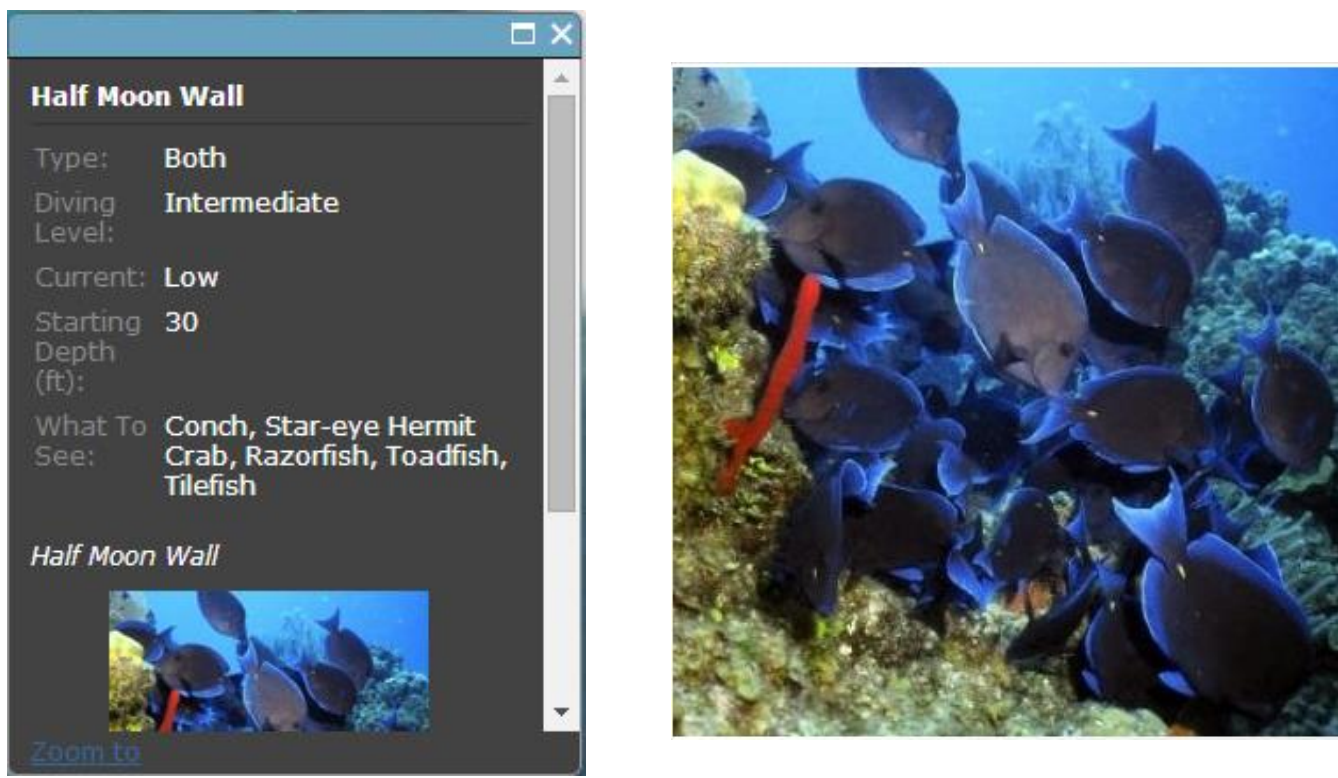

Figure 6-2: Half Moon Wall Pop-up and enlarged dive photo.

To find out popular dive sites, the user clicks the Popular Sites tab on the top right of the main map to reveal a drop-down list of preset and labeled extents. The map also provides basic navigation tools that allow zooming in and out or panning in all directions. If the user wants to return to the opening display extent, he/she could click the Home button, located just below the zooming tools on the top-left hand side of the main map. Figure 6-3 shows the results from a user who clicked on the Great Blue Hole bookmark from the Popular Sites tab.

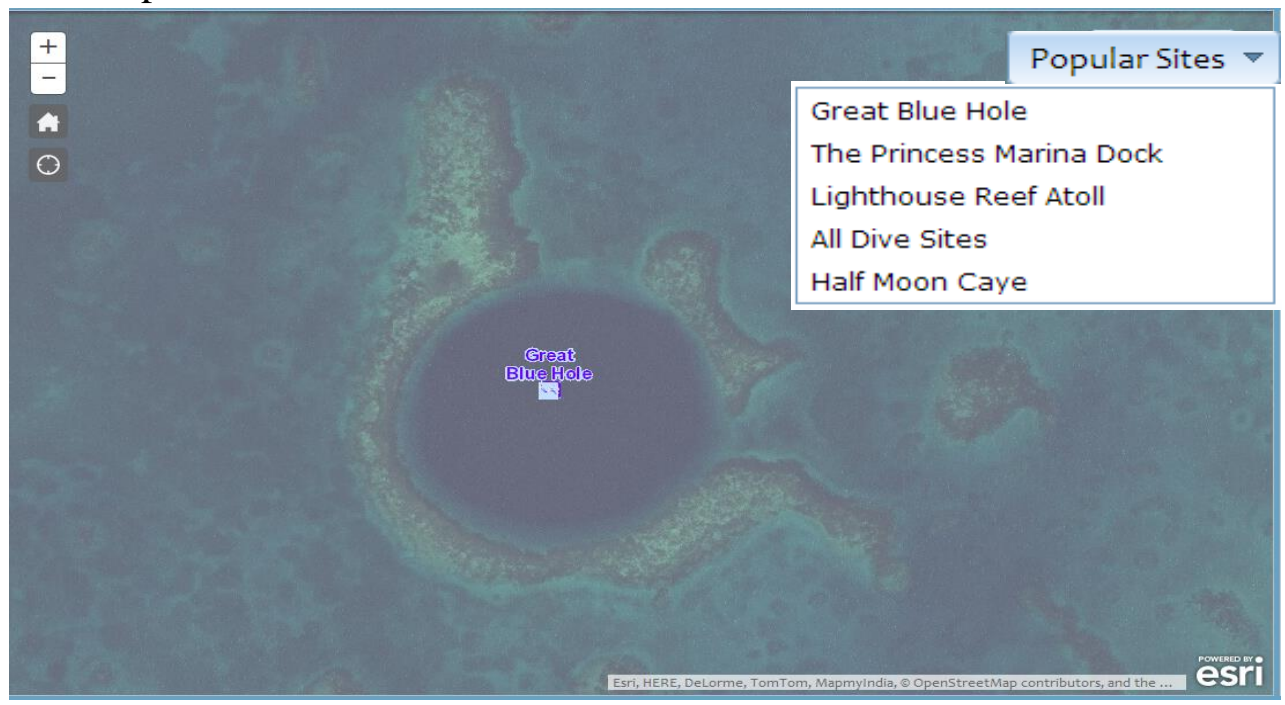

Figure 6-3: Great Blue Hole extent with bookmark drop down. 
Aside from the diving sites, the user is also interested in learning about the hiking trails. To make trail features more prominent, the user clicks the Toggle Layer tab, located just below the legend tab. The Toggle Layer tab displays the available layers that the user can turn on or off by clicking the boxes next to the layer name. Figure 6-4 shows a setup where the Parcels and Trails layers are checked. The user altered the check marks to only display Trails layer, which resulted in the display depicted in Figure 6-5.

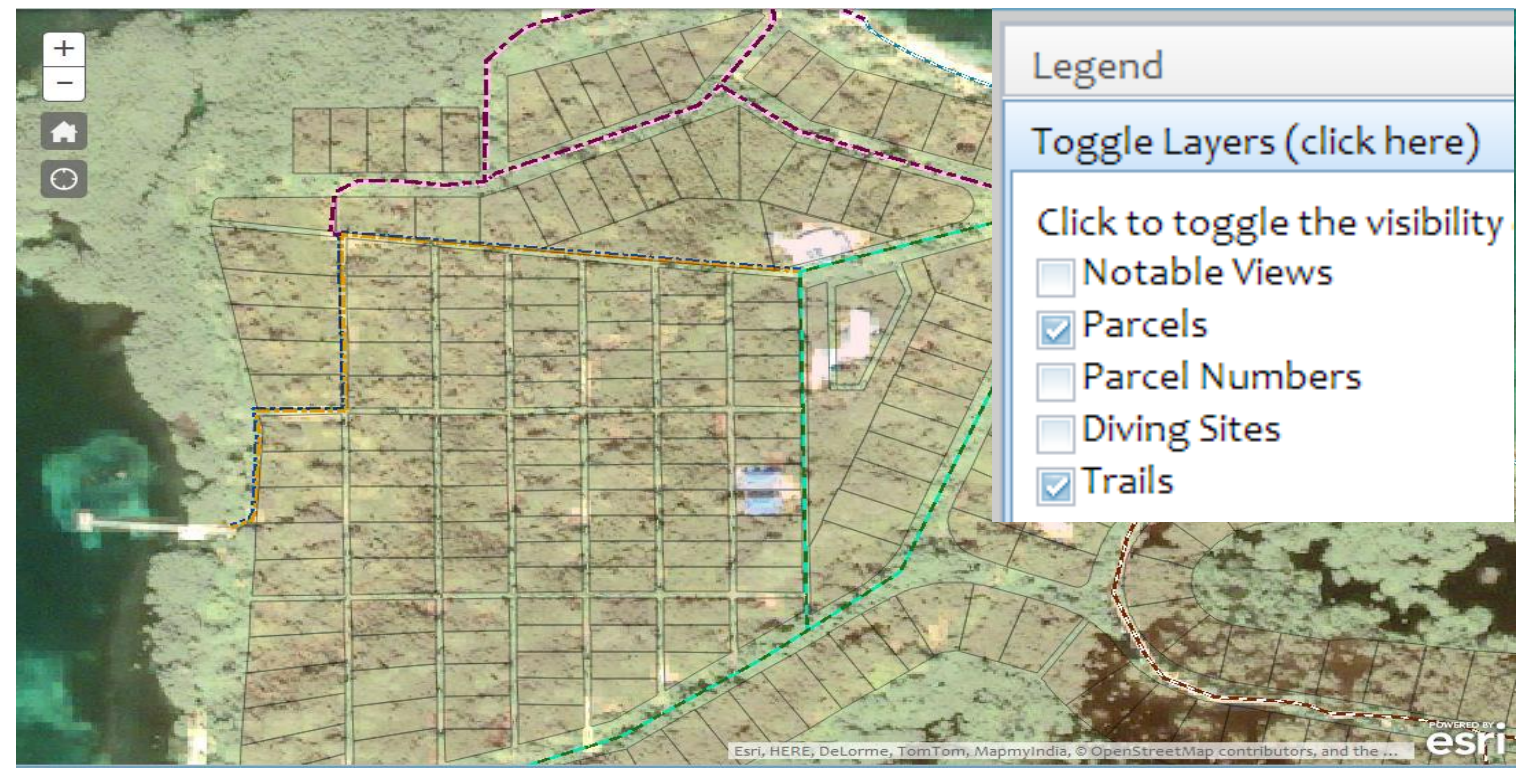

Figure 6-4: Display of Parcels and Trails layers.

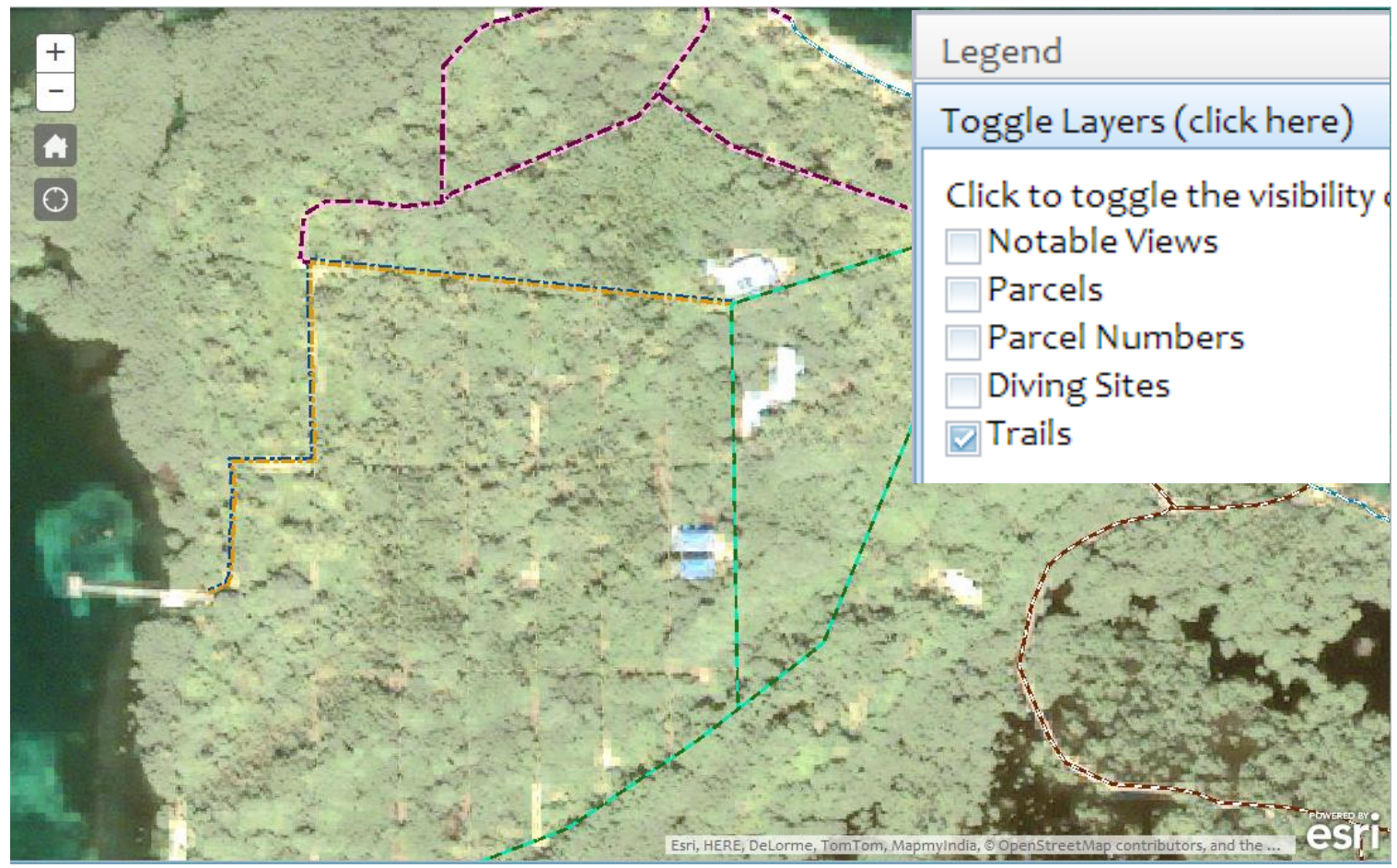

Figure 6-5: Display of only the Trails layer. 
To evaluate the differences between each trail, the user could reference the Legend tab. The Legend tab only displays legends of layers that have been checked from the toggle widget. This applies to any other layer the user chose to view. Figure 6-6 shows an example of legend content with only the Trails layer being displayed.

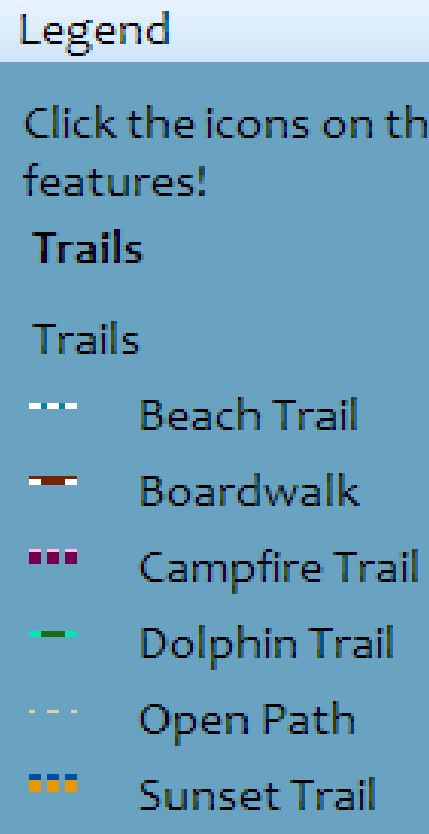

Figure 6-6: Legend of Trails.

This public application provides a user with descriptive details through the pop-up windows and legend, while geographic resources are provided through map navigation and a toggle widget. Users could access this application through any web browser with proper Internet connection. While the site is optimized to view on a computer, smartphones and tablets also accommodate site navigation.

\subsubsection{Web Application for the Long Caye Owners}

This internal application use case presents a scenario with an island owner as a user. The user intends to validate the location of parcel number 22. He also has an interest in planning new property lines for a new parcel. When the user launches the application, he presented with a dialog box requesting authentication of Long Caye Organizational account information. Figure 6-7 shows the screenshot of the Sign In dialogue box. 


Sign in $x$

\section{Please sign in to access the item on ArcGIS Online (item)}

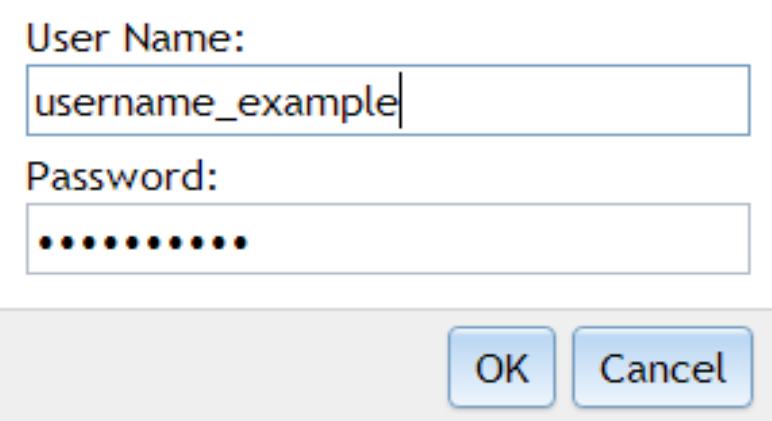

Figure 6-7: Sign-In prompt at application launch.

After that the user successfully signed in, the opening interface is revealed. Figure 6-8 shows that the user was granted access to view the initial display of internal content.

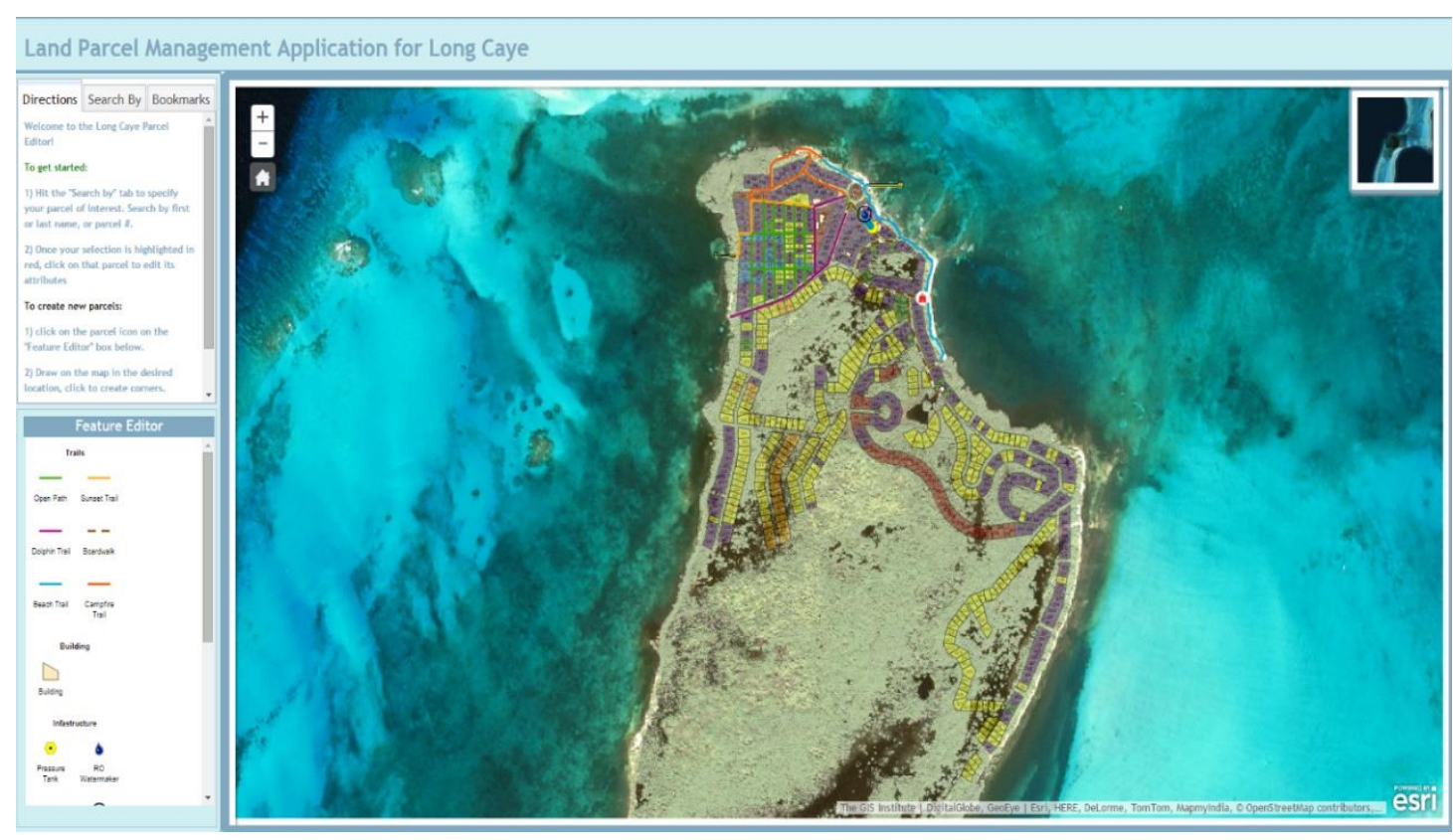

Figure 6-8: Interface for authorized user.

In order for the user to validate existing information and the current location of parcel 22, he navigates to the Directions tab on the top-left hand corner. He can read the description to learn that he can query a parcel from the Search By tab. Figure 6-9 shows the instructional content within the Directions tab. 


\section{\begin{tabular}{l|l|l} 
Directions & Search By & Bookmarks
\end{tabular}}

Welcome to the Long Caye Parcel

\section{Editor!}

To get started:

\section{1) Hit the "Search by" tab to specify your parcel of interest. Search by first or last name, or parcel \#. \\ 2) Once your selection is highlighted in red, click on that parcel to edit its attributes}

\section{Figure 6-9: Contents of directions tab for parcel querying.}

After navigating to the Search By tab, the user types in the number " 22 " in the box labeled Parcel ID\#, to query the parcel. To verify the name of the property owner, the user clicks on the highlighted parcel to display its attribute table. Figure 6-10 shows the location where the user typed in the Parcel ID\# box, and Figure 6-11 shows the zoomed in, retrieved result of the parcel 22 query.

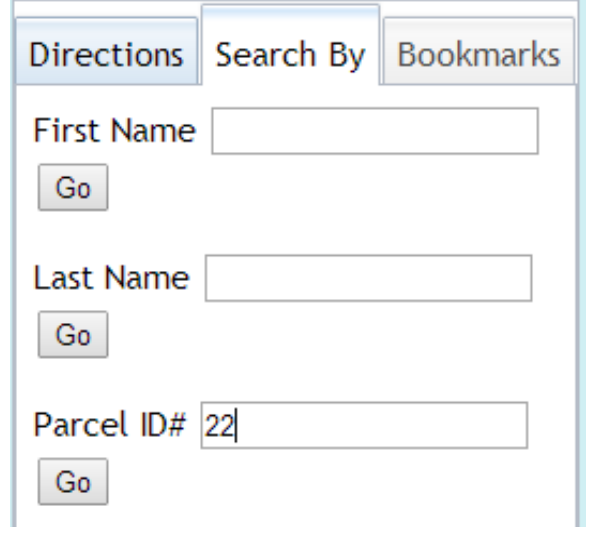

Figure 6-10: Search By tab with parcel ID\# 22 input.

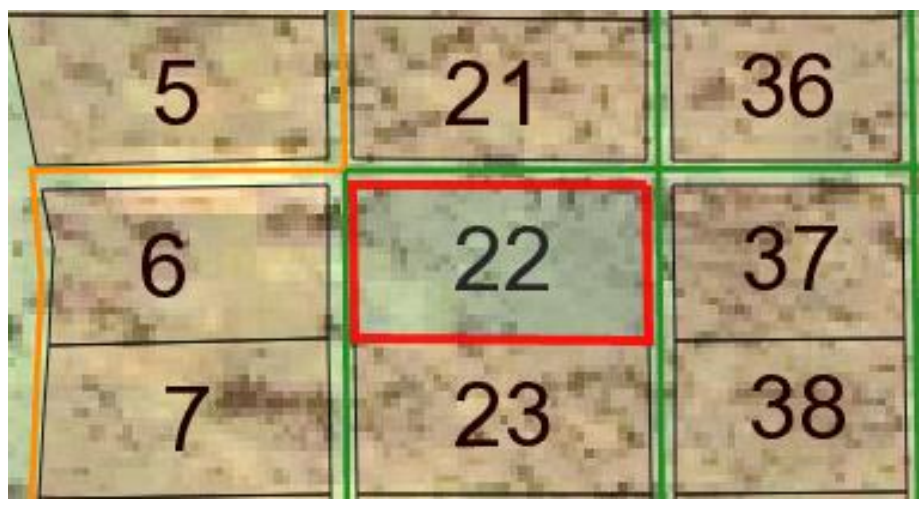

Figure 6-11: Highlighted result of parcel ID\#22 query. 
The user is also interested in planning the perimeter for the area along the eastern coast of the island. To do this, the user clicks on the parcel symbol inside the Feature Editor widget on the bottom-left side. The widget functions as both a legend for reference and a drawing template, as depicted in Figure 6-12.

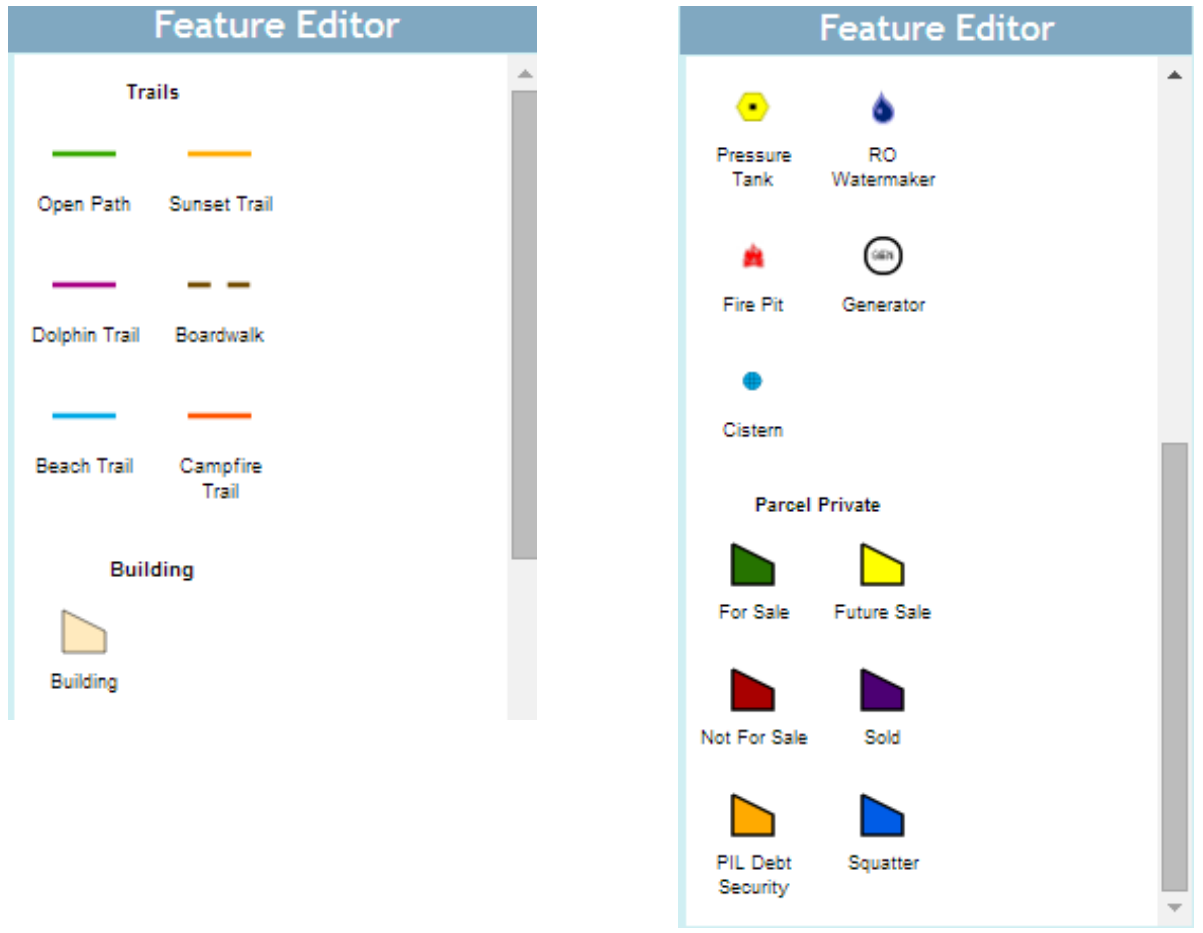

Figure 6-12: Top (left) and bottom (right) half of the feature editor.

Clicking on the parcel symbol means that the user has the ability to work with operational polygons. This enables the user to sketch the polygon by clicking on the map in the desired areas for the new parcel. Figure 6-13 shows the map area where the user drew a polygon next to an existing parcel on the eastern coast.

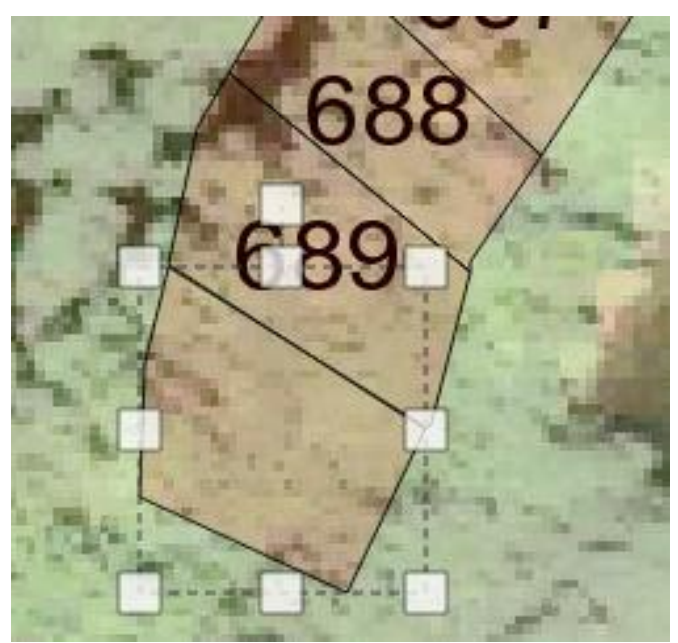

Figure 6-13: Drawn parcel polygon with empty attributes. 
After the user completes the sketch by double-clicking, an attribute box of empty parcel data appears. This allows the user to type in information for each field. In this case, the user types in the parcel number as "690" and the potential sales price he wants within the property lines. He should be noted that the parcel is only a representation because any polygons made after parcel 689 were not professionally surveyed. Figure 6-14 shows the edits made to parcel 690's attributes.

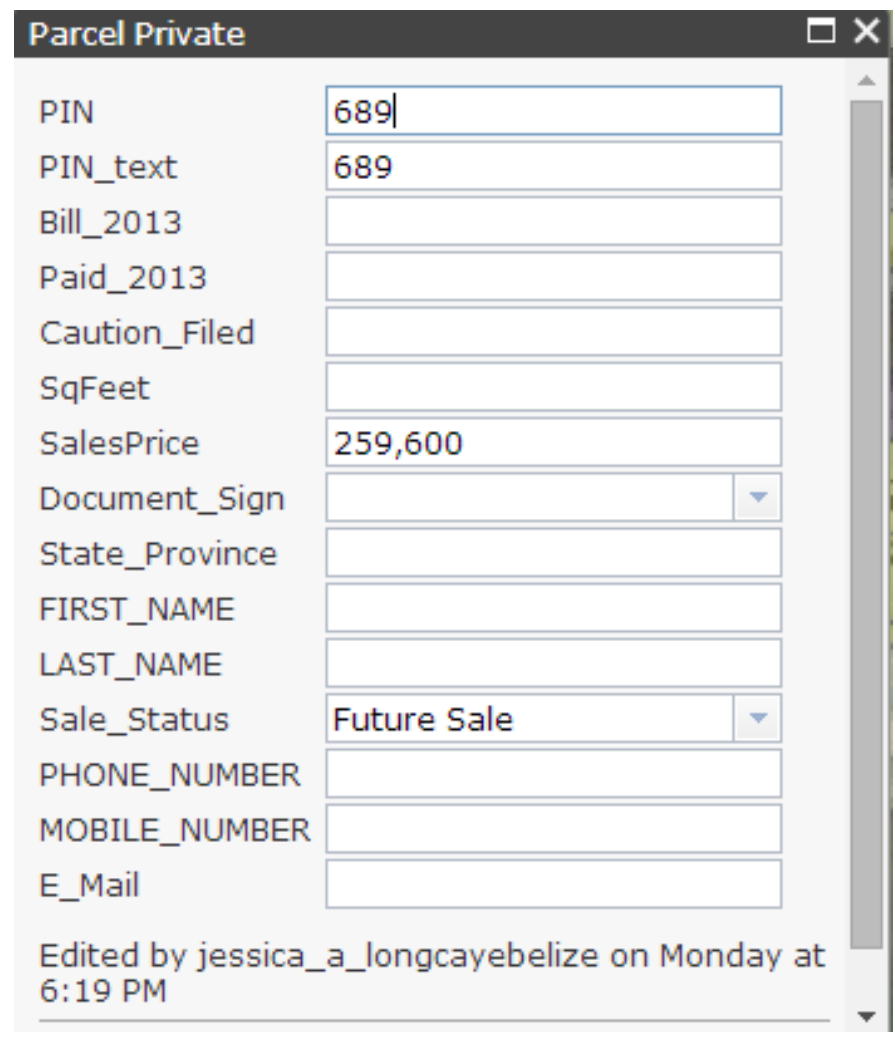

Figure 6-14: Attribute box with editor time stamp.

Any edits made to a parcel are automatically saved after input, without the need for the user to click a save button. The user can also delete a parcel by clicking the Delete button on the bottom of the attribute dialogue. For the user to see the activity of other users, he can scroll to the attribute dialogue to view the details of the user name, date, and time stamp of its last edit. This helps the user keep track of which areas other users had already worked on. With proper credentials and an Internet connection, the user can access this application through a web browser via computers, smart-phones, or tablets.

\subsection{Application Testing and Results}

Testing of the applications occurred both on and off the island. This was done to verify that the applications are accessible from around the world. 


\subsubsection{Public Application Testing and Results}

The public application was tested in five continents. While the testing method was informal, its purpose was to ensure that access to the application is available. Figure 6-15 presents a map with points depicting where the application was tested.

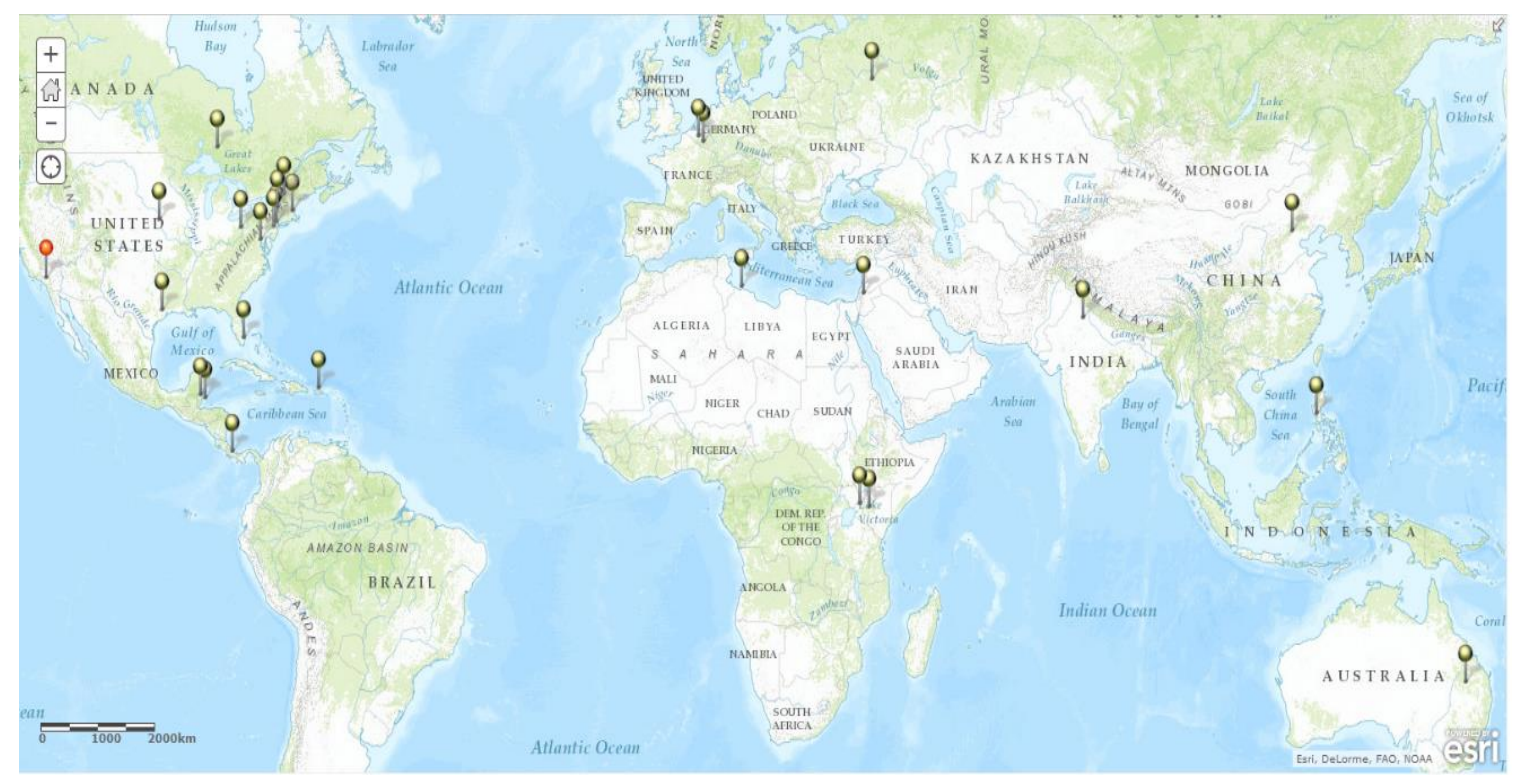

Figure 6-15: Public application testing sites.

Many of these application testers were colleagues, colleagues of friends, friends, or family members. The testers launched the application through either a desktop computer or a smart tablet. The web browsers varied, with testers utilizing Safari, Mozilla Firefox, 360, Google Chrome, Internet Explorer, and Sogou. The main goal of this test was to assess web site accessibility and improve the public application based on feedbacks.

\subsubsection{Internal Application Testing and Results}

Only the Long Caye owners tested the internal application. Testing sessions occurred while Mr. Ross and his partners were either in the U.S or in Long Caye. The testers were able to read and follow basic instructions provided in the application to use the search bar and editing tools. No issues were brought up, other than modifying the initial colors of the web template to allow text to be displayed more prominently. The user credentials worked fine for all testers and all the layers were successfully loaded and displayed properly. The only major suggestion that the clients made was to add analysis tools for land suitability. It was advised that this would have to be a whole new project and was outside the scope of this project. However, this idea allows for future addition to the current applications.

\subsection{Summary}

Overall, each application had alterations made after a large amount of testing and evaluation feedback. The pop-up function proved to be the widget of greatest interest 
based on the inputs from the testers for the public application. Various locations were used for public testing to ensure accessibility, while testing of the internal application restricted usage to only three testers in two different areas. Ultimately, both tests generated critical opinions for the quality of the final deliverables and paved the way for future work. 


\section{Chapter 7 - Conclusions and Future Work}

Two web applications were developed to address two problems faced by the client. The two problems addressed the low quality and quantity of geographic information delivery, as well as the lack of a centralized database system. This resulted in a project plan to develop one application for the general public and one application for the island owners.

The final deliverables of this project fulfilled all the requirements listed in Chapter 3. The functionality and design of the applications were approved by the client and his business partners. Testing feedback provided design improvements and ideas for future work on this project.

Since the island owners have little GIS exposure, a number of additional project ideas can be envisioned. Image analysis can determine the marine and vegetation features around and on the island. This could serve as a conservation analysis for construction planning while using the internal application. The web applications could also be transformed into a mobile application to conduct parcel inspections. Mobile development could incorporate more media to share on numerous social media applications.

Underwater exploration of bathymetric data is very possible for this area since the waters are quite shallow. The client has expressed an interest to invest in Lidar technology to investigate the lagoon topography.

In conclusion, the purpose of this project was to enhance effectiveness for internal management and public outreach for the owners of Long Caye. It also provided the owners with spatial data resources and innovative technology to help the resort business networking. Introducing web GIS to the remote island of Long Caye aspires to motivate integration of GIS usage for future resort development. 


\section{Works Cited}

Alesheikh, A. A., Helali, H., \& Behroz, H.A. (2002, July). Web GIS technologies and its applications. In Symposium on geospatial theory, processing and application. Tehran, Iran. Vol. 15.

Boulos, M., Gong, J., Warren, J., \& Yue, P. (2010). Web GIS in practice VIII: HTML5 and the canvas element for interactive online mapping. International Journal of Health Geographics, 9-14.

Briguglio, L., Butler, R., \& Harrison, D. (1996). Sustainable tourism in islands and small states: The Case of Malta. Island Study Series. London, UK/Cassell. Vol. 2.

Caneday, L., \& Chang, G. (2011) Web-based GIS in tourism information search: Perceptions, tasks, and trip attributes. Journal of Tourism Management, 32(6), $1435-1437$.

Ciamacca, C., Jansen, B., \& Spink, A. (2008) An Analysis of Travel Information Searching on the Web. Journal of Information Technology and Tourism, 10, $1-18$.

Diedrich, A. (2007). The impacts of tourism on coral reef conservation awareness and support in coastal communities in Belize. Coral Reefs, 26(4), 956-996.

Esri. (2007). GIS Technology for Land Records Management. Retrieved July 15, 2014, from http://www.esri.com/library/brochures/pdfs/gis-tech-for-landrecords.pdf. The ArcGIS REST API

Esri. (2014). Retrieved July 1, 2014, from http://resources.arcgis.com/en /help/arcgis-rest-api/index.html\#//02r3000000tq000000.

Fu, P., \& Sun, J. (2011). Web GIS Principles and Applications. Redlands, California: 


\section{Esri Press.}

Kraak, M.J. (2004). The role of the map in a Web-GIS environment. Journal of Geographical Systems, 6(2), 83-93.

Tomlinson, R.F, (2007). Thinking about GIS: Geographic Information System Planning for Managers ( $3^{\text {rd }}$ ed.). Redlands, CA: Esri Press. 


\section{Appendix A. Public Application Script}

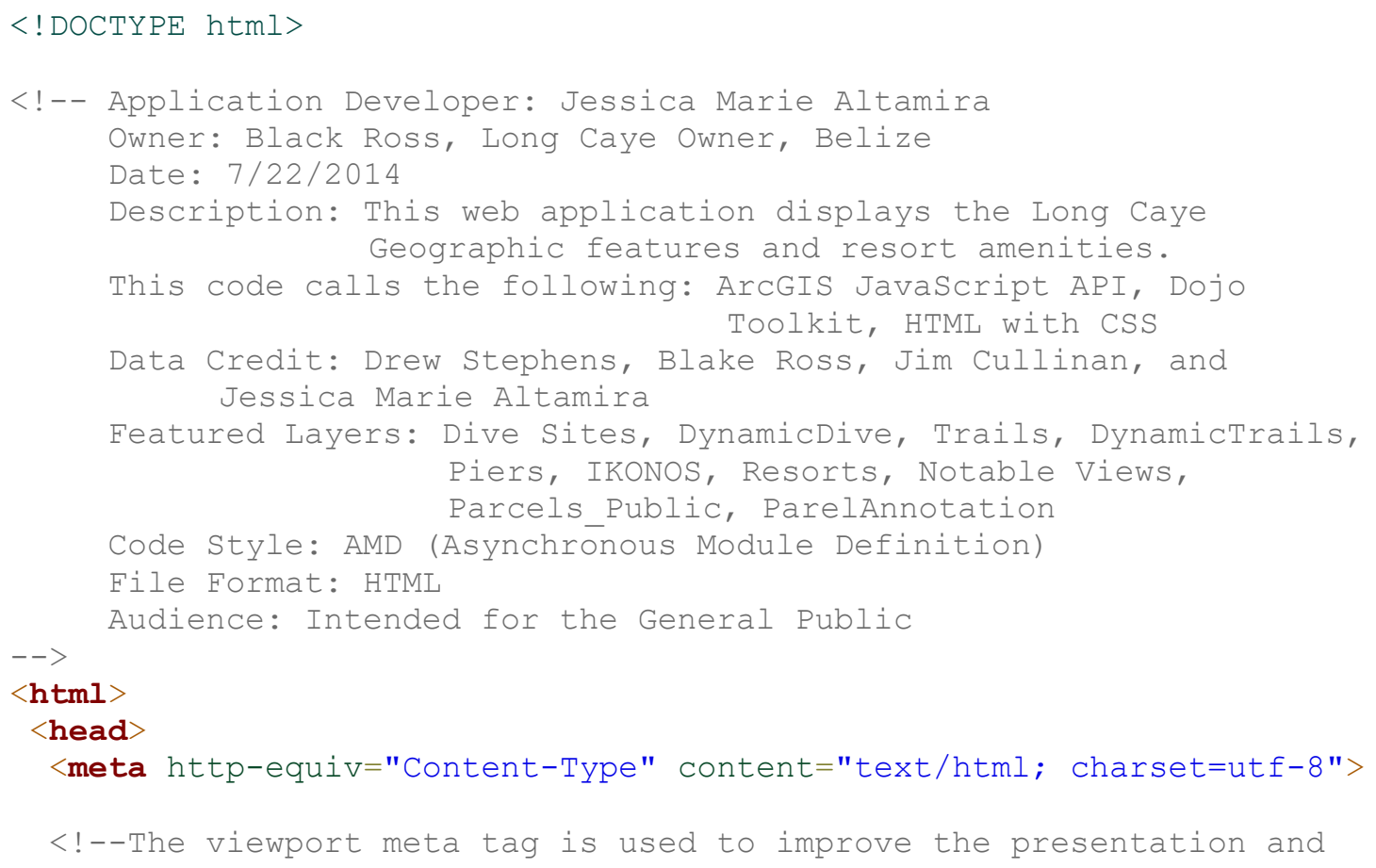




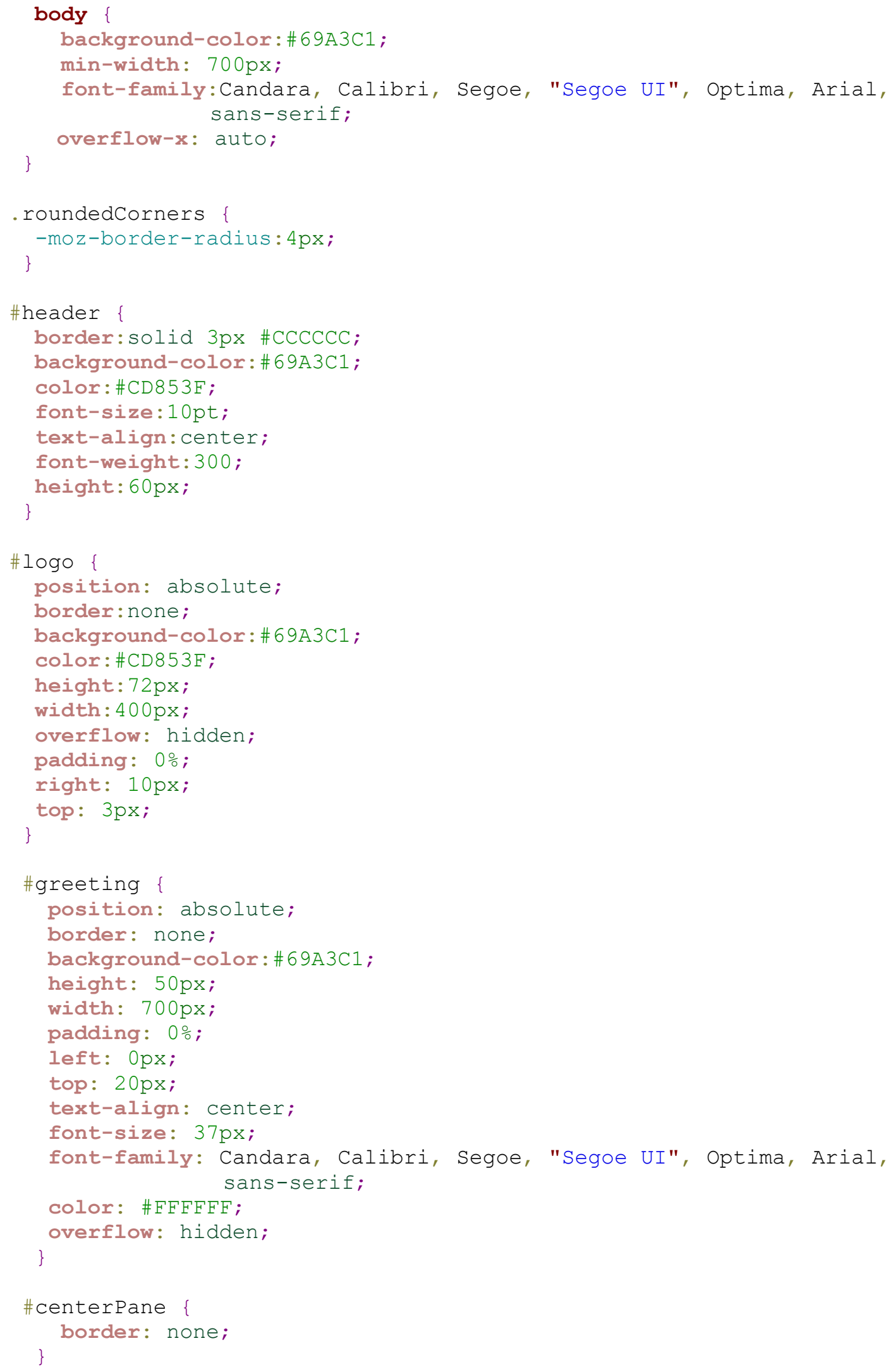




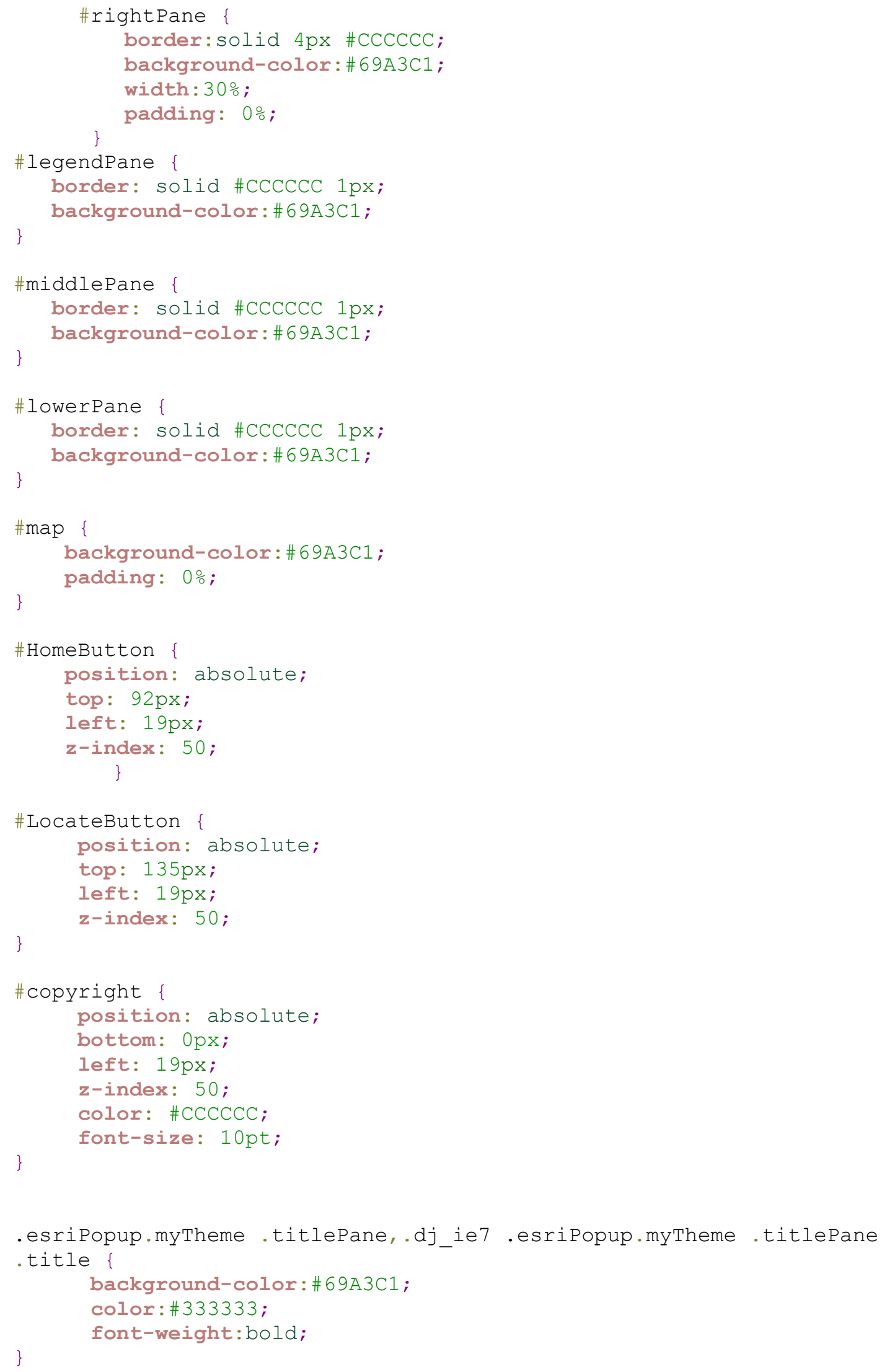




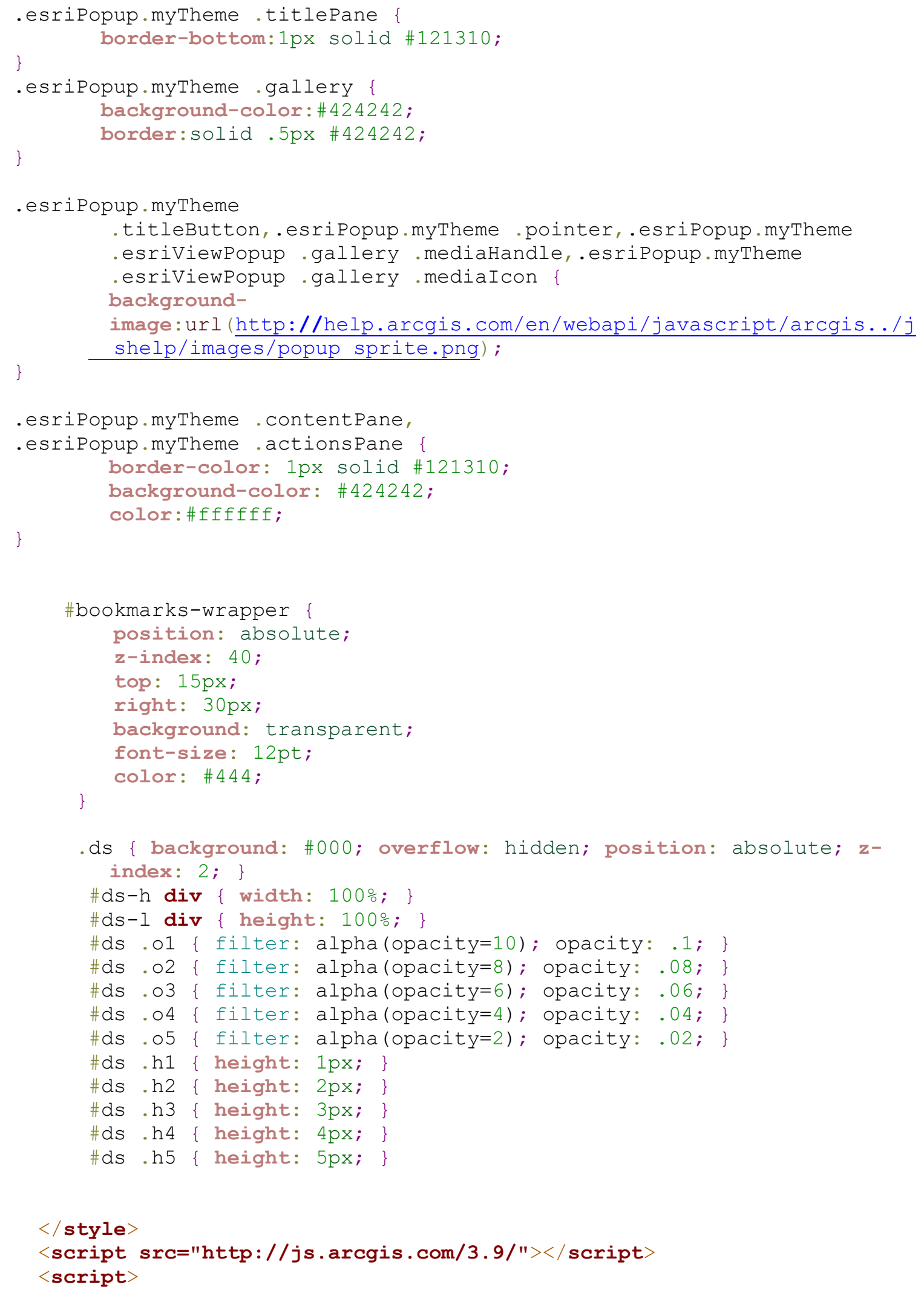




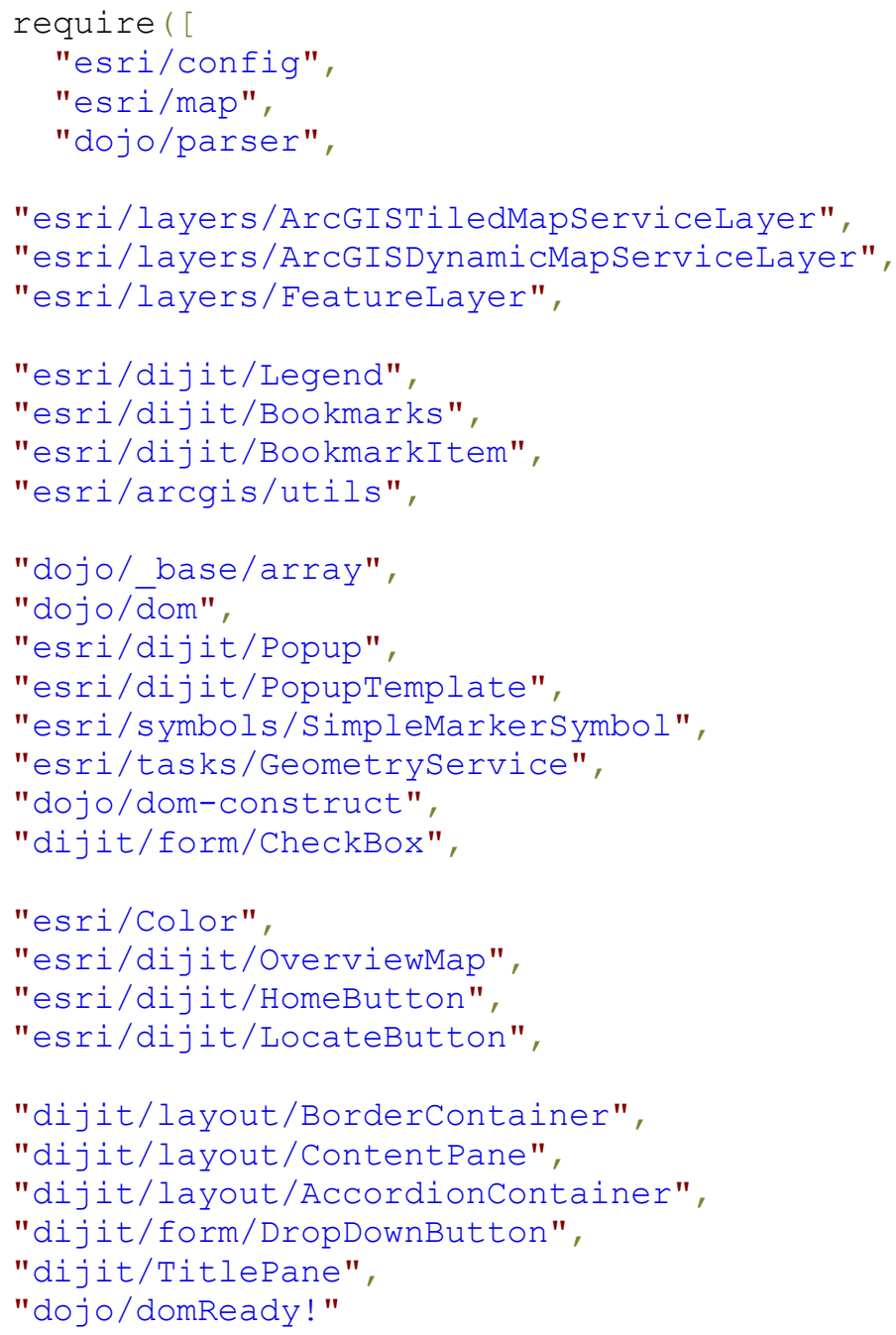

\section{], function}

esriConfig,

Map,

parser,

Tiled, ArcGISDynamicMapServiceLayer, FeatureLayer,

Legend, Bookmarks, BookmarkItem, arcgisutils,

arrayutils, dom, Popup, PopupTemplate, SimpleMarkerSymbol, Geometryservice, 


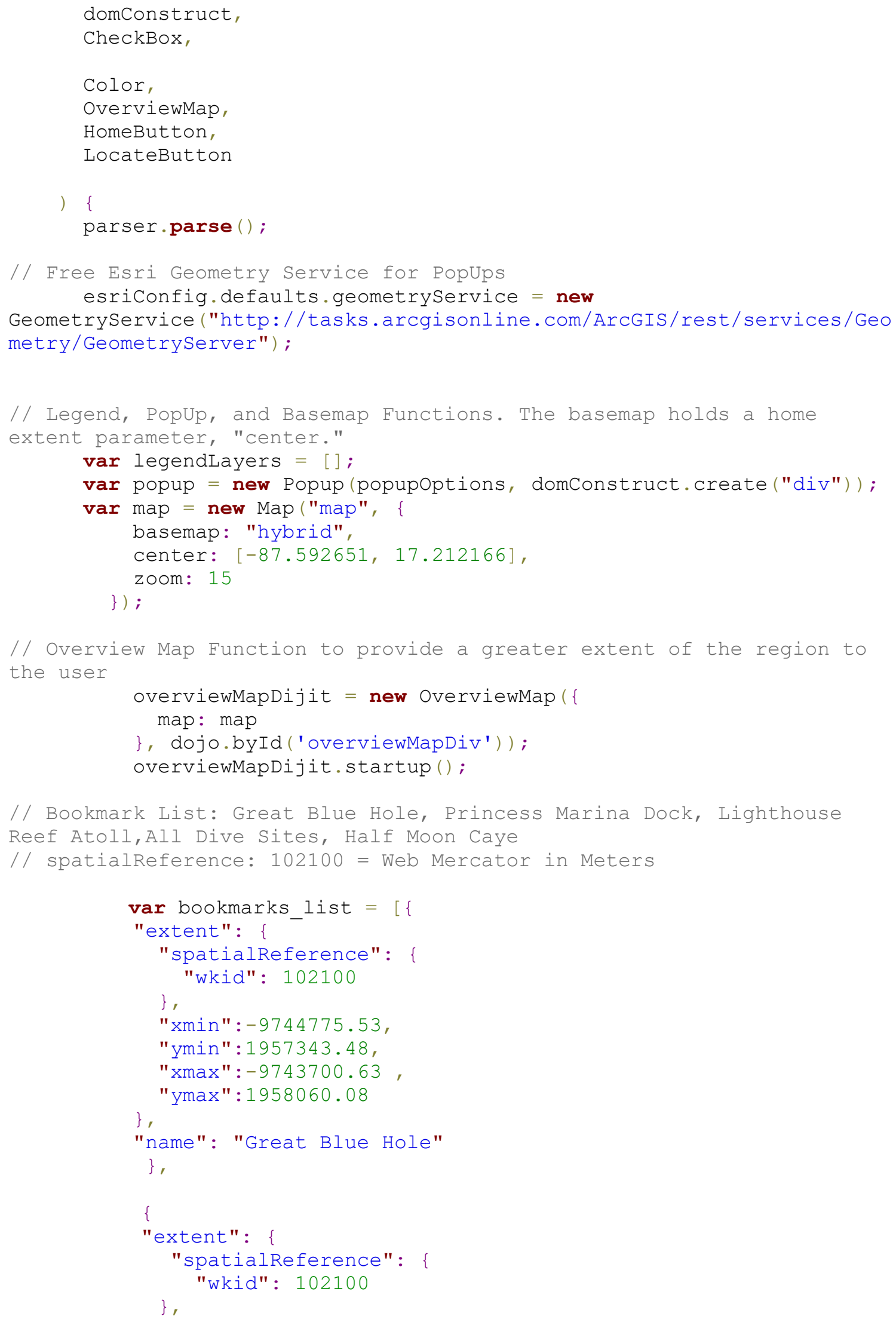




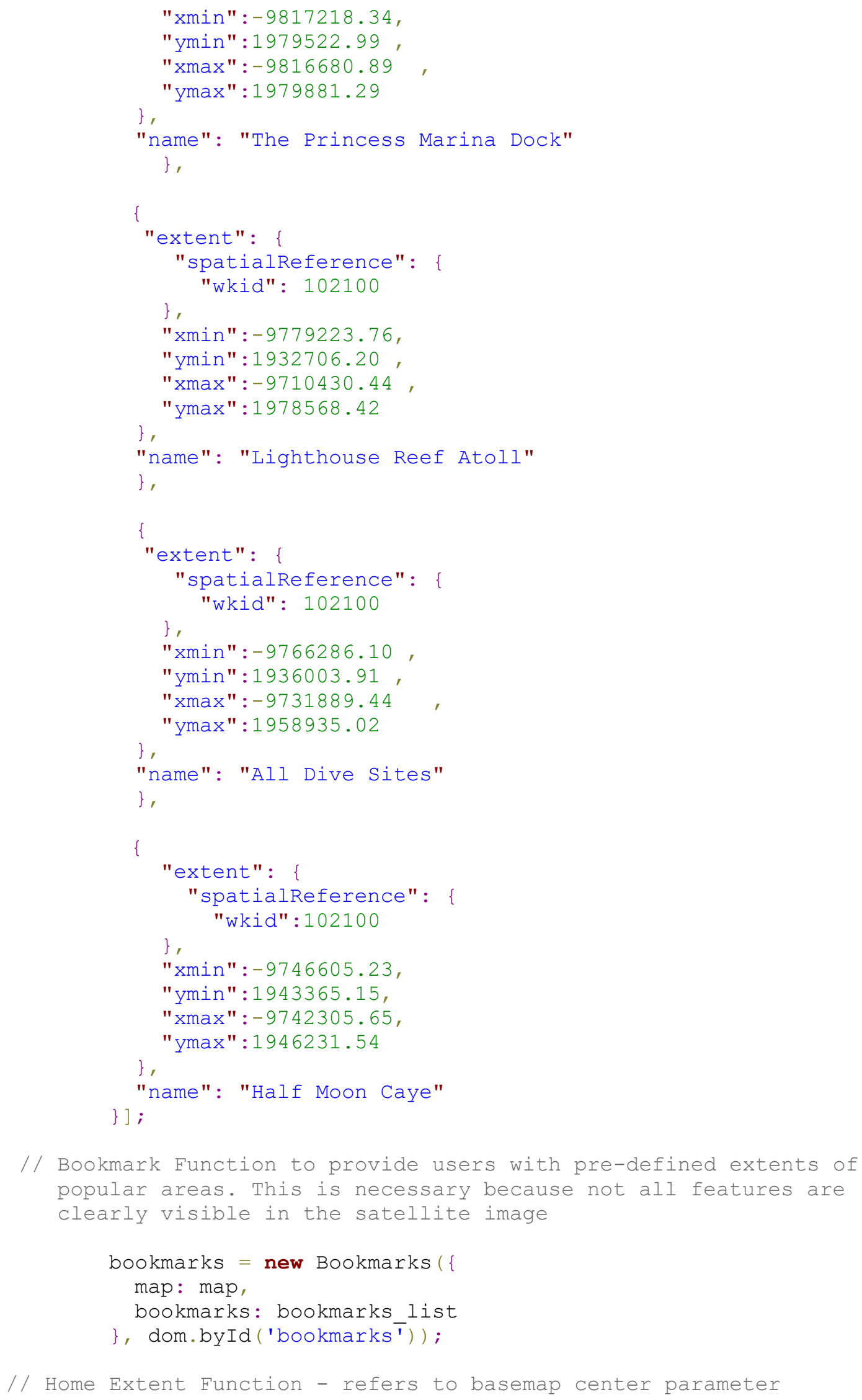




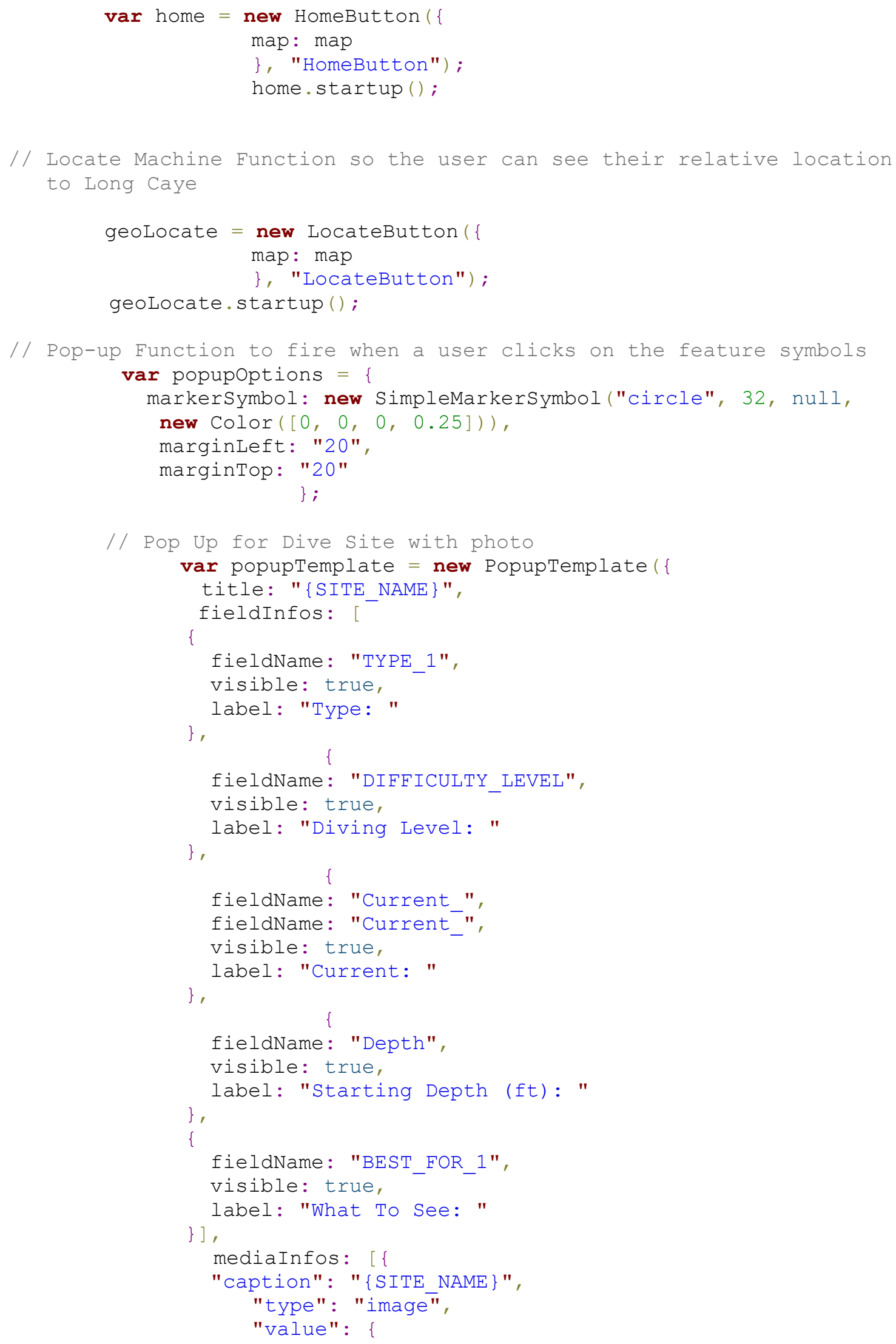




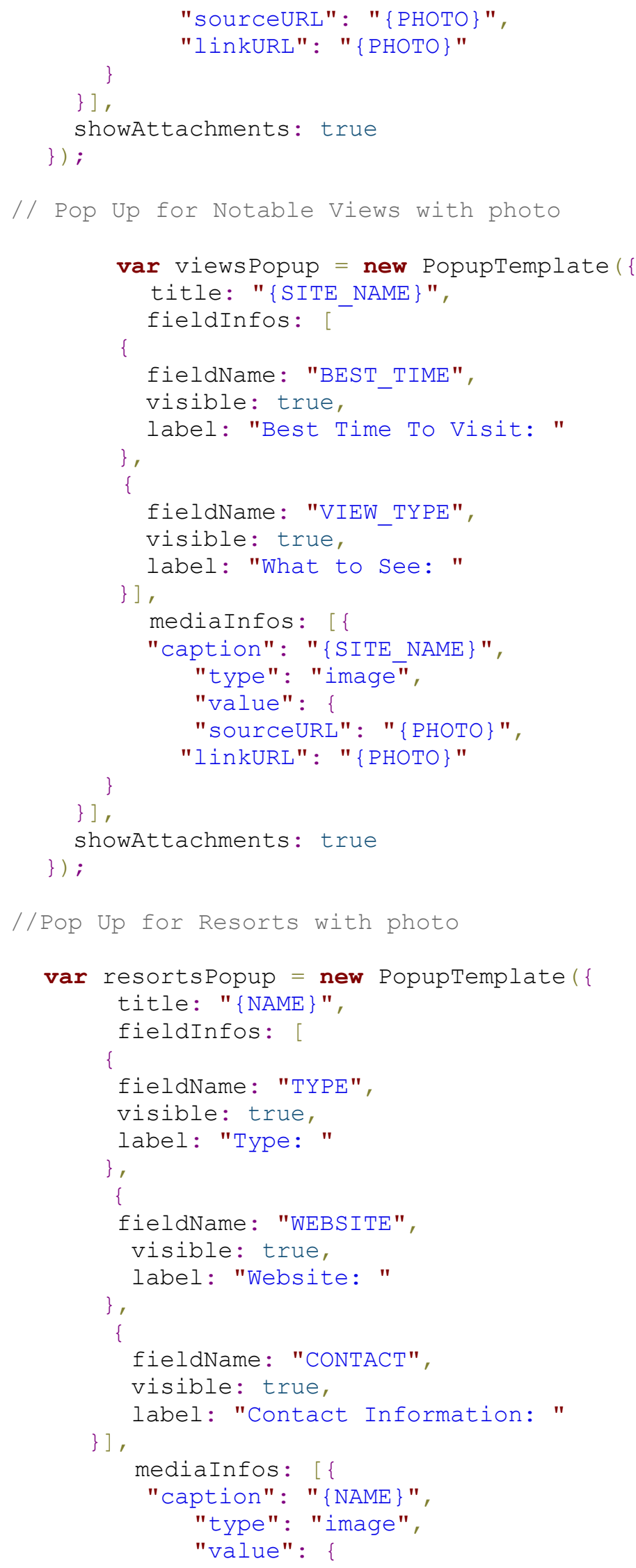




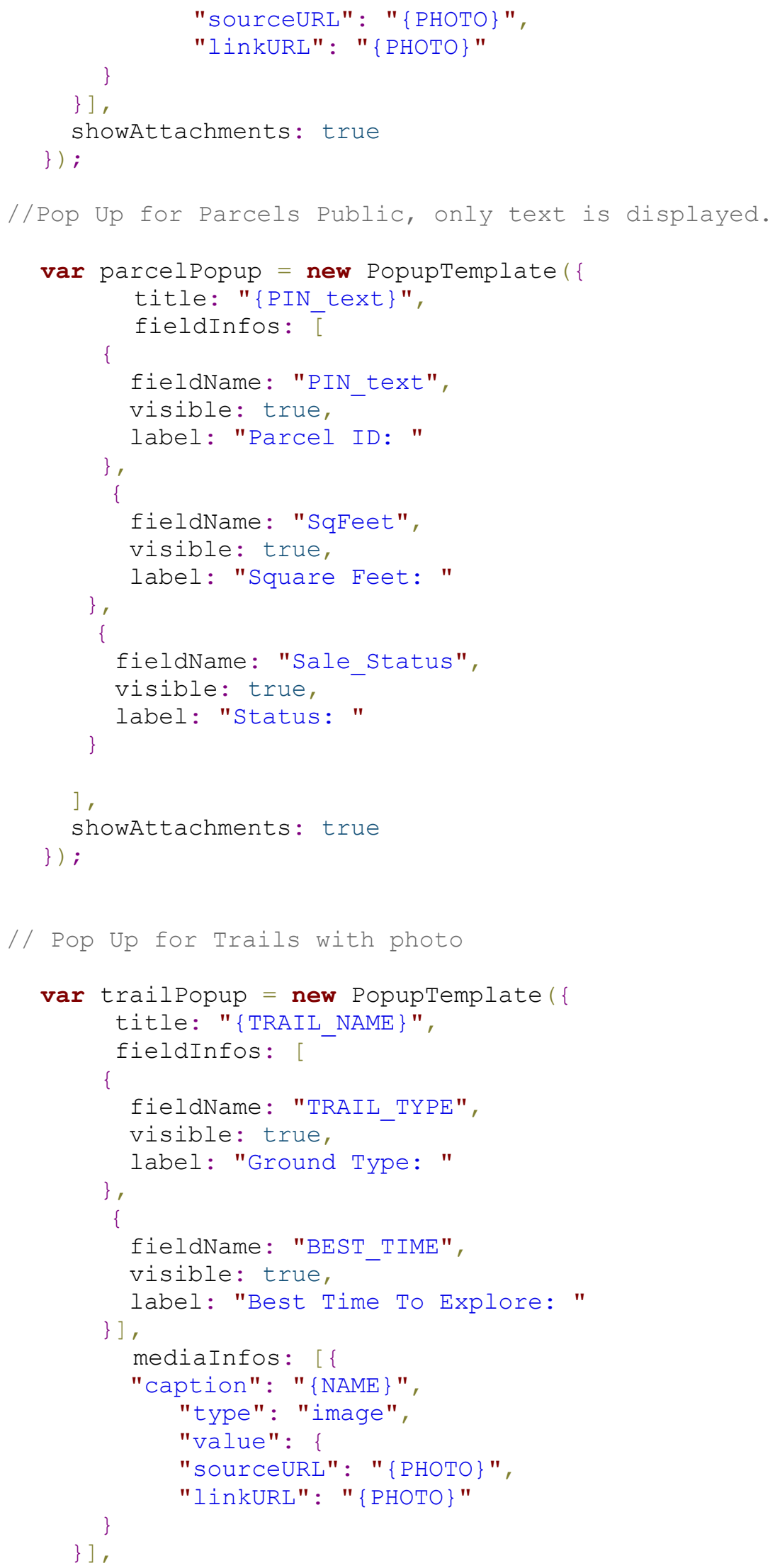


showAttachments: true

\}) ;

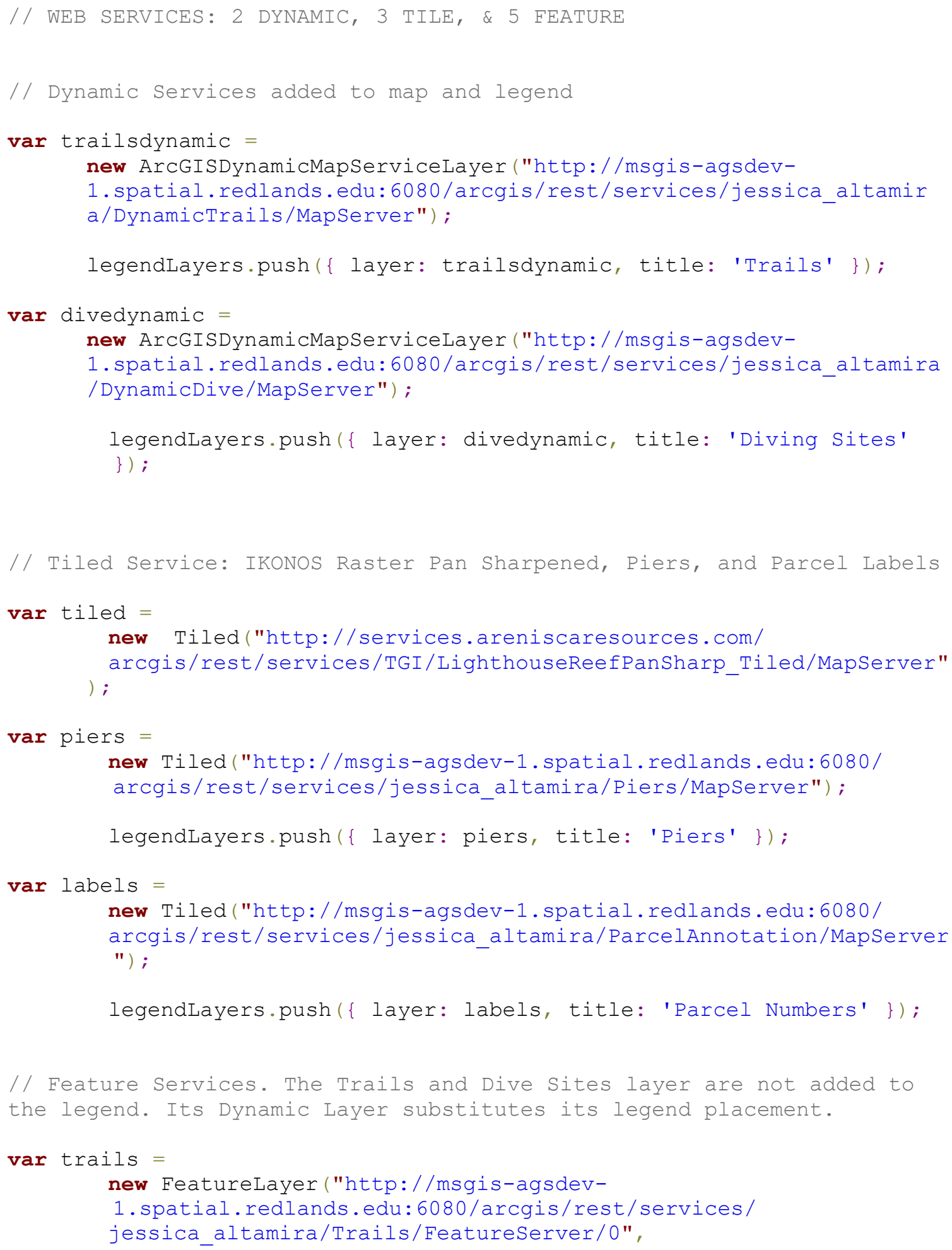




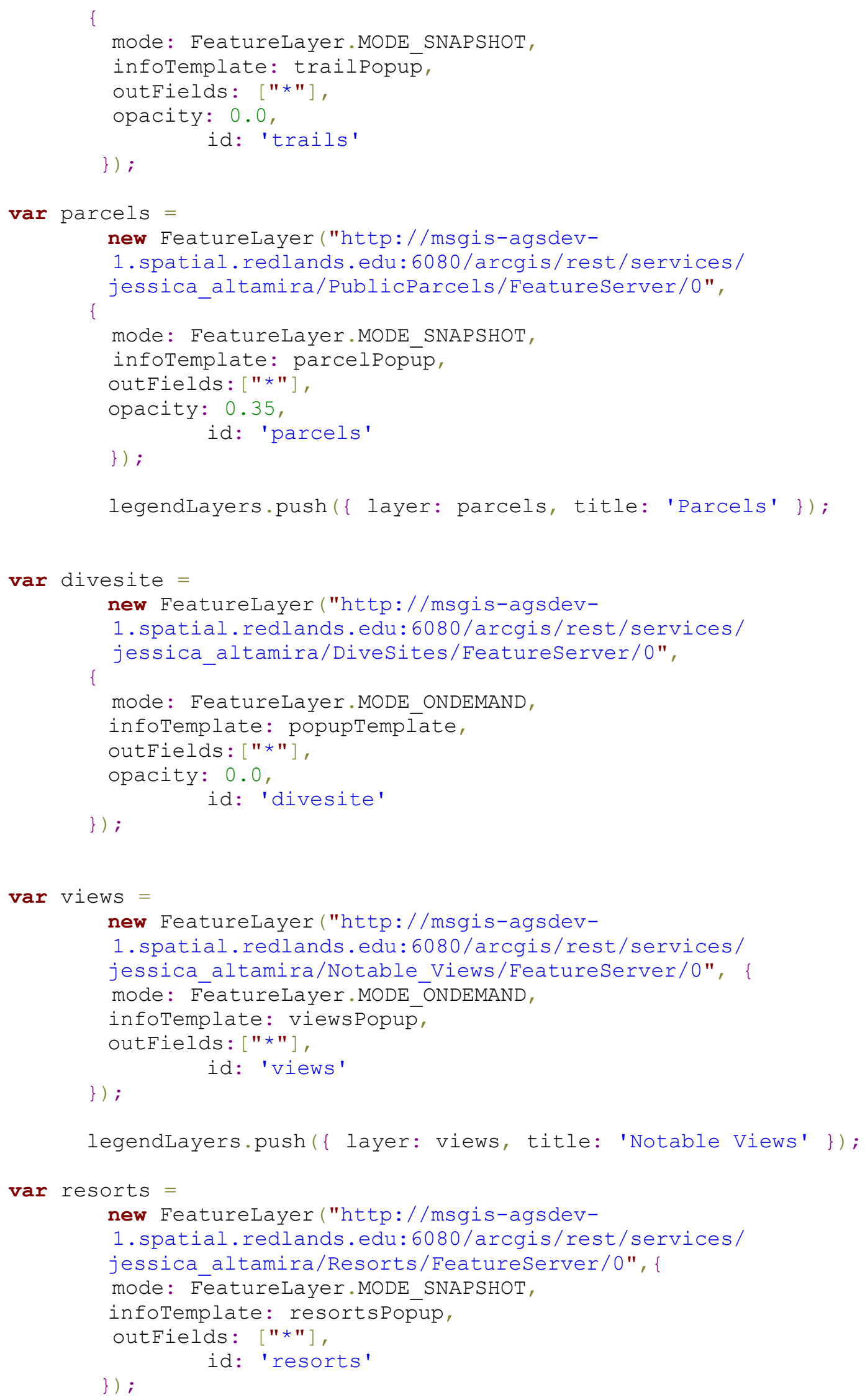




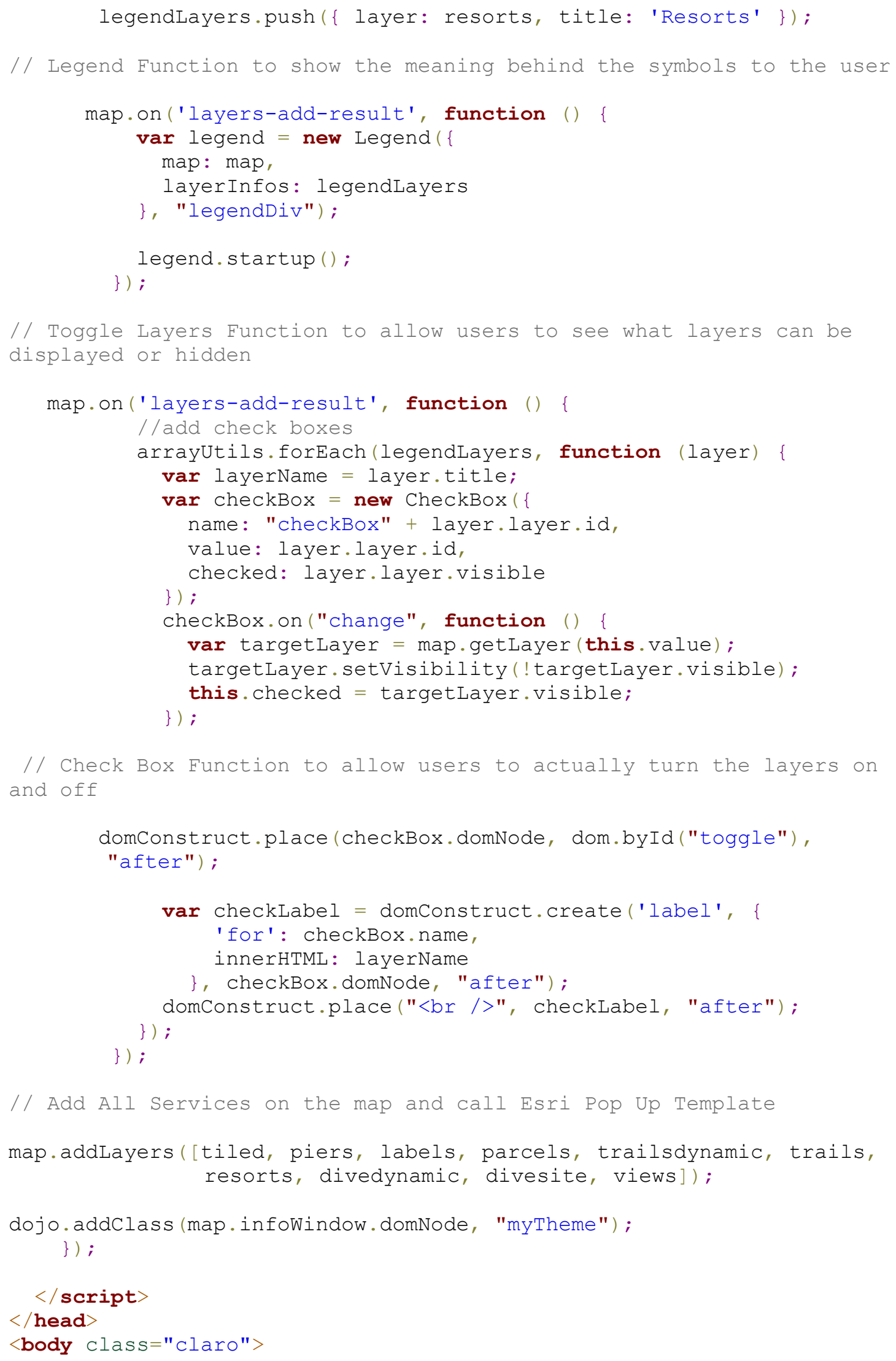




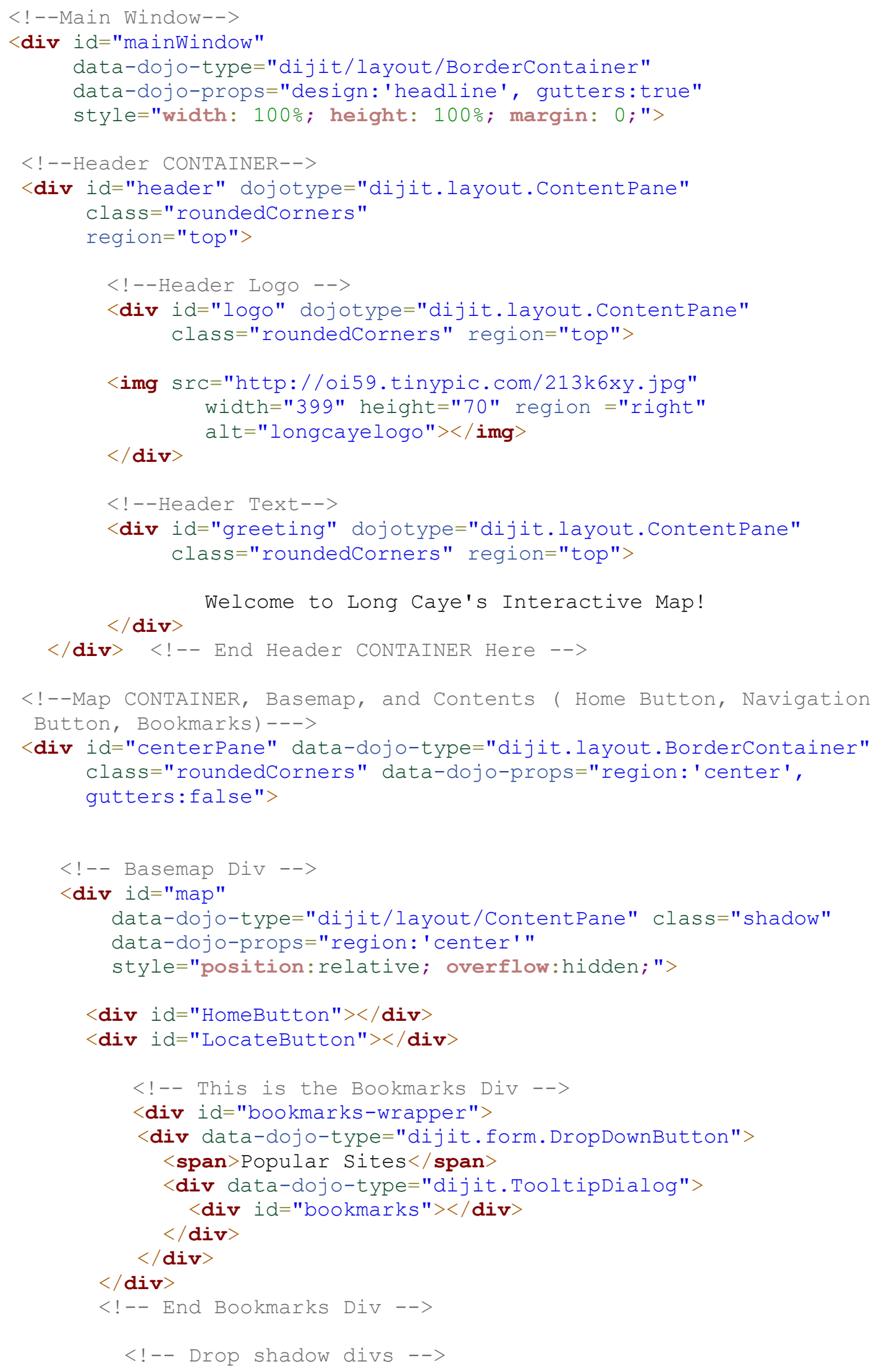




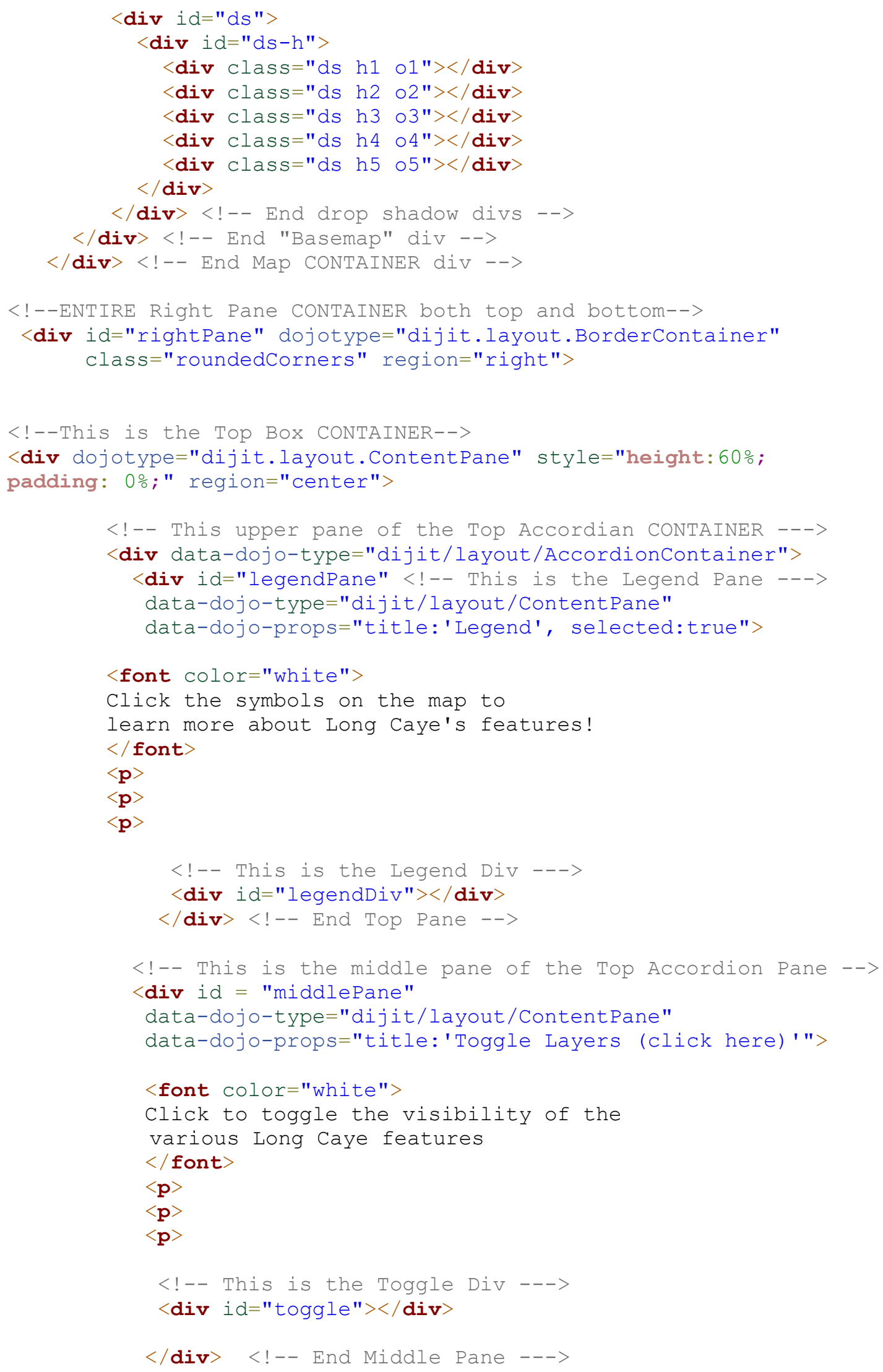




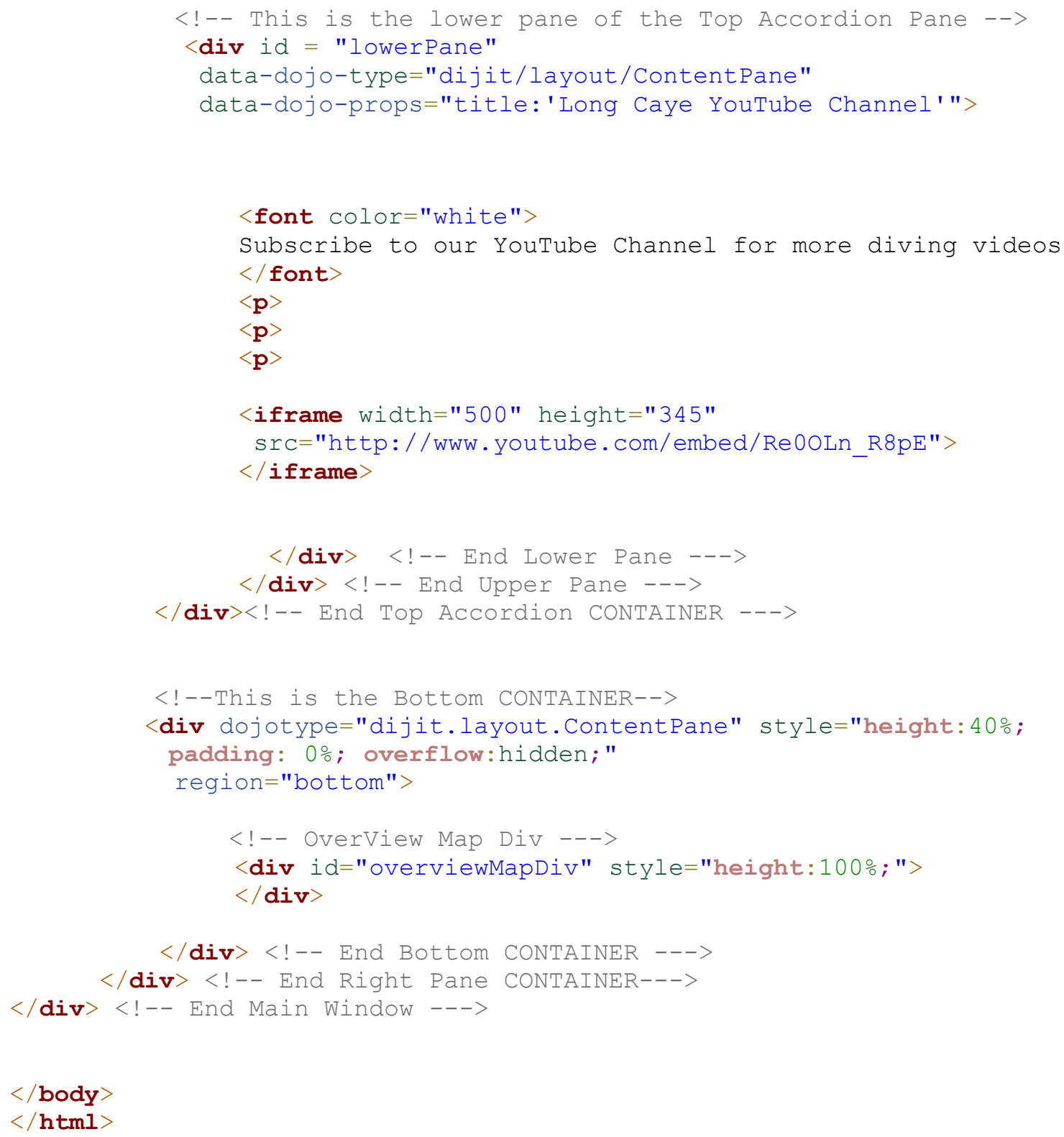




\section{Appendix B. Internal Application Script}

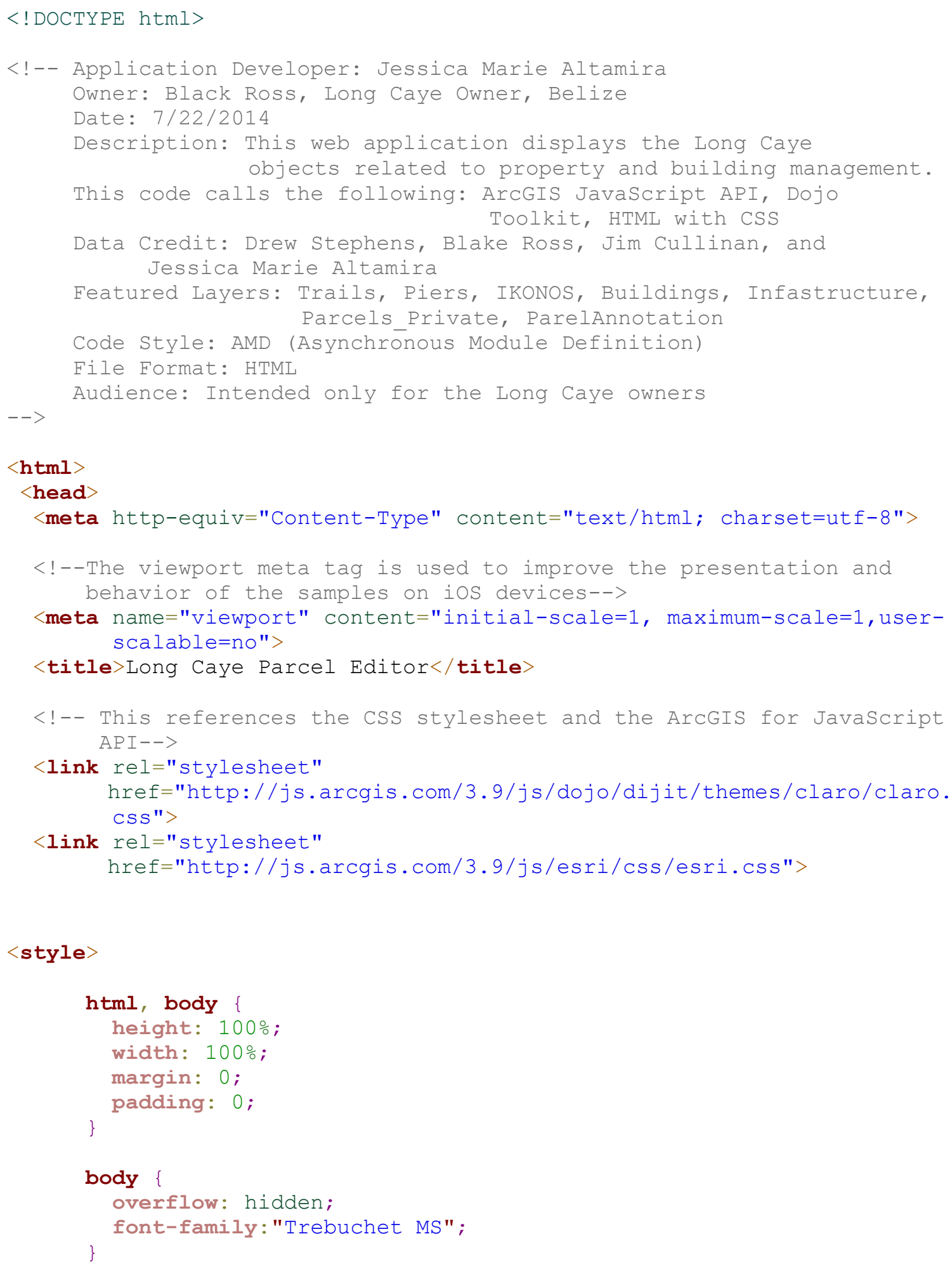




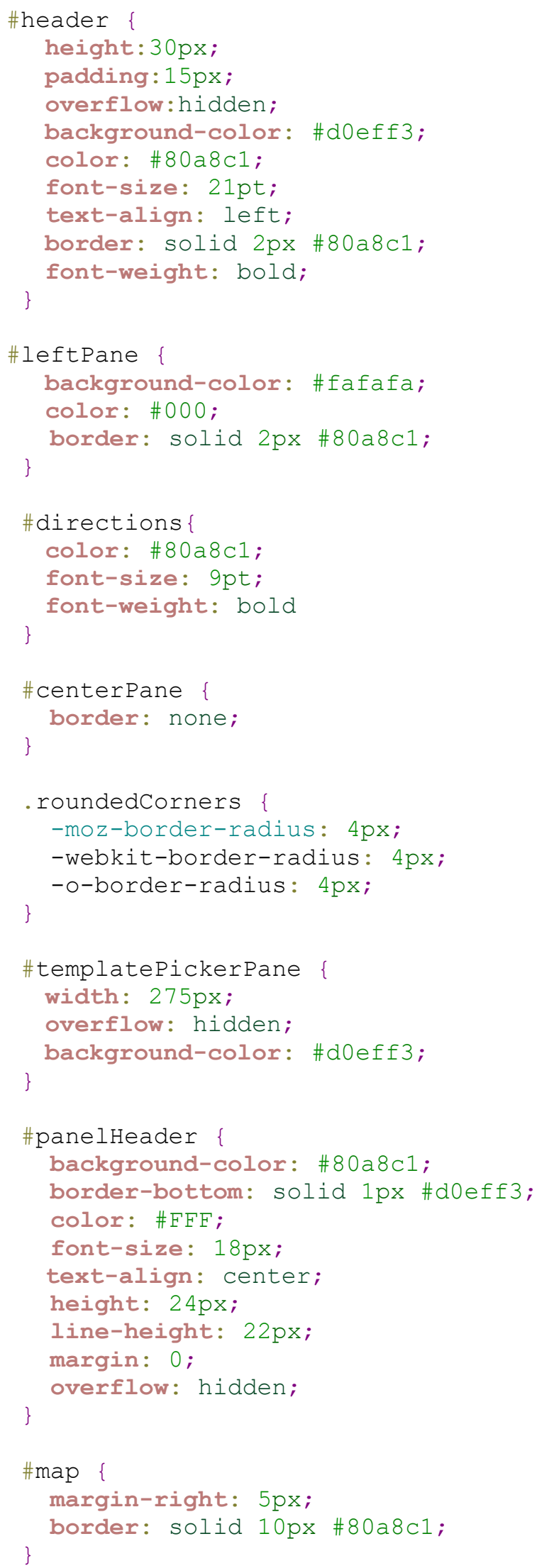




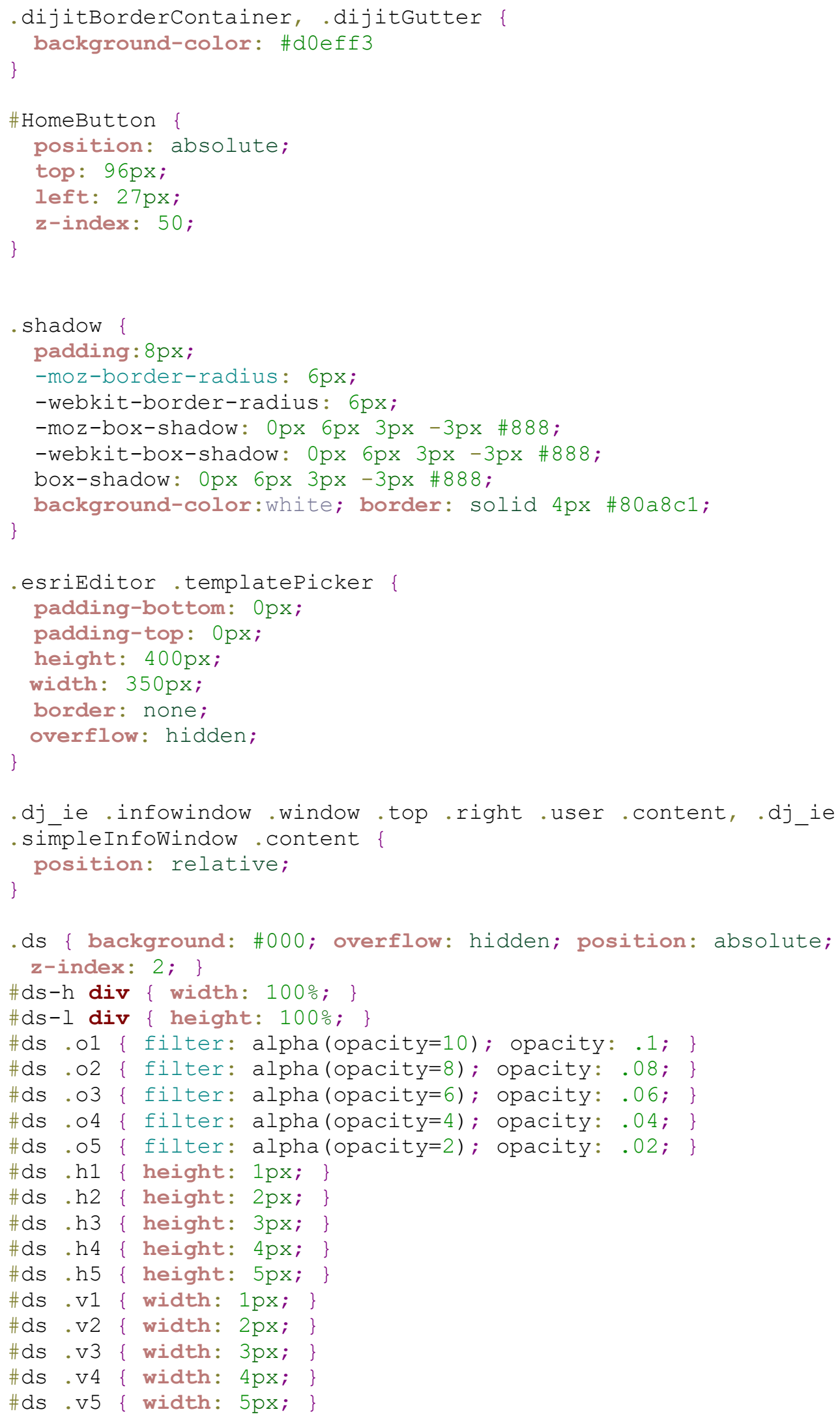




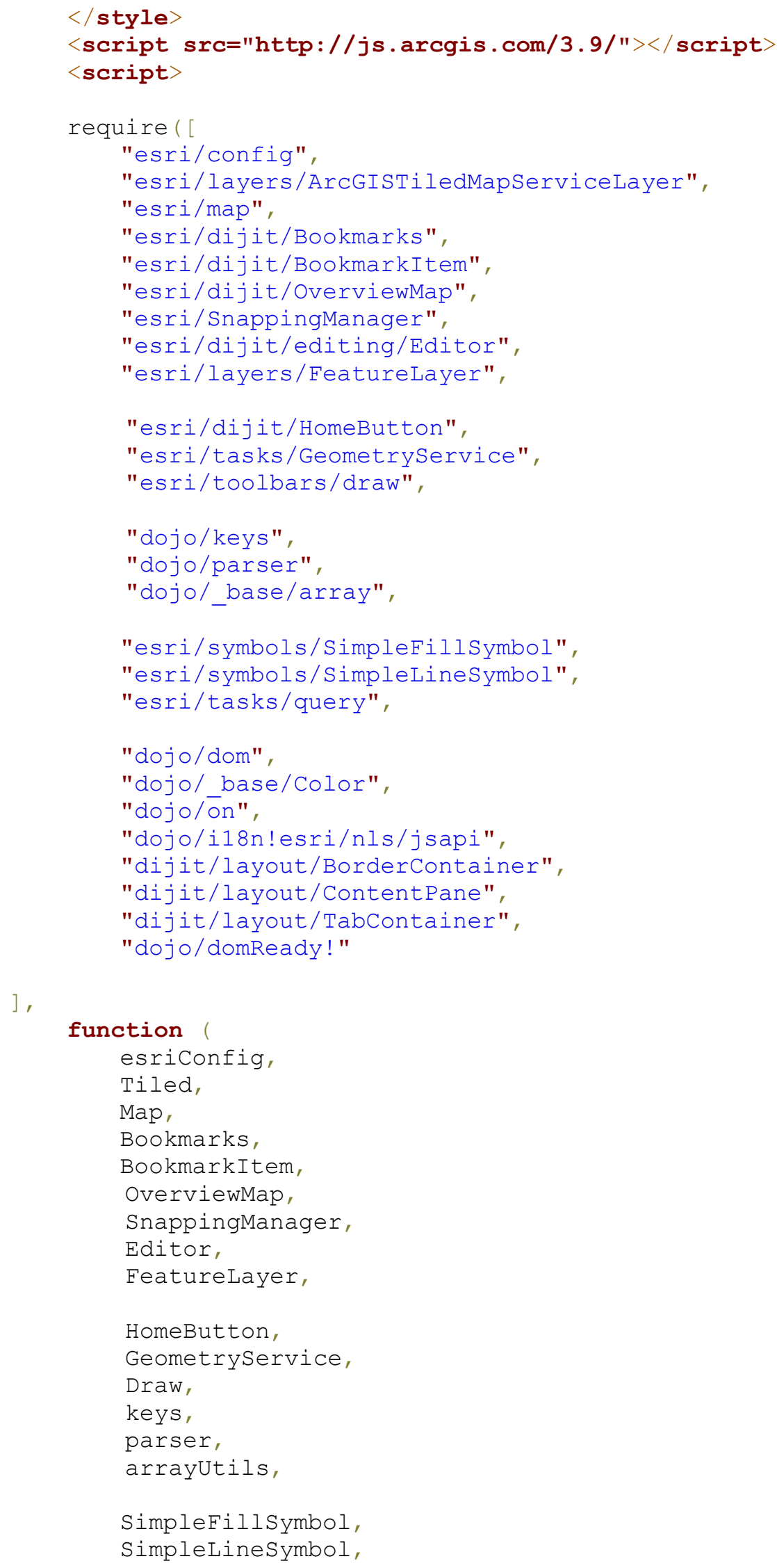

\section{function (}

esriconfig, Tiled,

Map,

Bookmarks, BookmarkItem,

OverviewMap,

SnappingManager,

Editor,

FeatureLayer,

HomeButton,

GeometryService,

Draw,

keys,

parser,

arrayutils,

Simplefillsymbol, SimpleLinesymbol, 


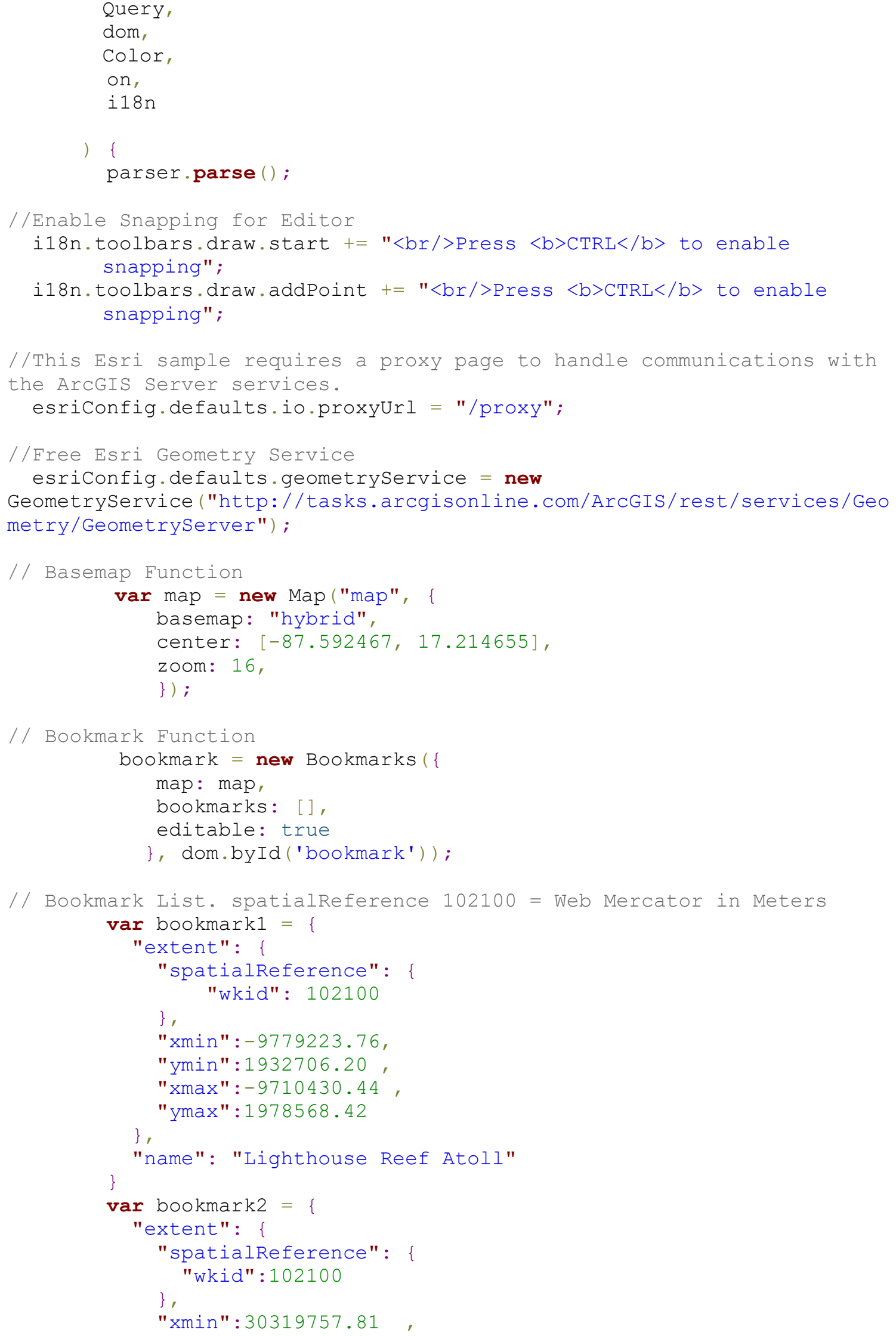




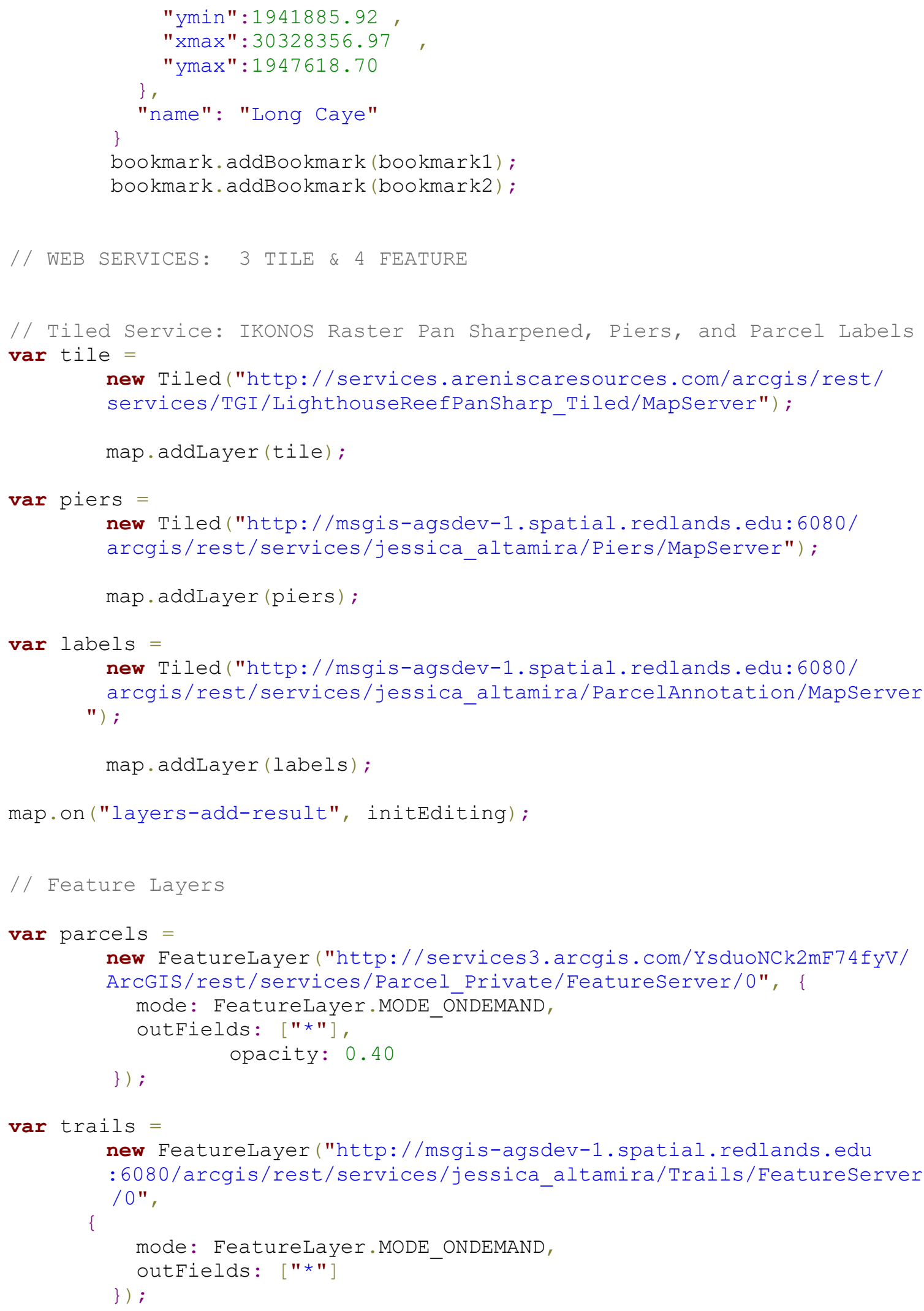




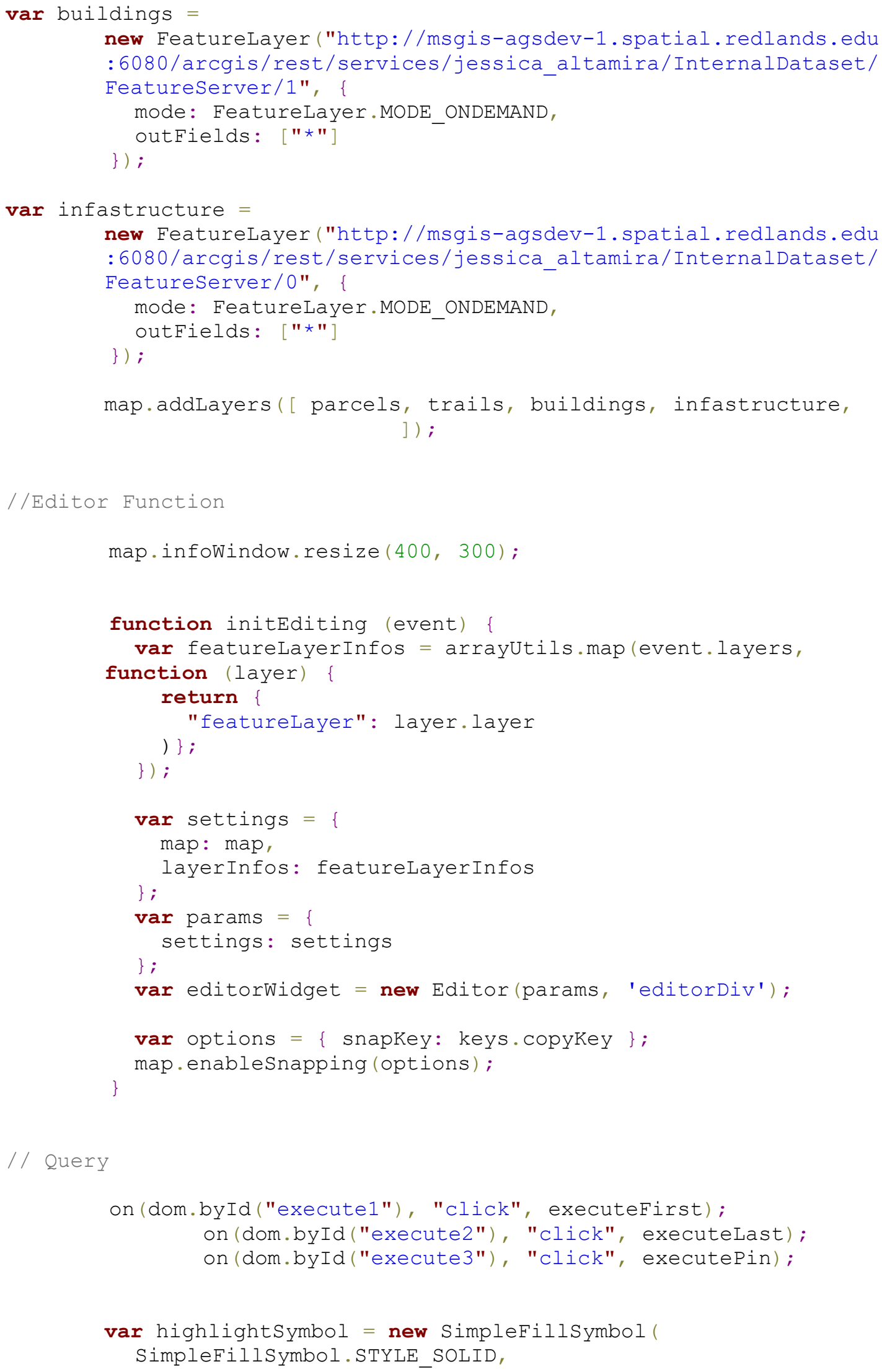




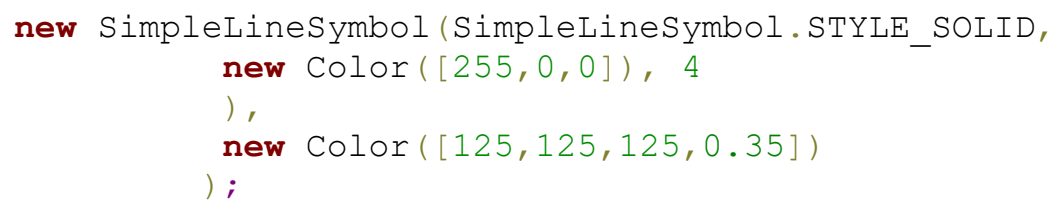




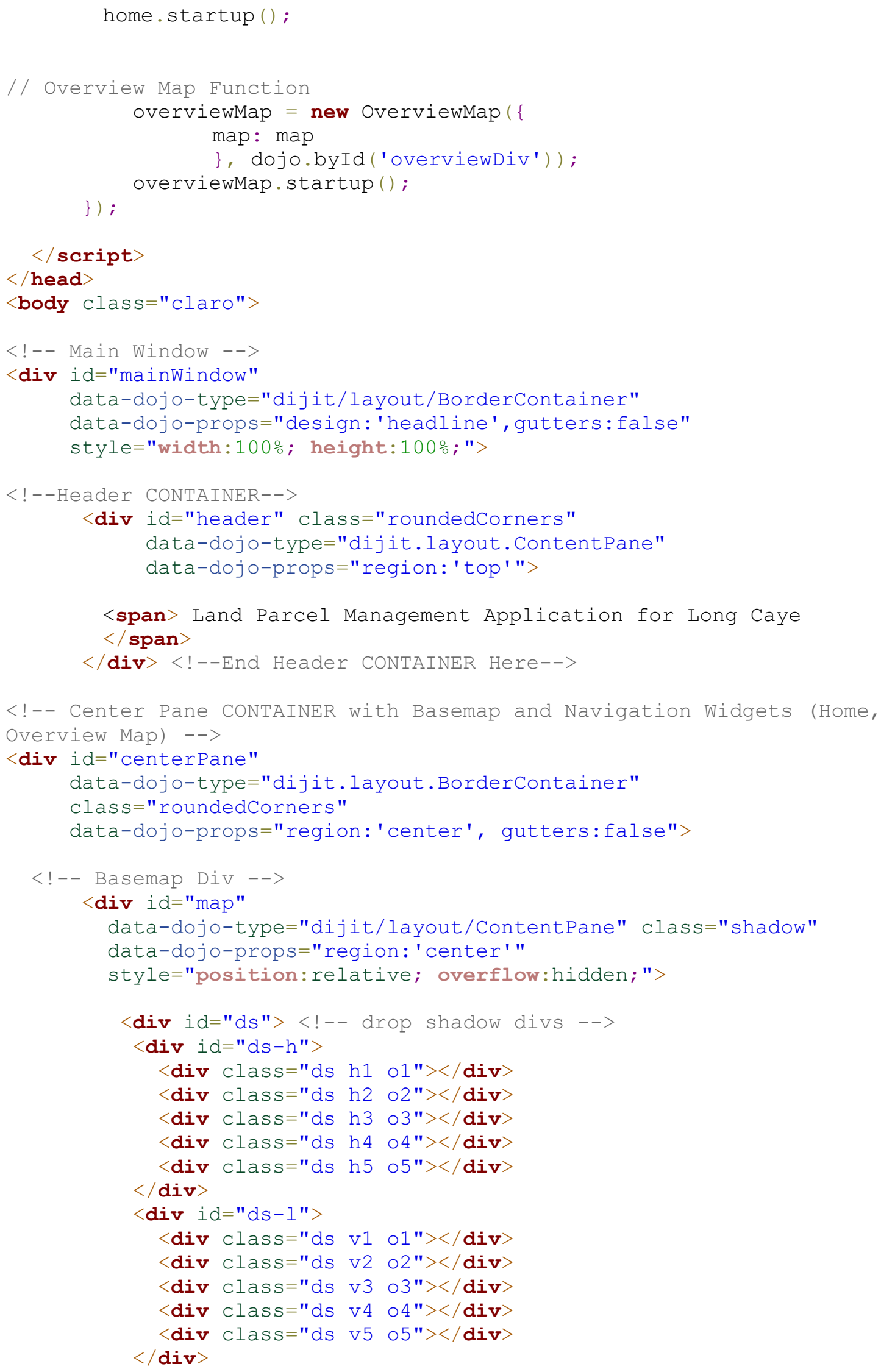




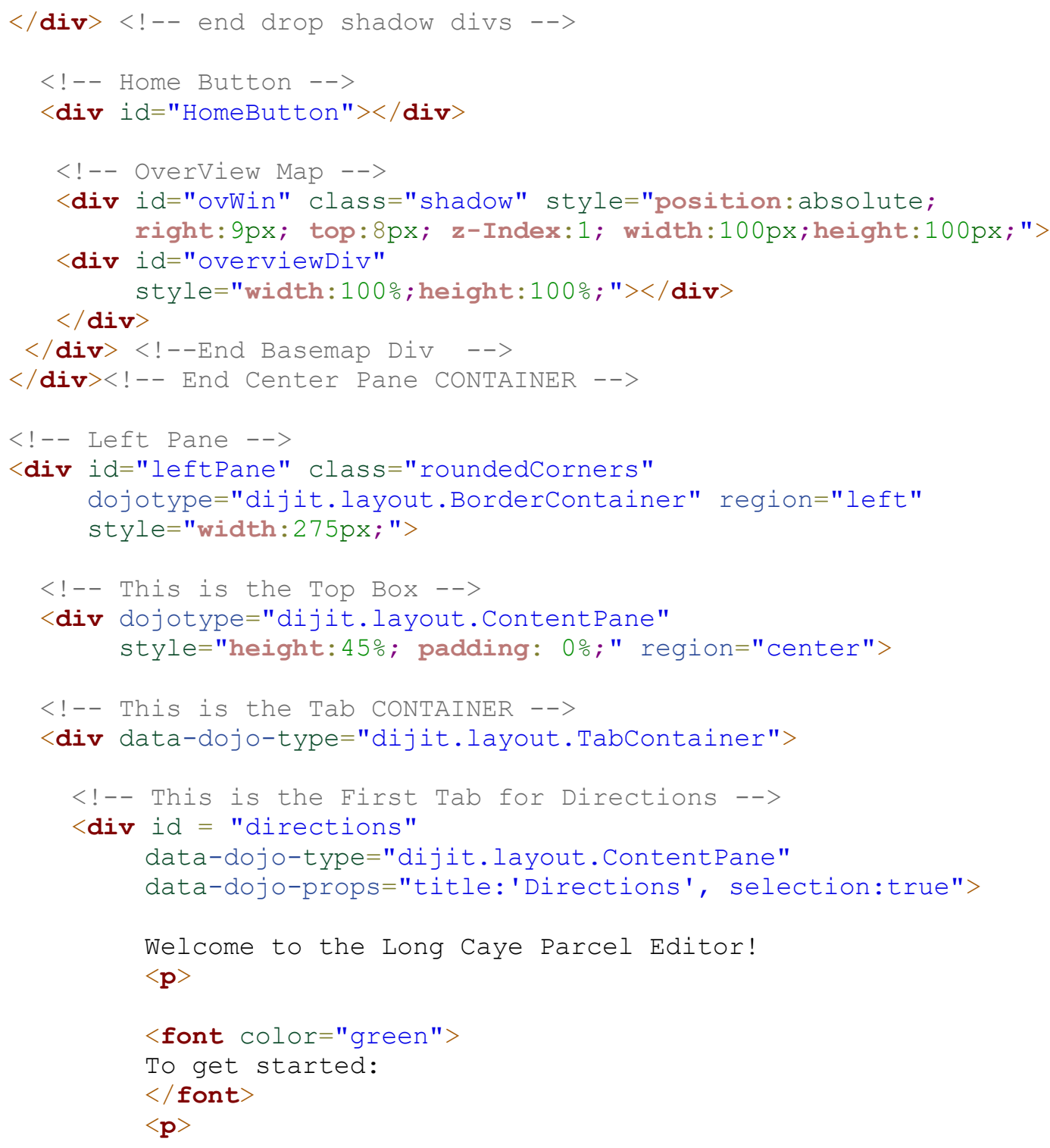

2) Once your selection is highlighted in red, click on that parcel to edit its attributes

$\langle\mathbf{p}\rangle\langle$ font color="black" $>$ To create new parcels: $\langle/$ font $\rangle\langle$ p $\rangle$

1) Click on the parcel icon on the "Feature Editor" box below. $<\mathbf{p}>$

2) Draw on the map in the desired location, click to create corners. $<\mathbf{p}>$

3) Connect all sides and double click to finish. Update the attributes as needed. 


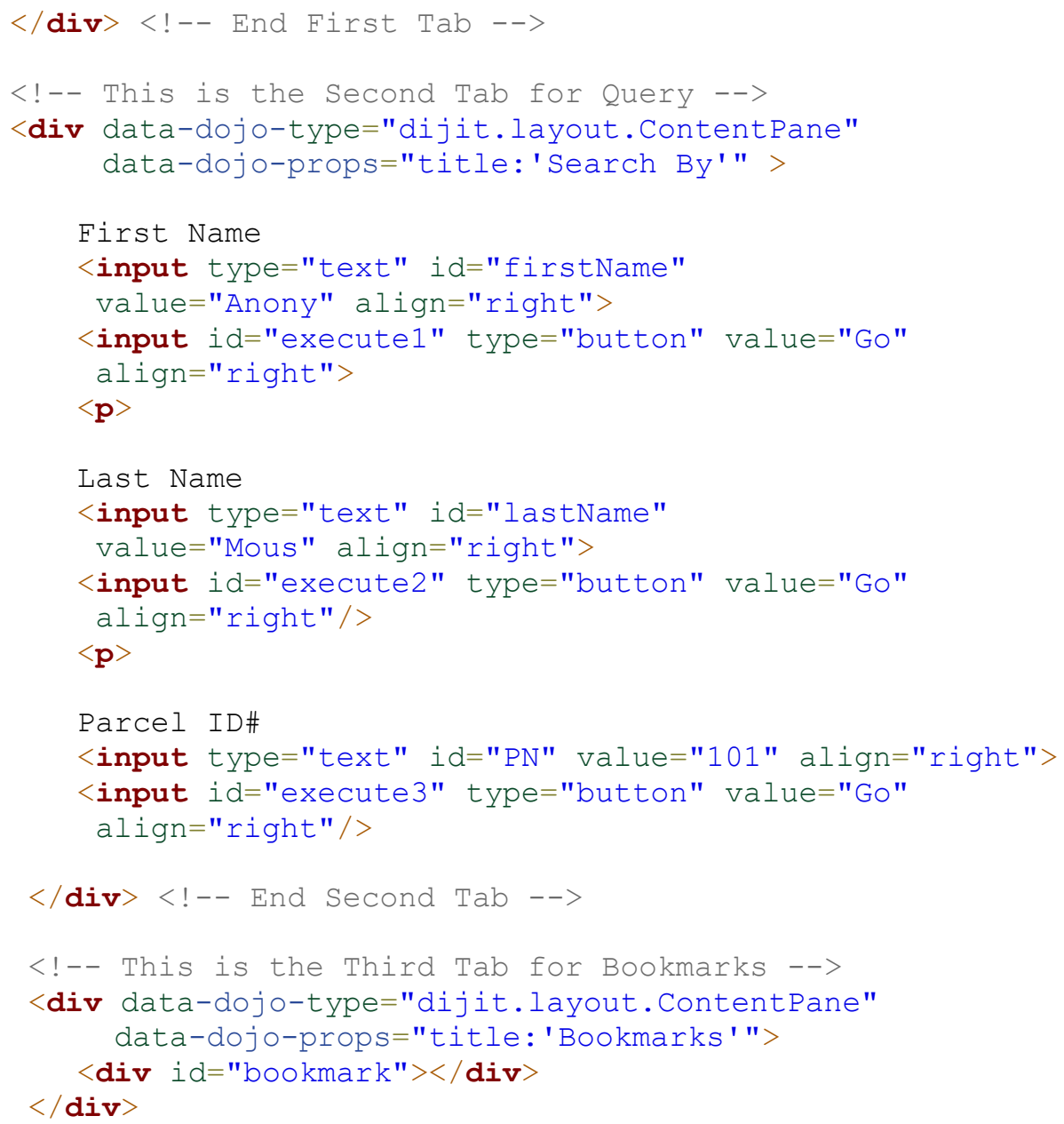




\section{Appendix C. Help Documentation}

These two applications are intended for public education and editing parcel data. The audiences are either the general public or internal management.

In order to use the public application, proceed using the following steps:

1) Launch the application, click and drag on the map to navigate throughout the island. Click on the map symbols to launch pop-ups. Click on the home button to return to the initial extent

2) Click the "Toggle" tab underneath the legend to find a list of operational layers to turn on and off. Check or uncheck the boxes next to the layer of interest.

3) Click the "YouTube" tab underneath the "Toggle" tab to view the Long Caye YouTube streaming channel.

4) Click the Popular Sites tab on the map to display a drop down of bookmarks. Click the bookmark item of interest.

In order to use the internal application, proceed using the following steps:

1) Sign in using the Long Caye organizational account information.

2) Click the "Search By" tab and type in one of the three criteria to search for a parcel. Hit Go.

3) Edit the features as needed by clicking on the feature template to choose a layer to draw. Clicking on the completed feature fires an attribute dialogue box to edit information. To delete, click delete. To save, simply close out of the attribute dialogue.

4) To add bookmarks, hit the Bookmarks tab. Zoom to an extent of interest, then click the pencil symbol in the Bookmarks tab and name the extent. 